\title{
WestVirginiaUniversity
}

THE RESEARCH REPOSITORY @ WVU

Graduate Theses, Dissertations, and Problem Reports

2004

\section{Manufacturing and evaluation of structural products with recycled polymers}

\author{
Raghuram Phani Aditham \\ West Virginia University
}

Follow this and additional works at: https://researchrepository.wvu.edu/etd

\section{Recommended Citation}

Aditham, Raghuram Phani, "Manufacturing and evaluation of structural products with recycled polymers" (2004). Graduate Theses, Dissertations, and Problem Reports. 1876.

https://researchrepository.wvu.edu/etd/1876

This Thesis is protected by copyright and/or related rights. It has been brought to you by the The Research Repository @ WVU with permission from the rights-holder(s). You are free to use this Thesis in any way that is permitted by the copyright and related rights legislation that applies to your use. For other uses you must obtain permission from the rights-holder(s) directly, unless additional rights are indicated by a Creative Commons license in the record and/ or on the work itself. This Thesis has been accepted for inclusion in WVU Graduate Theses, Dissertations, and Problem Reports collection by an authorized administrator of The Research Repository @ WVU. For more information, please contact researchrepository@mail.wvu.edu. 


\title{
MANUFACTURING AND EVALUATION OF STRUCTURAL PRODUCTS WITH RECYCLED POLYMERS
}

\author{
Raghuram Phani Aditham \\ Thesis submitted to the \\ College of Engineering and Mineral Resources at \\ West Virginia University in \\ partial fulfillment of the requirements \\ for the degree of
}

Master of Science
in
Mechanical Engineering

Kenneth H. Means, Ph.D., Chair

P.V. Vijay, Ph.D., Co-chair

Hota GangaRao, Ph.D.,

Charles F. Stanley, Ph.D.

Department of Mechanical and Aerospace Engineering

\author{
Morgantown, West Virginia \\ 2004
}

Keywords: Recycled plastics, ABS, PC, Tire, Vinyl ester, Guardrail offset block, Angles, Dowel bar, FEM, Infrared Thermography, Compression, Tension, Bending, Impact

Copyright 2004 Raghuram Phani Aditham 


\section{Abstract \\ MANUFACTURING AND EVALUATION OF STRUCTURAL PRODUCTS WITH RECYCLED POLYMERS}

\section{Raghuram Phani Aditham}

The rapid growth of Wastes from Electrical and Electronic Equipment (WEEE) can be attributed to the rapid developments in technology, leading to reduction in service life to less than 2 years in certain products. Thermoplastics such as AcrylonitrileButadiene-Styrene (ABS) and Polycarbonate (PC) form a significant percent of the Electronic Shredder Residue (ESR) that were used in this research to manufacture and evaluate structural products with recycled polymers.

In this research, offset blocks for highway and bridge guardrail systems were developed using recycled polymers reinforced with glass fabric as shell and discarded tire strips/wood as core materials. Optimum compression molding process parameters for typical manufacturing core block modules $(12.5 " \times 4.5 " \times 2$ ") were 20 minutes of preheating followed by 15 tons of load application at $450^{\circ} \mathrm{F}$ for about 15 minutes, however, prototype offset block were preheated for about 30 minutes at $450^{\circ} \mathrm{F}$ followed by applying 30 tons of load for about 30 minutes at the same temperature. These blocks were successfully manufactured and installed near the Star city bridge, Morgantown, WV in 2004 and found to be in excellent shape after 8 months of installation based on visual inspection.

In order to evaluate mechanical properties of recycled polymers (ABS) used to manufacture offset blocks, coupon specimens were manufactured conforming to ASTM standards, with and without glass fabrics and tested in compression, tension, bending, and impact. A limited comparison was made with vinyl ester (thermoset) specimens with and without glass fabric and with specimens cut from a field-installed wooden offset block.

Use of chopped fibers reduced its impact resistance while use of continuous fabric increased the impact resistance of pure ABS whereas use of continuous fibers increased the impact resistance of pure ABS. ABS specimens with continuous fabric (bi-directional fibers) showed higher impact strength than the specimens cut from a field installed wooden offset block.

In order to study heat propagation in thermoplastics (ABS) during processing, a sliced section of a guardrail-offset block manufactured at CFC-WVU was tested for its heat conduction properties using infrared thermography. A finite element model was created to represent the manufactured specimen and analyzed under the effect of thermal loading. Results from FEM and thermography support the amount of time used to manufacture offset blocks.

Additional composite products like angle plates and dowel bars were manufactured using recycled ABS and their properties were evaluated under 3-point bending test. Optimum process temperature and pressure were suggested for laboratory manufacture.

Use of recycled polymer resins (thermoplastic ABS) for manufacturing structural/non-structural composite products and their mechanical property evaluation indicate significant potential for wide range of applications. Finally, recommendations based on this research and suggestions for future research have been provided. 


\section{ACKNOWLEDGEMENTS}

I am thankful to my committee chair Dr. Means for all his help and suggestions during my study at WVU. I would like to thank my research advisors Dr. Hota and Dr. Vijay (Co-chair) for their guidance and encouragement throughout the period of my Masters study and research. I am sincerely thankful for their patience and time when guiding me. I am thankful for the valuable suggestions of Dr. Stanley, member of my committee. I am thankful to the CFC for funding this research and giving me an opportunity to work in this team.

I am thankful to Jerry Nester, David Turner and Bill Comstock for their help in the laboratory. I am thankful to all my colleagues in B62 who have helped me throughout, especially Aneesh, Renee, Vijay, Praveen, Deepika, Srikanth, Amarnath, Meru and Sachin. I would like to extend thanks to my friends, Chaitanya, Bhyrav, Hem, and Sam who always helped me with testing. I would also like to thank my roommates for making my stay in Morgantown a very pleasant and memorable one.

I am thankful to my family, who made me realize the importance of advanced studies. Their support and love gave me the motivation to do my best. 


\section{DEDICATION}

This Thesis is dedicated to my Parents who have made it possible for me to complete my Masters Degree 


\section{Table of Contents}

Abstract ii

Acknowledgements iii

Table of contents $\quad$ v

List of figures $\quad$ xiii

List of tables $\quad$ xviii

\section{Chapter 1}

1. Introduction 1

1.1. General Remarks 1

1.2. Objectives 2

1.3. Scope 4

Chapter 2

2. Literature review

$\begin{array}{ll}\text { 2.1. Recycling of plastics } & 7\end{array}$

2.2. Identification and recovery of plastic constituents 8

2.3. Previous research on the recycled polymers 15

2.4. Recycled composite bridge 16

$\begin{array}{ll}\text { 2.5. Conclusions } & 17\end{array}$

Chapter 3

3. Materials, manufacture of coupon specimens, testing methods 19

3.1. Introduction 19

$\begin{array}{ll}\text { 3.2. Materials } & 20\end{array}$

$\begin{array}{ll}\text { 3.2.1. Recycled polymers } & 20\end{array}$ 


\section{Chapter 4}

4. Manufacture of guardrail offset block 
4.2.2. Glass fabric $\quad 32$

4.2.3. Rubber tires $\quad 32$

4.3. Equipment and accessories $\quad 33$

4.4. Manufacturing process 34

4.4.1. Pre-molding operations $\quad 35$

4.4.2. Testing the compatibility of resins 35

4.4.3. Process outline for manufacturing offset blocks 38

4.4.4. Intermediate stages in determining final manufacturing procedure for offset block 38

$\begin{array}{ll}\text { 4.4.4.1. Stage } 1 & 39\end{array}$

$\begin{array}{ll}\text { 4.4.4.2. Stage } 2 & 40\end{array}$

4.4.4.3. Stage $3 \quad 42$

4.4.4.4. Stage $4 \quad 43$

4.5. Blocks with wood/tire strips as core 45

4.5.1. Wood core 45

4.5.2. Rubber tire core 47

4.6. Introducing new features in offset block production 48

4.6.1. Pre-molded pipes $\quad 49$

4.7. Field Installation 51

4.8. Summary 51

\section{Chapter 5}

5. Test results of coupon specimens 53

5.1. Introduction 53 
5.2.1. Results of ABS specimens 53

5.2.1.1. Analysis and discussion on ABS specimens 54

5.2.2. Results of vinyl ester specimens $\quad 54$

5.2.2.1. Analysis and discussion on vinyl ester specimens 55

5.2.3. Summary of results $\quad 55$

5.2.4. Results of compression test specimens cut from wood guardrail offset block $\quad 56$

5.2.5. Conclusions $\quad 56$

$\begin{array}{ll}\text { 5.3. Tension test } & 57\end{array}$

5.3.1. Results of ABS specimens $\quad 57$

5.3.1.1. Analysis and discussion on ABS specimens 58

5.3.2. Results of vinyl ester specimens 58

5.3.2.1. Analysis and discussion on vinyl ester specimens 58

5.3.3. Results of tension test specimens cut from wood guardrail offset block $\quad 59$

5.3.4. Summary of results $\quad 59$

$\begin{array}{ll}\text { 5.4. Bending test } & 60\end{array}$

5.4.1. Results of ABS specimens 60

5.4.1.1. Analysis and discussion on ABS specimens 60

5.4.2. Results of vinyl ester specimens 61

5.4.2.1. Analysis and discussion on vinyl ester specimens 61 
5.4.3. Results of bending test specimens cut from wood guardrail offset blocks

5.4.4. Summary of results $\quad 62$

5.5. Impact test 63

5.5.1. Results of ABS specimens $\quad 63$

5.5.1.1. Analysis and discussion on ABS specimens 63

$\begin{array}{lll}\text { 5.5.2. Results of vinyl ester specimens } & 64\end{array}$

5.5.2.1. Analysis and discussion on vinyl ester specimens 65

5.5.3. Results of impact test specimens cut from wood guardrail $\begin{array}{ll}\text { offset blocks } & 65\end{array}$

5.5.4. Summary of results $\quad 65$

$\begin{array}{ll}\text { 5.6. Conclusions } & 65\end{array}$

5.7. Bending tests on dowel bars 66

$\begin{array}{ll}\text { 5.7.1. Pultruded bending test sample-1 (BRD) } & 67\end{array}$

5.7.2. Pultruded bending test sample -2 (BGD) 68

5.7.3. Compression molded bending test sample (BWD) 69

$\begin{array}{ll}\text { 5.7.4. Summary } & 70\end{array}$

\section{Chapter 6}

6. Recycled composite products $\quad 71$

$\begin{array}{ll}\text { 6.1. Introduction } & 71\end{array}$

$\begin{array}{ll}\text { 6.2. Dowel bars } & 72\end{array}$

6.2.1. Manufacturing dowel bar with recycled ABS 73

$\begin{array}{ll}\text { 6.2.2. Details of the mold } & 74\end{array}$ 
$\begin{array}{ll}\text { 6.2.3. Dowel bar manufacturing process } & 75\end{array}$

$\begin{array}{ll}\text { 6.2.4. Summary } & 78\end{array}$

$\begin{array}{ll}\text { 6.3. Angles } & 78\end{array}$

6.3.1. Details of the mold 78

$\begin{array}{ll}\text { 6.3.2. Manufacturing process of angle } & 79\end{array}$

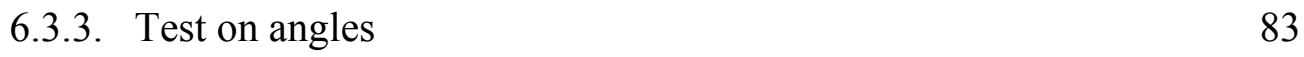

$\begin{array}{ll}\text { 6.3.3.1.Test specimen } & 83\end{array}$

$\begin{array}{lll}\text { 6.3.3.2. } & \text { Specimen preparation } & 84\end{array}$

$\begin{array}{lll}\text { 6.3.3.3. } & \text { Test procedure } & 84\end{array}$

$\begin{array}{lll}\text { 6.3.3.4. } & \text { Results } & 85\end{array}$

6.3.3.5. Remarks 86

6.4. Summary $\quad 86$

\section{Chapter 7}

7. Thermo-mechanical properties of the offset block 87

$\begin{array}{lr}\text { 7.1. Infrared Thermography } & 87\end{array}$

$\begin{array}{lr}\text { 7.1.1. Introduction } & 87\end{array}$

$\begin{array}{ll}\text { 7.1.2. } & \text { ThermaCAM } \\ & \text { TM } \\ \end{array}$

7.1.3. Testing Procedure 89

$\begin{array}{lll}\text { 7.1.3.1. } & \text { Summary } & 89\end{array}$

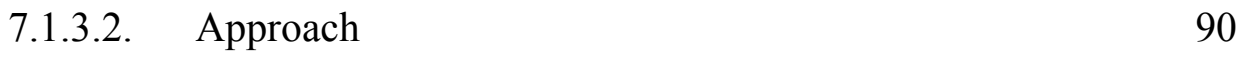

$\begin{array}{lll}\text { 7.1.3.3. Process } & 90\end{array}$

7.1.4. Limitations of infrared imaging 91

7.1.5. Summary 92 
7.2. Characterization of thermal propagation properties

7.2.1. Experimental set-up

7.3. Summary

\section{Chapter 8}

8. Finite Element Analysis

8.1. Introduction

8.2. Creating the geometry

8.3. Define materials and properties

8.4. Meshing

95

8.5. Applying loads

96

8.6. Applying constraints

96

8.7. Exporting the analysis model

97

8.8. Solving the model and viewing the results

97

8.9. Results

97

8.10. Summary

106

8.11. Limitations of FE analysis

8.12. Experimental study of the heat propagation within a sliced portion of the manufactured guardrail offset block

8.14. Observing temperature effect on test sample by analyzing FE model at $0^{\circ} \mathrm{F},-20^{\circ} \mathrm{F}$ and $-40^{\circ} \mathrm{F}$

8.15. Summary 


\section{Chapter 9}

$\begin{array}{ll}\text { 9. Conclusions } & 121\end{array}$

$\begin{array}{ll}\text { 9.1. Introduction } & 121\end{array}$

9.2. Summary of offset block manufacturing 121

$\begin{array}{ll}\text { 9.3. Summary of coupon specimens } & 124\end{array}$

$\begin{array}{ll}\text { 9.3.1. Compressive strength } & 124\end{array}$

$\begin{array}{ll}\text { 9.3.2. Tensile strength } & 125\end{array}$

$\begin{array}{ll}\text { 9.3.3. Bending strength } & 125\end{array}$

$\begin{array}{ll}\text { 9.3.4. Impact strength } & 126\end{array}$

$\begin{array}{lr}\text { 9.3.5. Conclusions } & 126\end{array}$

$\begin{array}{ll}\text { 9.3.6. Recommendations } & 127\end{array}$

9.4. Thermo-mechanical properties of the offset block 127

$\begin{array}{ll}\text { 9.4.1. Infrared thermography } & 127\end{array}$

$\begin{array}{ll}\text { 9.4.1.1. Limitations } & 129\end{array}$

$\begin{array}{ll}\text { 9.4.2. Finite element analysis } & 129\end{array}$

$\begin{array}{lr}\text { 9.4.3. Recommendations } & 130\end{array}$

$\begin{array}{ll}\text { 9.5. Summary of additional composite products } & 131\end{array}$

$\begin{array}{ll}\text { 9.5.1. Dowel bars } & 131\end{array}$

9.5.1.1. Recommendations 132

$\begin{array}{ll}\text { 9.5.2. Angles } & 132\end{array}$

9.5.2.1. Recommendations 133

$\begin{array}{ll}\text { 9.6. Recommendations for future research work } & 133\end{array}$

$\begin{array}{ll}\text { References } & 135\end{array}$

$\begin{array}{ll}\text { Appendix A } & 137\end{array}$ 


\section{List of Figures}

Figure 1-1 Guardrail system and cross-section of an offset block 5

$\begin{array}{ll}\text { Figure 2-1 Manual separation of solid waste } & 10\end{array}$

$\begin{array}{ll}\text { Figure 2-2 Gravity separator } & 10\end{array}$

Figure 2-3 Electrostatic separator 11

$\begin{array}{lr}\text { Figure 2-4 Clear PET bottles } & 12\end{array}$

$\begin{array}{lr}\text { Figure 2-5 HDPE bottles } & 13\end{array}$

Figure 2-6 Wheel barrow with green polypropylene hod 13

$\begin{array}{ll}\text { Figure 2-7 Wilton woven with polypropylene fibers } & 14\end{array}$

$\begin{array}{ll}\text { Figure 2-8 PVC pipes } & 14\end{array}$

Figure 2-9 ABS/PC major constituents in computer peripherals 15

Figure 2-10 Bridge over the Mullica River in Wharton State Park 17

Figure 3-1 Dog-bone tension test specimen with recycled ABS 21

Figure 3-2 Compression-molded tension test samples 22

Figure 3-3 Tension test of recycled ABS specimen in Instron machine with $\begin{array}{ll}\text { extensometer } & 23\end{array}$

Figure 3-4 Bending test specimen with recycled ABS 24

Figure 3-5 Bending test of ABS specimen with the loading head and supports 25

Figure 3-6 Compression test specimen 25

Figure 3-7 Compression test set up for ABS specimen 26

$\begin{array}{ll}\text { Figure 3-8 Impact test specimen with notch } & 27\end{array}$

Figure 4-1 Guardrail offset blocks and its constituents 29

Figure 4-2 Percentage composition of typical tire casting 32 
Figure 4-3 Representation of compression molding process

Figure 4-4 PHI Compression molding press with thermostat controls and temperature displays $\quad 34$

Figure 4-5 Steel frame for molding resin plates using compression molding $\quad 36$ Figure 4-6 Plates $(6.5 " \times 7.5 " \times 0.25 ")$ made out of different recycled blends 36

Figure 4-7 Offset block formed by bolting half blocks $\quad 40$

Figure 4-8 Unblended pellets on the block surface $\quad 42$

Figure 4-9 Inadequate amount of resin at sides creates voids and gaps 43

Figure 4-10 Final offset block with recycled ABS 44

Figure 4-11 Final offset block with recycled PC 44

Figure 4-12 Core module wrapped with glass fabric 45

Figure 4-13 Glass fabric wrapped around wooden core with premolded

$\begin{array}{ll}\text { polymer plates } & 45\end{array}$

Figure 4-14 Positioning the core modules in the 6" mold with additional resins on all sides and heaped on top $\quad 46$

Figure 4-15 Guardrail system with polymer offset block

Figure 5-1 Cross-section view of dowel bar $\quad 66$

$\begin{array}{ll}\text { Figure 5-2 Dowel bar sample-1 (Pultruded) } & 67\end{array}$

Figure 5-3 Dowel bar sample-2 (Pultruded) 68

Figure 5-4 Dowel bar sample-3 (Compression molded) 69

$\begin{array}{ll}\text { Figure 6-1 FRP dowel bars } & 73\end{array}$

$\begin{array}{ll}\text { Figure 6-2 Dowel bars in concrete slabs } & 73\end{array}$

Figure 6-3 Experimental mold setup for dowel bar manufacture $\quad 74$ 
Figure 6-4 Unblended resin pellets in the dowel due to inadequate heat transfer 75

Figure 6-5 Mold with dowel bar after first process cycle 76

Figure 6-6 Mold with additional pellets and premolded bar for following cycles 76

Figure 6-7 Appreciable surface finish and blending in dowel, with increase in $\begin{array}{ll}\text { process time } & 77\end{array}$

$\begin{array}{ll}\text { Figure 6-8 Angle mold top and bottom plates } & 79\end{array}$

Figure 6-9 Angle mold being filled with ABS resin $\quad 80$

Figure 6-10 Angle mold filled with ABS resin reinforced with glass fabric $\quad 80$

$\begin{array}{ll}\text { Figure 6-11 Mold compressed under pressure and temperature } & 81\end{array}$

Figure 6-12 Mold being cooled in the compression press under dead load $\quad 81$

Figure 6-13 Angle made of recycled ABS 82

Figure 6-14 Cross-section of the angle $\quad 82$

Figure 6-15 Tension coupons cut from angle 83

Figure 6-16 Tension test specimen in Baldwin machine $\quad 84$

Figure 6-17 Close up of the tension test setup $\quad 85$

Figure 6-18 Stress vs. Strain graph of tension specimen-1 cut from $\begin{array}{ll}\text { angle } & 85\end{array}$

Figure 7-1 Sample Infrared image with color graph $\quad 88$

Figure 7-2 Infrared camera, ThermaCAM ${ }^{\mathrm{TM}}$ S60 89

Figure 7-3 Thermal images of the hot mold taken at various time intervals during the manufacturing process of the block 91

Figure 8-1 Test sample modeled using FEMAP for thermal analysis 98 
Figure 8-2 Finite Element images of the sample during the heating phase

Figure 8-3 Finite element images of the specimen during cooling phase

Figure 8-4 Temperature curves at different distances from heat source in the test sample vs. time (heating phase)

Figure 8-5 Temperature curves at different distances from heat source in the test sample vs. time (cooling phase)

Figure 8-6 Temperature curves at different distances from heat source in the test sample with changed thermal conductivity (k') value vs. time (heating phase)

Figure 8-7 Temperature curves at different distances from heat source in the test sample with changed thermal conductivity (k') value vs. time (cooling phase)

Figure 8-8 Variation in temperature progression due to change in thermal conductivity $(\mathrm{k})$ values in heating phase

Figure 8-9 Variation in temperature progression due to change in thermal conductivity $(\mathrm{k})$ values in cooling phase

Figure 8-10 Sliced offset block on heated platen

Figure 8-11 Time vs. Temperature curves for points at different distances from heat source from Infrared images during heating phase $\left(250^{\circ} \mathrm{F}\right)$

Figure 8-12 Time vs. Temperature curves for points at different distances from heat source from both Infrared images and FE analysis during heating phase $\left(250^{\circ} \mathrm{F}\right)$

Figure 8-13 Time vs. Temperature curves for points at different distances 
from heat source from Infrared images during cooling phase $\left(70^{\circ} \mathrm{F}\right)$

Figure 8-14 Time vs. Temperature curves for points at different distances from heat source from both Infrared images and FE analysis during cooling phase $\left(70^{\circ} \mathrm{F}\right)$

Figure 8-15 Temperature vs. Time $\left(0^{\circ} \mathrm{F}\right)$ at different distances from heat source 112 Figure 8-16 Temperature vs. Time $\left(70^{\circ} \mathrm{F}\right)$ at different distances from heat source 112 Figure 8-17 Temperature vs. Time $\left(-20^{\circ} \mathrm{F}\right)$ at different distance from heat source 113 Figure 8-18 Temperature vs. Time $\left(70^{\circ} \mathrm{F}\right)$ at different distances from heat source 114 Figure 8-19 Temperature vs. Time $\left(-40^{\circ} \mathrm{F}\right)$ at different distance from heat source 114 Figure 8-20 Temperature vs. Time $\left(70^{\circ} \mathrm{F}\right)$ at different distances from heat source 115 Figure 9-1 Guardrail offset blocks on Star city bridge, WV, after 8 months of field installation. 


\section{List of Tables}

Table 3-1 Dimensions for tension test specimen 21

Table 3-2 Dimensions of bending test specimen 23

Table 4-1 Compatibility of polymers 50

Table 5-1 Compression test results of ABS specimens $(0.5 " \times 0.5 " \times 1 ")$ with and without glass fabric

Table 5-2 Average compressive stiffness and strength values of ABS specimens with and without glass fabric

Table 5-3 Compression test results of vinyl ester specimens $\left(0.5{ }^{\prime} \times 0.5 " \times 1\right.$ ") with and without glass fabric

Table 5-4 Average compressive stiffness and strength values of vinyl ester specimens with and without glass fabric

Table 5-5 Comparison of average compressive strength and stiffness values of ABS and vinyl ester samples with and without glass fabric

Table 5-6 Compressive stiffness and strength values of wood specimens

Table 5-7 Tension test results of ABS and without glass fabric specimens with and without glass fabric

Table 5-8 Average tensile stiffness and strength values of ABS specimens with and without glass fabric

Table 5-9 Tension test results of vinyl ester specimens with and without glass fabric

Table 5-10 Average tensile stiffness and strength values of vinyl ester specimens with and without glass fabric 
Table 5-11 Tensile stiffness and strength of wood test specimens

Table 5-12 Comparison of average tensile strength and stiffness values of ABS and vinyl ester samples with and without glass fabric

Table 5-13 Bending test results of ABS specimens $(0.5$ " $\times 0.25$ ”) with and without glass fabric

Table 5-14 Average bending stiffness and strength values of ABS specimens with and without glass fabric

Table 5-15 Tension test results of vinyl ester specimens $(0.5 " \times 0.25$ ") with and without glass fabric

Table 5-16 average bending stiffness and strength values of vinyl ester specimens with and without glass fabric

Table 5-17 Bending strength and stiffness values for wooden specimens $(0.5 ” \times 0.25 ”)$

Table 5-18 Comparison of average bending strength and stiffness values of ABS and vinyl ester samples with and without glass fabric respectively

Table 5-19 Impact test results of ABS specimens $(2.5 " \times 0.5 " \times 0.25 ")$ without glass fabric

Table 5-20 Impact test results of ABS specimens $(2.5 " \times 0.5 " \times 0.25 ")$ with glass fabric

Table 5-21 Impact test results of vinyl ester specimens $\left(2.5{ }^{\prime \prime} \times 0.5 " \times 0.25\right.$ ") without glass fabric

Table 5-22 Impact test results of vinyl ester specimens $\left(2.5{ }^{\prime \prime} \times 0.5 " \times 0.25\right.$ ") with glass fabric 
Table 5-23 Impact test results of wood specimens $(2.5 " \times 0.5 " \times 0.125$ ")

Table 5-24 Comparison of impact strength values of ABS, vinyl ester $\begin{array}{ll}\text { with and without glass fabric and wood specimens } & 65\end{array}$

Table 5-25 Notation of the dowel bars for bending test 66

Table 5-26 Bending strength and stiffness values of the dowel bars 70

Table 6-1 Dimensions of the tension test specimens 83

Table 6-2 Maximum tensile strength and stiffness values for the tensile $\begin{array}{ll}\text { test samples } & 86\end{array}$

Table 8-1 Thermal properties of fiber reinforced polymers 95

Table 8-2 Time taken to attain fraction of final temperature at 0.25 in distance from heat Source

Table 8-3 Time taken to attain different fractions of final temperature at 0.5 in distance from heat source

Table 8-4 Time taken to attain different fractions of final temperature at 1 in distance from heat source

Table A-1 Error in stress calculation 


\section{CHAPTER 1 \\ INTRODUCTION}

\subsection{General Remarks}

Approximately 1 billion pounds of plastics are being produced in the United States each year, and used for various applications like packaging (29\%), building (15\%), consumer products $(14 \%)$, transportation $(5 \%)$, furniture $(4 \%)$, electrical $(4 \%)$, exports (13\%), and others (16\%) (Stevens, 2002). Plastic waste streams from post-consumer products such as electronic, automotive and appliance industries often contain high value plastics. Separating these mixed plastics and using them for manufacturing industrial products have reduced their deposition in the landfills.

Environmental concerns and reduction in the available landfill capacity have promoted recycling of plastics from disposal of electrical and electronic equipment such as computer casings, housings, switchboards, keyboards and other similar components known as electronic shredder residue (ESR). The automotive industry is another substantial source for recycled engineering plastics (ABS, PP, and PC). Shredder residues recovered from obsolete appliances, disassembled car parts, industrial scrap plastics and consumer electronics mainly consist of polycarbonate (PC), polypropylene (PP), and acrylonitrile-butadiene-styrene (ABS). PC, PP and ABS filled streams represent about $85 \%$ of the plastic content being recovered (Kobler, 2002). The recovered resins are mixed with adequate amount of modifiers, stabilizers and compatibilizers during extrusion to improve process ability to approach virgin-material specifications.

Recycled polymers have been a cheap source of material for manufacturing several plastic and composite products used in numerous applications. The applications 
of thermoset composites have been widely demonstrated in construction, marine/waterfront structures, repair and rehabilitation of highways, bridges and beams, corrosion reduction, and other structural alternatives (Busel, 1995). Designing, developing, manufacturing and implementing recycled thermoplastic composite products will help the crucial issue of disposing plastic materials.

In order to manufacture and evaluate recycled thermoplastic composite products for highway and automotive applications, this research focused on various factors such as materials, manufacturing techniques, structural integrity, and design requirements. Development of offset blocks for highway and bridge guardrail systems using recycled thermoplastics is one of the main goals of this study. This work on thermo-mechanical property characterization of recycled thermoplastics is a part of the ongoing research at Constructed Facilities Center, West Virginia University (CFC-WVU) (Bargo 2000, Basto 2002).

\subsection{Objectives}

The objectives of this research are to:

- Refine the design and manufacturing process of guardrail offset blocks with discarded rubber tire core and recycled polymer shell with glass reinforcement that was previously developed by Basto (CFC-WVU) to satisfy field installation requirements in terms of:

- Dimensional requirements

○ Connection details

- Use of pre-manufactured thermoplastics inserts

○ Constituent/Component integrity 
○ Single vs. multiple offset block modules

- Identify processing parameters in terms of temperature, pressure and time for manufacturing the offset block with recycled polymers including optimum quantity of materials for manufacturing.

- Carry out finite element analysis on a section of manufactured offset block with thermal loading for identifying temperature profile within the sample and evaluate temperature increase with respect to time.

- Determine heat propagation in a coupon sample cut from the manufactured block exposed to a constant heat source through infrared imaging.

- Characterize strength and stiffness values of recycled ABS coupons (recovered from ESR) under tension, bending, compression and impact with and without glass fabric and make limited comparison with thermoset vinyl ester polymers.

- Carry out field installation of offset blocks manufactured with recycled polymers.

- Manufacture additional composite products such as angle plates (used as signpost, utility pole etc.) and dowel bars using recycled ABS, and characterize their mechanical properties.

- Evaluate manufacturing of composite products with new breed of thermoplasticcoated glass fibers composites (Twintex) and discuss its utilization for structural applications. 


\subsection{Scope}

\section{Coupon specimens}

Tensile, bending, impact and compressive tests were carried out on coupon specimens made of recycled thermoplastic (ABS) and thermoset vinyl ester with and without glass fibers to observe and compare their mechanical properties. Limited comparison was made with thermoset vinyl ester-glass composite specimens and conclusions were drawn. Tests were also done on coupon specimens cut from a field installed wooden guardrail offset block and compared with those made of recycled polymers that were used to manufacture offset blocks for highway guardrail applications. Long-term performance of these specimens due to aging is not considered in this study.

\section{Guardrail offset block}

Offset block connects post and rail of a guardrail system (Figure 1-1). Single or two-stage manufacturing was used to produce prototype-offset block during this research. Recycled polymer comprising ABS, and PC recovered from computer casings (ESR), were used with discarded rubber tires as core material to manufacture offset blocks. In addition to rubber tire strips, wood was also used as a core material in some of the blocks. 

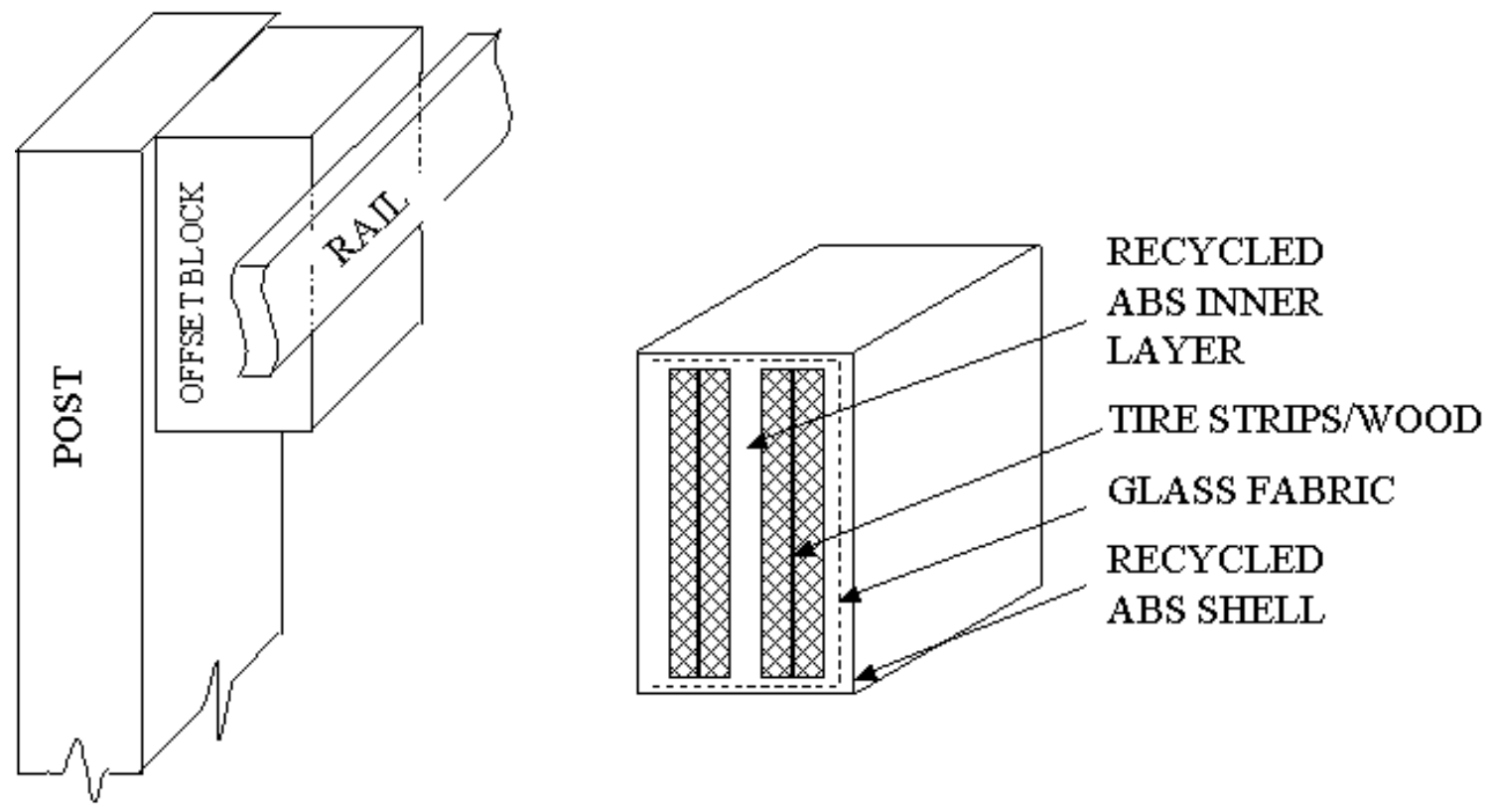

Figure 1-1 Guardrail system and cross-section of an offset block

Single offset block modules of thickness 6" to 8" thick were manufactured (Basto 2002). Processing parameters such as temperature, pressure and time were determined for manufacturing blocks or modules of different sizes. Several compression-molding trials were carried out to determine processing parameters for obtaining a good block with regard to uniformity in blending of resin pellets. Establishing and refining the manufacturing details for a final WVDOT specified dimension of 14 " $\times 6$ " $\times 6$ " offset block was carried out, about 25 blocks were manufactured. Few of these blocks were installed in field near Star City Bridge, Star City, WV.

Heat conduction properties of guardrail-offset block were evaluated using infrared imaging technique by testing a sliced section and studying temperature profile with respect to time. A finite element model was created representing the offset block section used in the experiment and analyzed under the effect of thermal loading with respect to time. 


\section{Recycled composite products}

Additional composite products such as angles and dowel bars were manufactured using recycled thermoplastics, mainly ABS through compression molding process. About 6 angles were manufactured using recycled ABS and glass fabric reinforcement and optimum process parameters in terms of temperature, pressure and time were determined after several trial of compression molding.

This report is organized into following chapters: Chapter 2 briefly discusses recycled materials, recycling methods, processing of polymers, application of recycled polymer composite products in various fields, including infrastructure. Chapter 3 includes details of the materials necessary to manufacture coupon specimens, their preparation and testing procedures used in this research. Chapter 4 explains manufacturing of guardrail offset blocks and provides process details. Chapter 5 presents test results of the specimens described in Chapter 3. Chapter 6 presents the manufacturing procedure for angles and dowel bars. Some of the tests performed on recycled polymer products are also discussed in this chapter.

Chapter 7 discusses application of infrared thermography, a non-destructive testing method to observe the heat flow pattern from mold to offset block specimen during manufacturing. Chapters 8 discusses results from finite element thermal analysis conducted on a sliced section of the offset block manufactured with recycled ABS reinforced with glass fabric, and discarded rubber tire strips. Chapter 9 provides conclusions drawn from this study and recommendations for future study. 


\section{CHAPTER 2 \\ LITERATURE REVIEW}

\subsection{Recycling of plastics}

Plastic recycling has become an established national industry with an expanding market for recycled plastic products. There are more than 1300 plastic products with recycled content known from the updates in Recycled Plastic Products Source Book by The American Plastics Council (Plastics Recycling, 2000). Potential recycling includes high-volume consumer products like soft drink bottles, discarded appliances, computers, and automotive wastes.

Waste management and recycling have been initiated due to the benefits as given below:

- Reduction in the need for disposal capacity

- Reduction in litter and improper disposal

- Reductions in energy use

- Reduction in manufacturing process impacts long-term value of conservation of raw materials

The process of waste reduction through recycling has many other advantages. Recycling reduces costs, creates jobs and businesses, and improves the environment and public health. By minimizing disposals in landfills, recycling helps in conserving global material resources.

The recyclable items reasonably viable in terms of technology and economics today are:

- Newspapers 
- Aluminum and steel cans

- Glass bottles and jars

- Plastic beverage containers

- Electronic shredder residue

- Automotive wastes

It is important to realize that the recovery and reuse of waste materials, residue, or scrap is constantly changing and expanding. Technology continues to advance and new ways are being found to process and make use of discarded materials that were formerly part of the waste stream.

Electronic waste is considered to be one major source of plastics recovery through the recycling process. Recyclers process more than 1.5 billion pounds of electronics equipment, annually and it is further accelerated by environmental conscious designs, take-back programs (Descul, 2004). An analysis commissioned by the Microelectronics and Computer Technology Corporation (MCC) estimated that the total electronics plastic scrap amounted to more than 1 billion pounds per year.

Plastics recycling require good knowledge in following four areas viz.,

1) Collection of plastics

2) Separation

3) Reprocessing technology, and

4) Markets for recycled products.

\subsection{Identification and recovery of plastic constituents}

Individual component of the recycled plastic supply stream are separated using techniques such as grinding, washing, and rinsing the shredder residue followed by skin 
floatation in which air bubbles attach to specific materials and enable the polymers with overlapping densities to be separated. The process of separation begins with tearing the incoming materials by shredding them through a pulper. Various mechanisms like magnetic separator, eddy current device, disc screen, trommel screens, traveling chain screen, and an air classifier are used for the separation process (Bargo, 2000).

Different types of separation techniques based on material type, size and physical properties are:

- Recover ferrous material: Magnetic separator

- Recover aluminum material: Eddy current device

- Separate smaller from larger material: Disc screen, Trommel screen.

- Separate material according to mesh size: Vibrating screen, Oscillating screen.

- Separate according to density difference: Traveling chain curtain

- Separate light material from heavy material: Air Classifier

Some of the separation methods used for separation of recycled material stream are:

Manual separation: The method is used at the incoming feed belt to scavenge easily separable items like paper, cardboard, glass containers and so on. It is one of the oldest techniques with little importance in modern plants (Figure 2-1).

Gravity separation: Vibrating tables, ballistic separators, and inclined conveyors for removal of stones and other heavy particles and fluidized bed separators are the commonly used gravity separators (Figure 2-2). 
Electrostatic separation: This method relies on the ability of some materials like plastics or paper, to acquire and hold an electrostatic charge. The particles are attracted to a charged roll or belt, or are deflected in an electrostatic field (Figure 2-3)

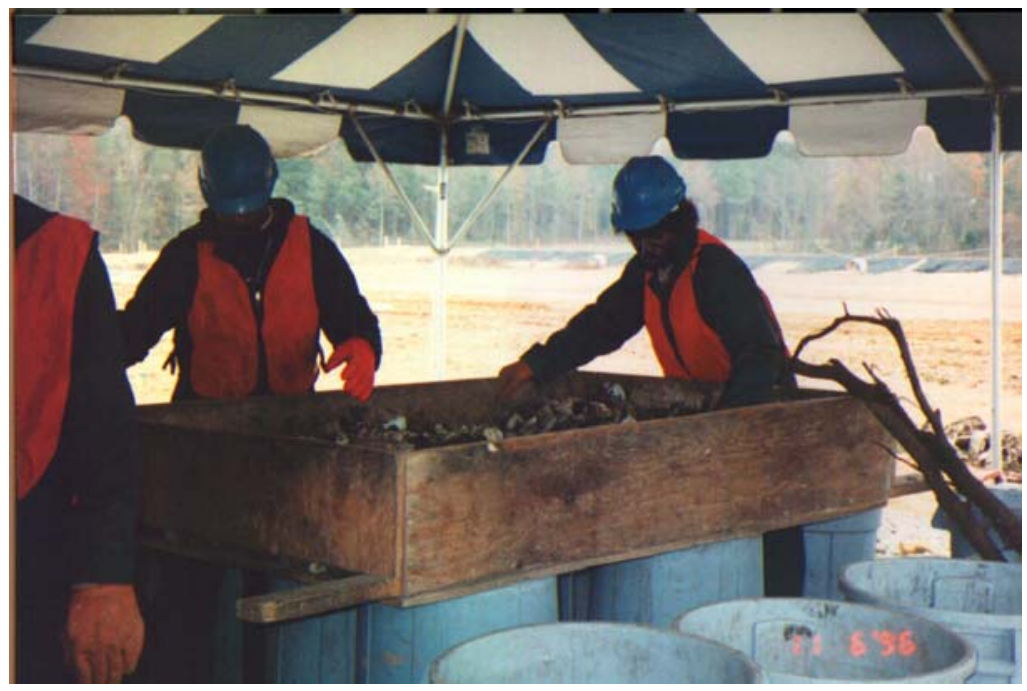

Figure 2-1 Manual separation of solid waste

(Ref: http://www-cee.engr.ucf.edu/classes/env4341/char6.htm)

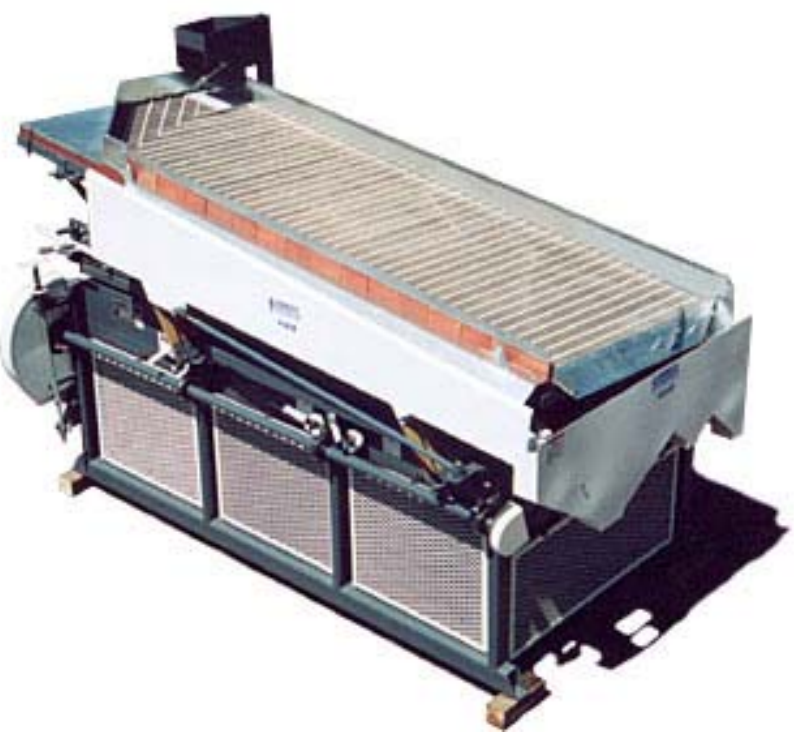

Figure 2-2 Gravity separator

(Ref: http://www.garrattindustries.com/separator_410B.html) 


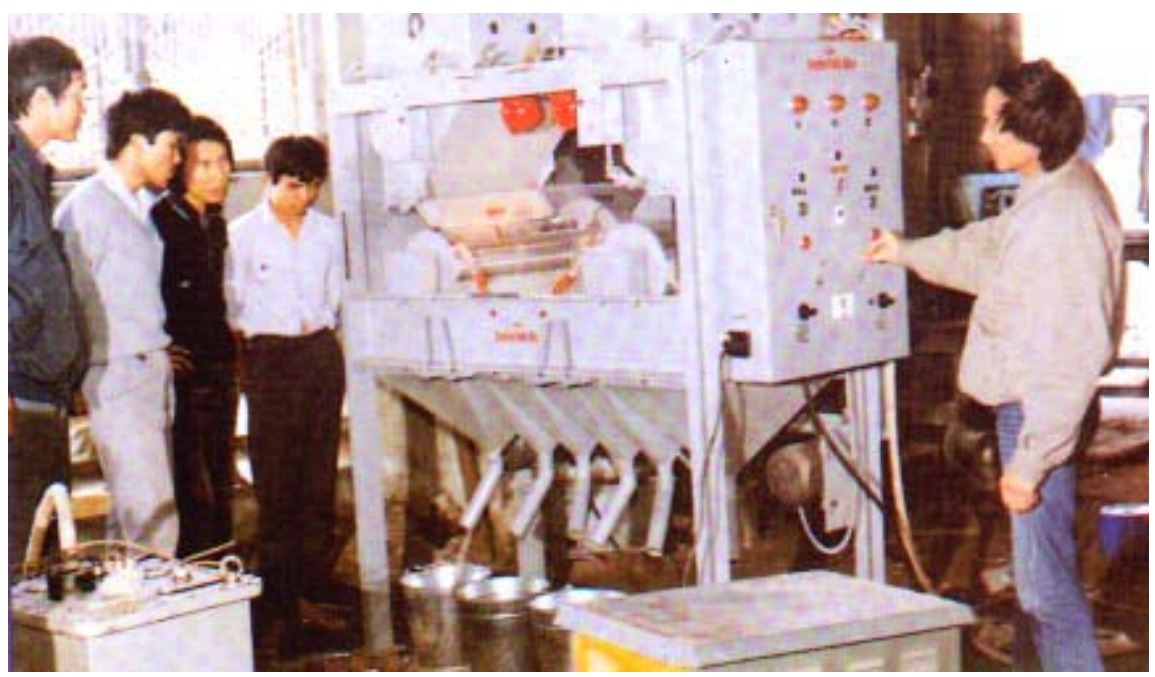

Figure 2-3 Electrostatic separator

(Ref: http://www.vaec.gov.vn/ ITRRE/TTTK.htm)

Color separation: This method may find use in the separation of colored plastics, in sorting of glass, according to color.

Air classification: Size, shape and specific gravity of the particles make this process possible. Air is fed through columns in different directions depending upon the degree of separation.

End use market research programs continues to focus on and expand the market utilization of the full range of polymers from waste stream including poly-ethylene terephthalate, high density poly-ethylene, poly-vinyl chloride (PVC), poly-styrene, polypropylene, poly-carbonates and acrylonitrile butadiene styrene. In the past decades a great deal of attention has been focused on recycling of plastics, both post-consumer commodity products, and engineering plastics as well. The global figure of dismantled cars was around 24 million in 1995, generating 2.2 million tons of plastic scrap (Liu, 1999).

Some of the recycled polymers and their market utility are described below: 
Poly Ethylene Terephthalate (PET) - Growth of PET container recycling is continuing with a rapid increase in the use of plastic beverage containers. Major markets for recycled PET continue to be in carpeting, fiberfill, and unsaturated polyester, polyols for urethane foam, strapping, engineering plastics and extruded products. New applications like thermoformed products and textiles/geo-textiles also offer additional marketing opportunities. The major soft drink companies, Coca-Cola Co. and Pepsi Co, Inc., are trying to utilize recycled PET in soft drink containers.

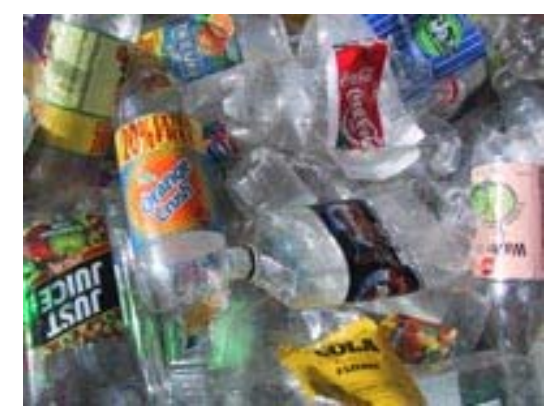

Figure 2-4 Clear PET bottles

(Ref: http://www.trashtransformers.com.au/recycling_how_what.html)

High Density Poly Ethylene (HDPE) - Many communities are beginning to collect milk and water jugs and detergent containers for HDPE recycling. Products for recycled HDPE are soft drink base cups, plastic pipes, plastic lumber, and various containers including household chemical containers. 


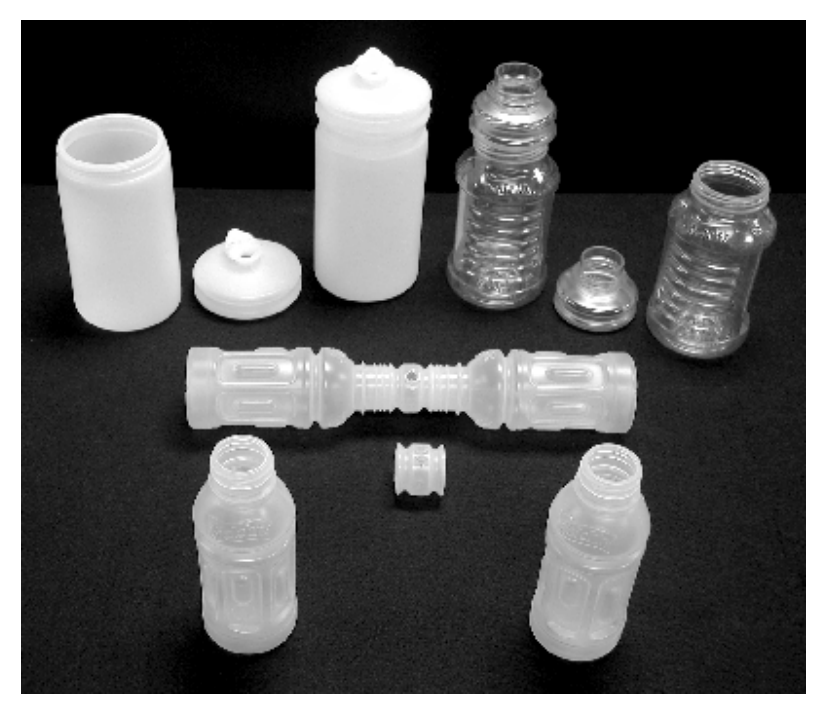

Figure 2-5 HDPE bottles

(Ref: http://www.belvac.com/)

Polypropylene (PP) - The list of products manufactured from recycled polypropylene PP resin include automotive batteries, bird feeders, furniture, pails, golf equipment, pallets, carpets to name a few.

Poly Vinyl Chloride (PVC) - Products not related to food or health care industries make excellent choices for manufacturing products from recycled (reprocessed) resins. Potential market includes downspouts, fencing and corrals, handrails, landscape timbers, sewer/drain pipe, telephone cables, window frames, refuse containers etc. A considerable amount of PVC is recycled as in-plant scrap.

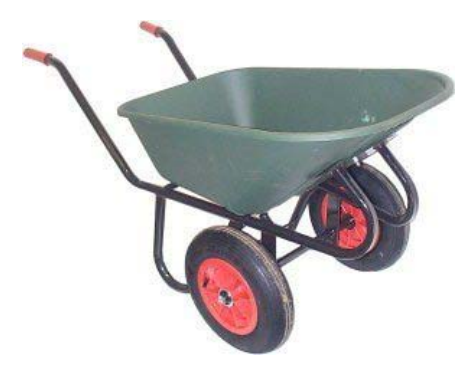

Figure 2-6 Wheel barrow with green polypropylene hod (Ref: http://www.easybarrow.co.uk/barrows/big_page_crs01.html) 


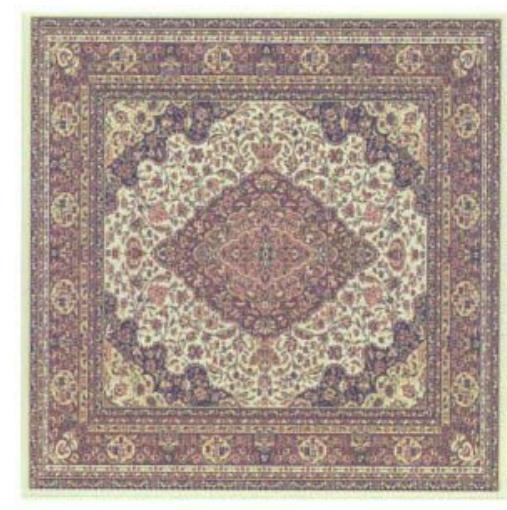

Figure 2-7 Wilton woven with polypropylene fibers

(Ref: http://www.dencities.com/denmall/denmall-rugs5a.html)

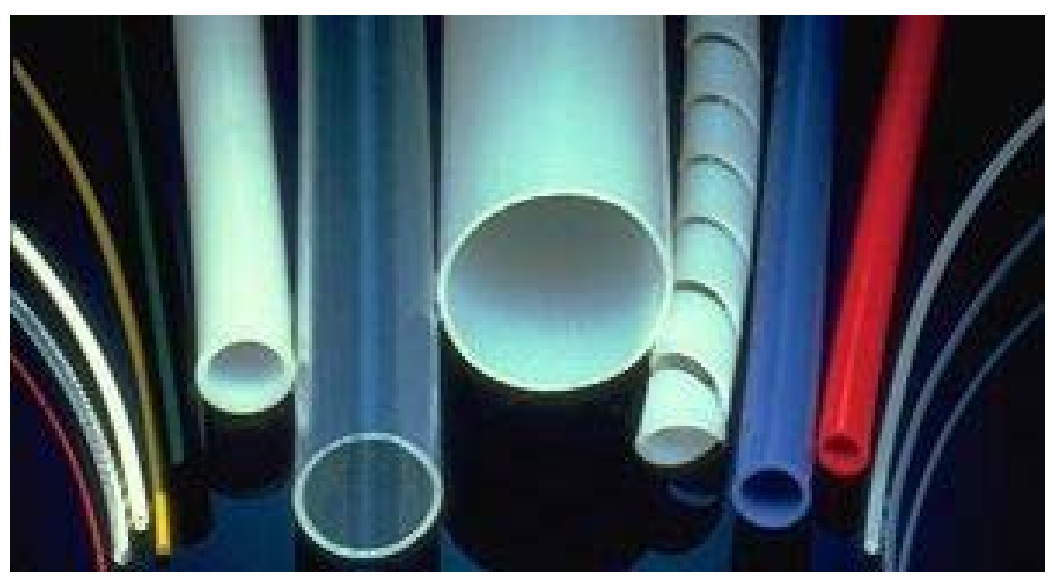

Figure 2-8 PVC pipes

(Ref: http://www.fluorplast.fi/termoplastisetletkut.html)

Polystyrene (PS) - Some potential products that can be manufactured from recycled PS resin include insulation board, appliance housings, and various trays.

Acrylonitrile Butadiene Styrene (ABS) - ABS is recovered from automotive appliances as well as electronic shredder residue. Bumpers, body panels, lighting systems, computer component housings, switches, sockets, wiring harnesses and circuit boards form very reliable sources of ABS and few other plastics in commingled form. 


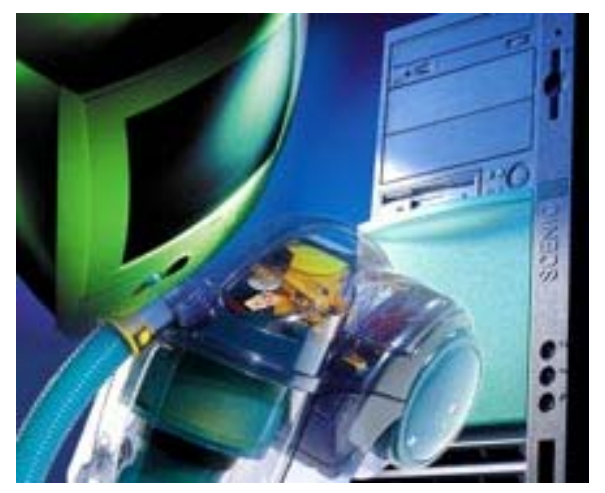

Figure 2-9 ABS/PC major constituents in computer peripherals (Ref: http://www.smc-alliance.com/gallery/gallery.html)

The polymers being recovered from computer casings, printer housings, and electronic applications providing electronic shredder residue comprises of combination of plastics, ABS and PC/ABS. The automotive shredder and electronic shredder residues are passed through a series of processing steps, which involve grinding, washing, and rinsing. Thermosets, polystyrene, nylon and other thermoplastics are removed by skin floatation stages. The effluent is treated and then discharged, while the recovered ABS, mixed plastics go to extrusion and pelletizing.

\subsection{Previous research on recycled polymers}

Dutta (1998) conducted an investigation of plastic composite materials for highway safety systems in 1998. Dutta's work on use of recycled polymers include highway barrier W-beam guardrail, posts, signposts, breakaway couplers, and crushable cushions for roadside sign or utility posts.

Guardrail systems for highway safety researched by Dutta included fiber reinforced polyester (FRP) and recycled plastics with saw dust as the fibrous additive. A $6.1 \mathrm{ft}$ long fiber-reinforced plastic (FRP) composite W-beam is designed and studied. 
Three different thicknesses were produced and tested under bending and crash impact to lead the following results:

- Maximum tensile strength of 65,000 psi was obtained after producing a series of batches by trial and error, showing that this design process is more an "art than science".

- FRP showed higher fracture initiation energy than steel. Due to the brittle nature of FRP, lower post-fracture energy absorption was observed.

- Stiffness was about one third of steel's stiffness. But this was not considered as a problem, since original shape of FRP beams is effectively recovered after load application, even after fracture of specimens.

- Study suggests that thickness should be higher for the W-beam made of FRP as compared to steel and recommends further research on splicing and jointing mechanisms which are critical areas of research. The joints are known to have early failures in pullout tests.

\subsection{Recycled composite bridge}

The thermoplastic bridge in New Baltimore, New York utilized recycled plastics for field implementation. It is a single lane bridge, $11 \mathrm{ft}$ wide with a $30 \mathrm{ft}$ span, designed for AASHTO H-15 truck. Its primary load carrying deck (superstructure) was made out of fiber reinforced plastic lumber (FRPL) (McLaren, et.al. 2001). The material used for this bridge consisted of 70,000 recycled one-gallon milk jugs. The total weight of the superstructure was $11,000 \mathrm{lb}$ with an addition of $5400 \mathrm{lb}$ of steel connection plates.

Environment News Service(2003) describes first all-plastic vehicular bridge that used unreinforced I-beams and other components made from recycled plastics installed in New 
Jersey. The $42 \mathrm{ft}$ single lane fire equipment access bridge over the Mullica River in Wharton State Park supports a loaded fire truck weighing 36,000 lbs. Post consumer recycled polymers like HDPE and Poly Styrene (PS) are used to develop a novel composite polymer material used for the bridge.

A recycled plastic bridge at Fort Leonard Wood, Missouri completed in 1998, on the Fort's Gammon Field used 13,000 pounds of recycled plastics. The structure was $25 \mathrm{ft}$ long and $26 \mathrm{ft}$ wide and supported by 6 steel beams that supported the original bridge and was designed to bear light-vehicles.

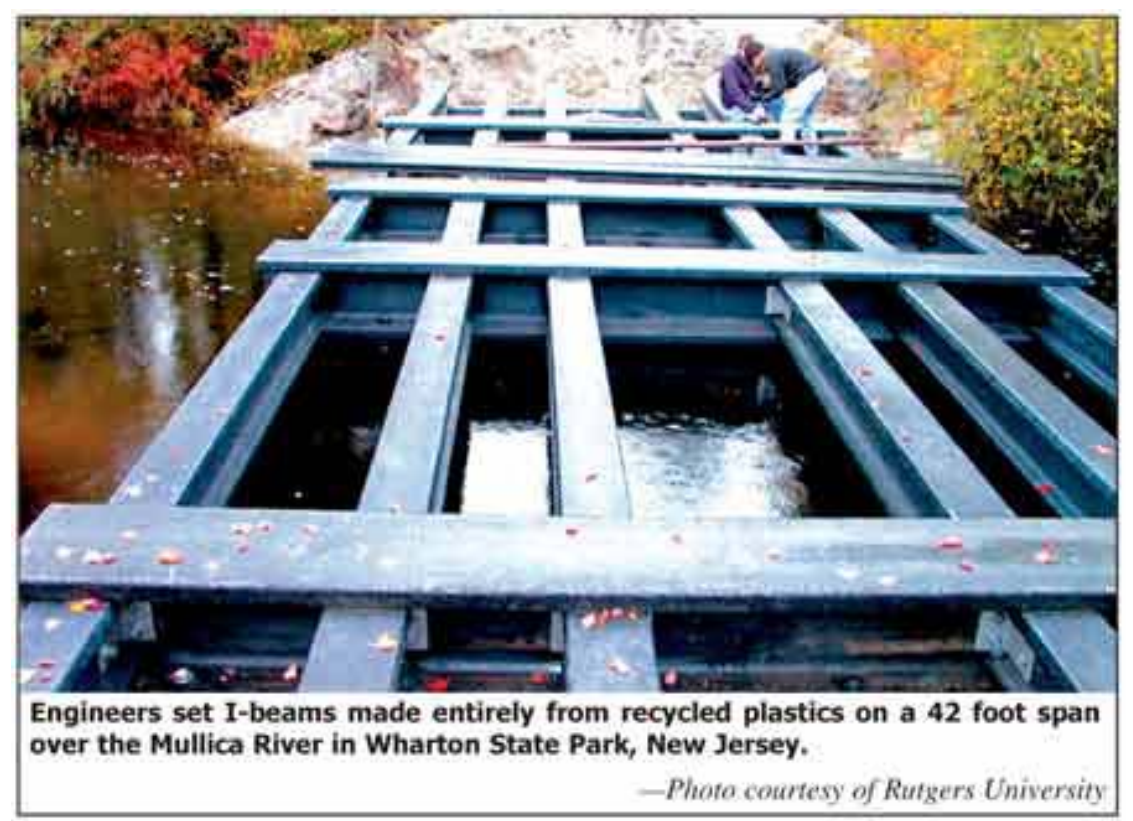

Figure 2-10 Bridge over the Mullica River in Wharton State Park

\subsection{Conclusions}

Polymer recycling is an emerging technology that has gained a good pace in the recent years, to an extent that research on molecular design of more recyclable polymers 
and additives is being actively explored. Properly designed recycled products have a reasonable market in the industry.

Recycled polymer composites have great potential as highway structural and nonstructural systems. Hence, manufacturing composite products using recycled thermoplastics and their mechanical property characterization were considered in this research.

Acrylonitrile Butadiene Styrene (ABS), the major constituent of ESR and ASR, was considered in this research. Compression molding process was used to manufacture recycled composite products. Guardrail offset blocks was considered as potential highway element that can be manufactured using recycled ABS reinforced with glass fabric and discarded rubber tire core. Other components such as angles and dowel bars were also considered as potential highway products made of recycled polymer composites. 


\section{CHAPTER 3}

\section{MATERIALS AND MANUFACTURING OF TEST COUPONS}

\subsection{Introduction}

Mechanical characteristics of the recycled thermoplastics is very important especially when they are used as raw materials in the manufacture of structural and nonstructural composite components related to different fields such as automotive, aerospace, construction and others. In a composite material, resins are combined with fibers to obtain products with specific properties such as high strength and stiffness. Fibers in a composite act as load-bearing elements whereas role of resin is to:

- Distribute applied loads to fibers

- Maintain fiber orientation

- Protect the fiber from environmental conditions

In this research, manufacturing process and processing parameters were determined based on the type of recycled thermoplastic resin (mainly ABS in our case). Glass fibers compatible with thermoplastic (ABS) resins were used to manufacture coupon specimens. In addition to ABS coupon specimens, vinyl ester specimens were prepared for comparison.

Description of the materials and summary of the testing procedure are provided in the following sections. Test specimens were manufactured in accordance with ASTM standards for tension, bending, compression, and impact tests. 


\subsection{Materials}

\subsubsection{Recycled polymers}

Acrylonitrile Butadiene Styrene (ABS), Polycarbonate (PC), Polypropylene (PP) and recycled resins were made available for research by SDR Plastics, a recycling plant located in Ravenswood, West Virginia. Resins were available in the form of flakes/pellets and their average size was less than 0.25 in.

\subsubsection{Glass fibers/fabric}

Two types of glass fabric available from Owens Corning Company and BGF industries were used in this research. The fabric was cut to required shape and dimensions to suit the various molds used to manufacture coupon specimens. The glass fabric supplied by Owens corning consisted of long continuous fibers woven in $0^{\circ}, 90^{\circ}$, and $\pm 45^{\circ}$. The glass fabric supplied by BGF industries consisted of bi-directional weave, $0^{\circ}$, and $90^{\circ}$, compatible with thermoplastic resins. This glass fabric was used with both recycled ABS and vinyl ester to make coupon specimens. Two layers of fabric were used to mold samples for the tests.

\subsection{Manufacturing of specimens}

Molds complying with ASTM standards were designed individually for each type of test: tension, bending, compression, and impact. Due to fiber wetting problems observed with $1 / 8$ " thick specimens, molds were redesigned to obtain product thickness of $1 / 4$ ". Fiber volume fraction of $3.68 \%$ was maintained in tension, bending and impact test specimens, while fiber volume fraction of compression test specimens was $1.84 \%$. 


\subsection{Tension test}

\subsubsection{Test specimen}

Dimensions for the tension test specimen molded with recycled ABS, conform to ASTM D3039/D 3039M (Figures 3-1 and 3-2). Dimensions of the test specimen are presented in Table 3-1. A steel frame was designed to mold the tensile test specimens.

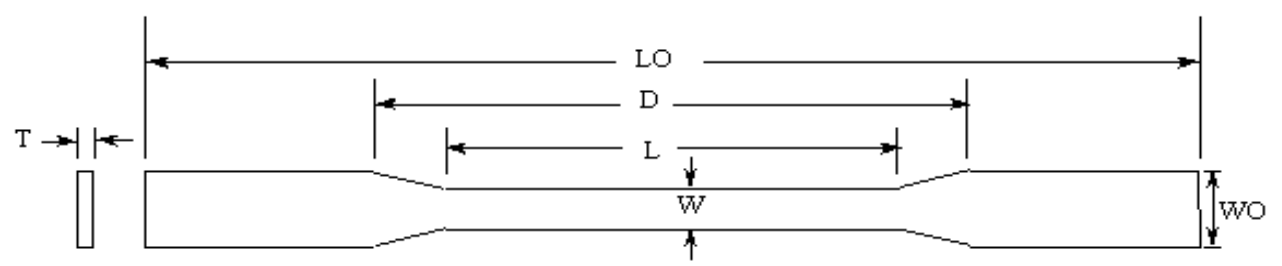

Figure 3-1 Dog-bone tension test specimen with recycled ABS

Table 3-1 Dimensions for tension test specimen

\begin{tabular}{|c|c|}
\hline Width of narrow section (W) & $0.5 "$ \\
\hline Width overall (WO) & $0.75 "$ \\
\hline Length overall (LO) & $8.5 "$ \\
\hline Thickness (T) & $0.125{ }^{\prime}$ \\
\hline
\end{tabular}

To manufacture samples with fabric, fabric was cut in accordance with the shape and dimension of the slots in the mold. However, disorientation of fibers in the fabric was noted during the fabric cutting including loosening of fibers. Samples were made with and without fabric using recycled ABS and vinyl ester. 
During later part of research, dog bone shape of the specimens was modified into rectangular shape. Steel tabs were attached to the ends of the rectangular test specimens to prevent slipping and crushing of the specimens at the grip location.

\subsubsection{Specimen preparation}

Test specimens were manufactured using compression molding equipment. Recycled ABS was filled into specific steel frame molds covered with aluminum plates (flash) for better surface finish and placed in between top and bottom plates of compression molding equipment. Surfaces of specimens were roughened at the ends for attaching steel plate grips using Pliogrip (adhesive).

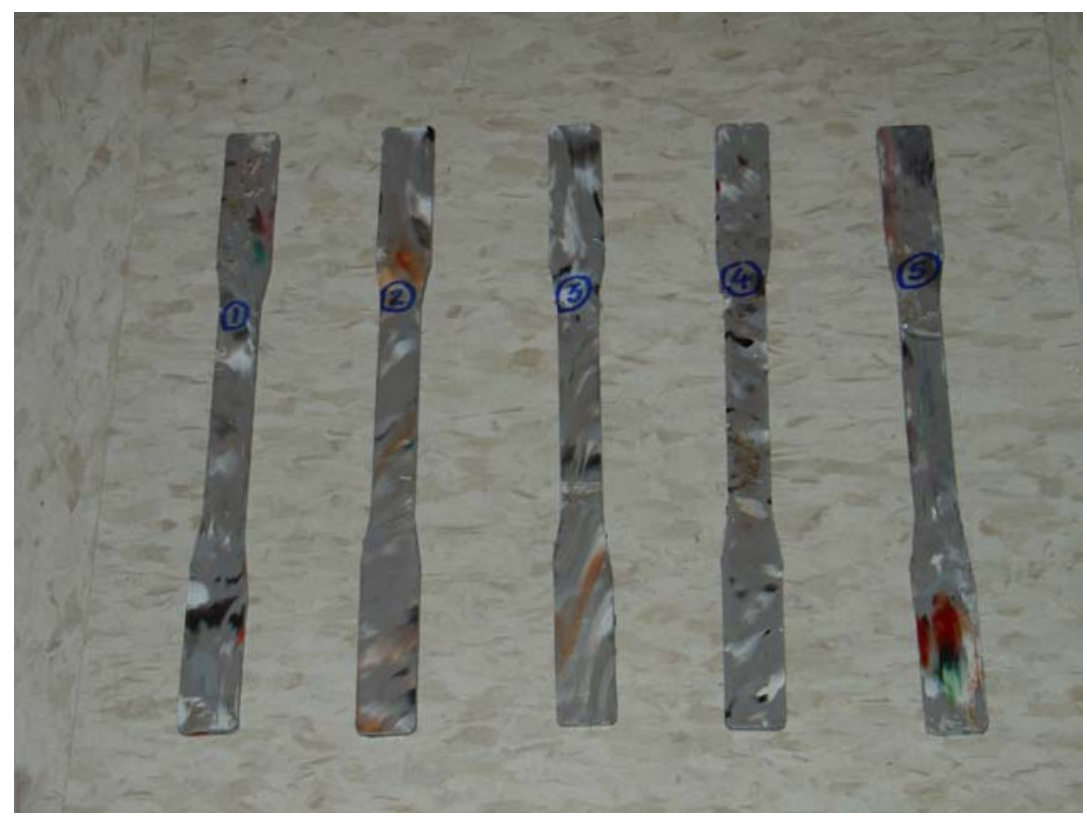

Figure 3-2 Compression-molded tension test samples

\subsubsection{Tension test setup and procedure}

An Instron 8500 two-column load frame-testing machine was used for performing the computer controlled tension test (Figure 3-3). "Wavemaker" software provided by the loading frame manufacturer was utilized to carry out the tests. A constant head 
displacement rate of $0.2 \mathrm{in} / \mathrm{min}$ was applied to a test specimen and maximum 2" elongation was specified as the end point. Tests were done to find the load vs. elongation values including strain value measurement using extensometer.

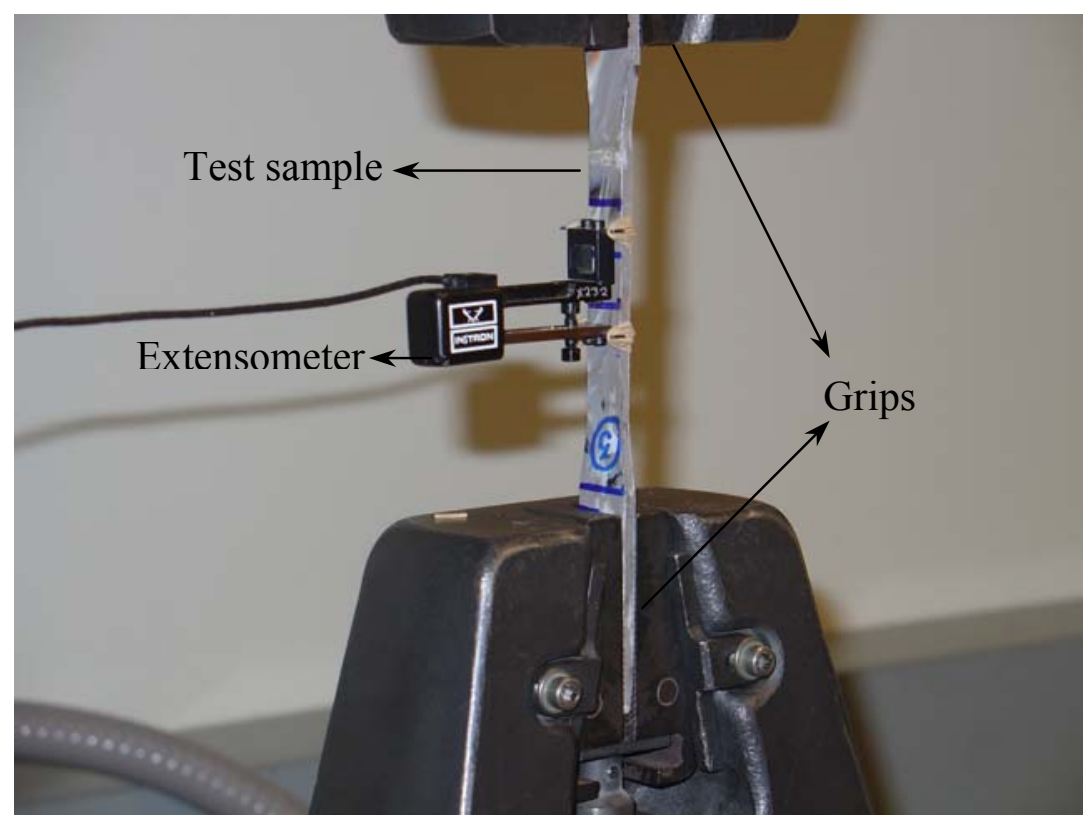

Figure 3-3 Tension test of recycled ABS specimen in Instron machine with extensometer

\subsection{Bending test}

\subsubsection{Test specimen}

Dimensions for bending test specimens molded from thermoplastic resin (ABS) were in accordance with ASTM D790-99 as shown in Table 3-2.

Table 3-2 Dimensions of bending test specimen

\begin{tabular}{|c|c|}
\hline Width (W) & $0.5 "$ \\
\hline Length overall (LO) & $5 "$ \\
\hline Distance between the supports (L) & 4 ” \\
\hline Thickness (T) & $0.25 "$ \\
\hline
\end{tabular}

*Refer to Figure 3-4 


\subsubsection{Specimen preparation}

A rectangular cross-sectioned $0.5 " \mathrm{X} 0.125 "$ sample was molded according to ASTM standards, to a length of 5". The thickness was increased to 0.25 " to manufacture specimens with fabric. For further testing, specimens with dimension $10 " \times 0.5 " \times 0.25$ " (support span of 7.5" was maintained in all the tests) were molded with and without glass fabric using recycled $\mathrm{ABS}$ and vinyl ester.

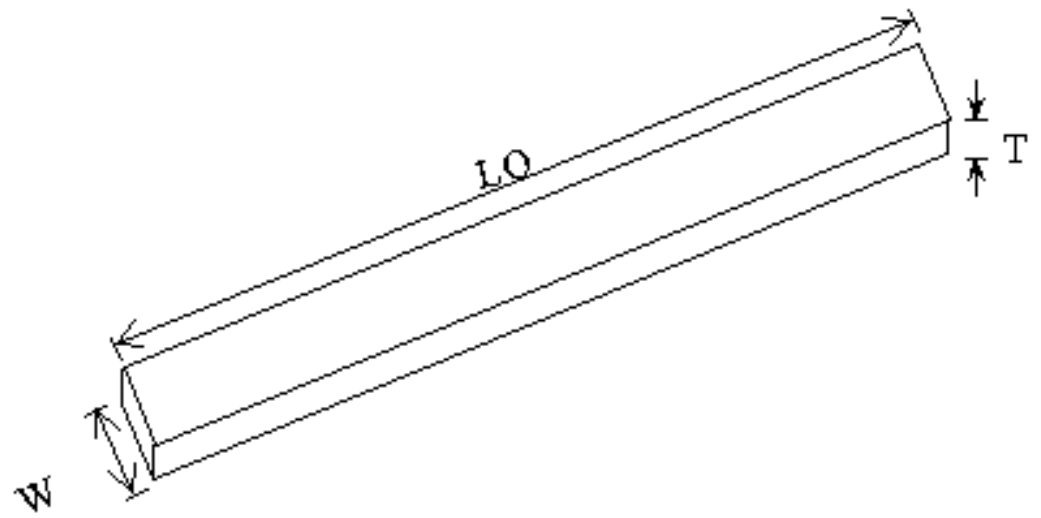

Figure 3-4 Bending test specimen with recycled ABS

\subsubsection{Bending test set-up and procedure}

Instron 8500 two-column load frame-testing machine was used for performing the computer controlled bending test (Figure 3-5). "Wavemaker" software provided by the loading frame manufacturer was utilized to carry out the tests while the strain data was recorded using a separate data acquisition apparatus installed with "Strain smart" software. Strain gauge was installed on the specimen at mid-span for strain measurement. A constant loading rate of $0.65 \mathrm{in} / \mathrm{min}$ was applied to specimen failure or until deflections greater than one third of the span were attained. The test was done to find load vs. deflection values of the specimens and test results are presented and analyzed in Chapter 5. 


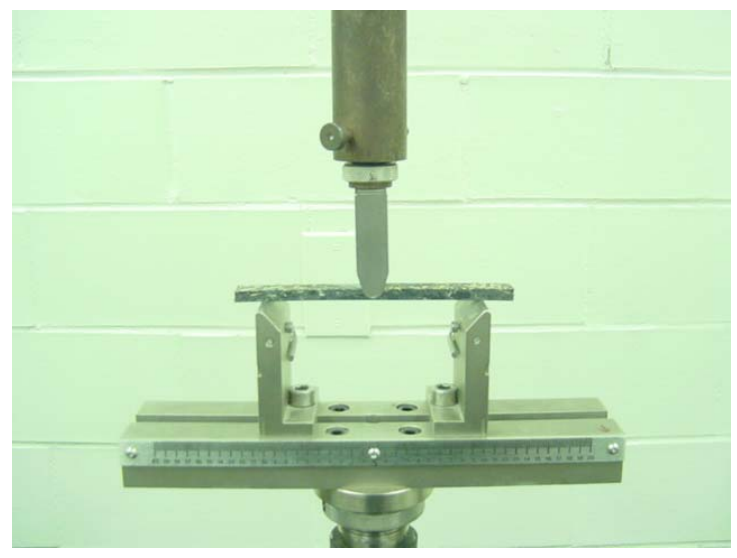

Figure 3-5 Bending test of ABS specimen with the loading head and supports

\subsection{Compression test}

\subsubsection{Test specimen}

Specimens with square cross section $\left(0.5^{\prime \prime}\right)$ with height 1 " were molded using thermoplastic resin (ABS). The dimensions were in accordance with ASTM D695-91 and an aspect ratio of 2 was maintained as shown in Figure 3-6.

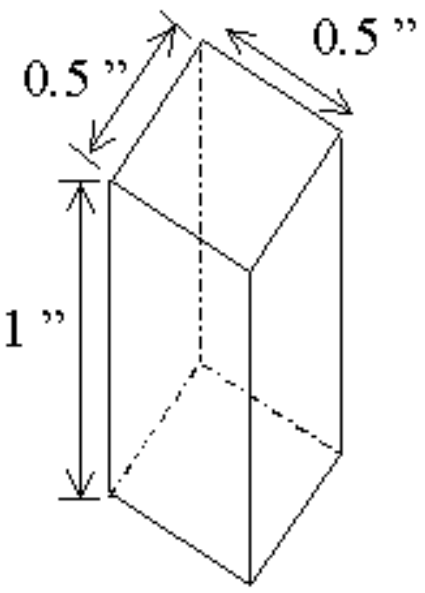

Figure 3-6 Compression test specimen 


\subsubsection{Compression test set-up and procedure}

An Instron 8500 two-column load frame-testing machine was used to perform the computer controlled compression test (Figure 3-7). "Wavemaker" software provided by the loading frame manufacturer was utilized to carry out the tests. A constant loading rate of $0.01 \mathrm{in} / \mathrm{min}$ was applied to specimen until failure. The test was done to find the load vs. deflection values of the specimen.

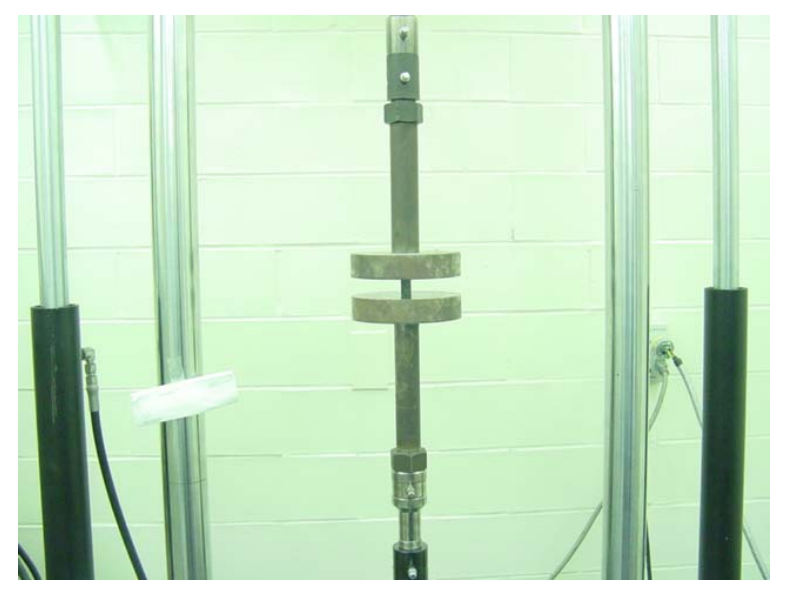

Figure 3-7 Compression test set up for ABS specimen

\subsection{Impact test}

\subsubsection{Test specimen}

Specimens with rectangular cross section $(0.5 " \times 0.125 " \times 2.5 ")$ were molded with recycled ABS and were in accordance with ASTM D25-93A. The thickness was increased to 0.25 " to manufacture specimens with fabric. Specimens with dimensions $0.5 " \times 0.25 " \times 2.5$ " were molded for further tests with and without glass fabric using recycled $\mathrm{ABS}$ and vinyl ester. 


\subsubsection{Specimen preparation}

The molded specimens were notched at mid span, to a depth of 0.1" (Figure 3-8). The included angle in the notch was $45^{\circ}$. Testing of the specimens was done after atleast 30 minutes for stress relaxation.

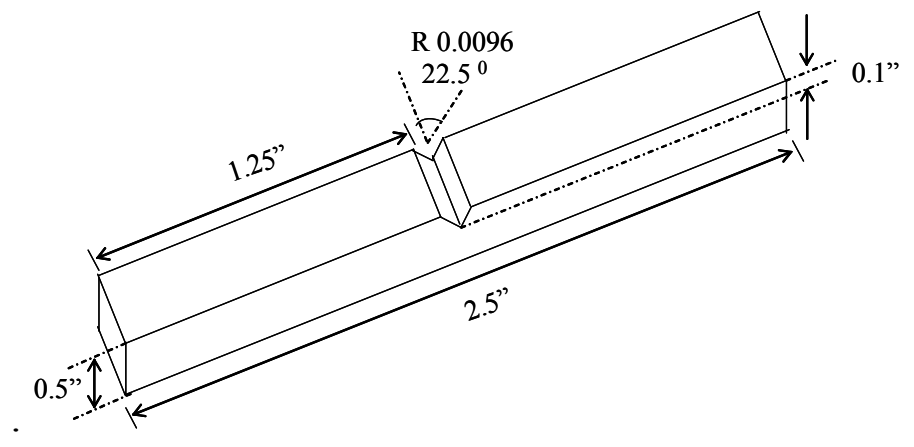

Figure 3-8 Impact test specimen with notch

\subsubsection{Impact test setup and procedure}

Izod type of testing was used, wherein a pendulum strikes the specimen and the impact strength value can be directly read from the scale attached. A BLI series impacttesting machine was used with no additional weights to the pendulum. A correction chart supplied by the manufacturer (BLI series manual, 1999) was used in accounting for pendulum friction and windage.

The pendulum was released freely without the specimen, and the pointer reading is noted. It is again released without setting back the pointer, until a steady value is obtained. These two values were plotted on the correction chart and a line as drawn to connect the both. Then, the values obtained from the specimens were plotted on this line to get the corrected values. 


\subsection{Summary}

Dimensions of the test specimens and their manufacturing procedures were discussed in this chapter. The specimen preparation, test procedure and test instrumentation for compression, bending, tension and impact were also discussed in this chapter. The results of these tests were discussed in Chapter 5. 


\section{CHAPTER 4}

\section{MANUFACTURING OF THE GUARDRAIL OFFSET BLOCK}

\subsection{Introduction}

Wooden offset blocks treated with Creosate oil were being used on guardrail systems on highways and bridges. Due to a potential attack of the on the groundwater table, research on use of alternate environmental-friendly materials (like recycled thermoplastics) were initiated. Offset blocks for the highway guardrail system were produced using recycled polymers with glass fabric reinforcement. Required design modifications were made to the recycled offset blocks previously manufactured at CFCWVU to suit the type of steel post for guardrail system used by WV Department of Transportation. An offset block with recycled polymers consisted of energy absorbing core made of scrap rubber tires to absorb impact energy that was enclosed in a shell made of recycled thermoplastic pellets and reinforced with glass fabrics (Figure 4-1). Modified blocks manufactured in this research were installed near Star City Bridge, Morgantown, WV.

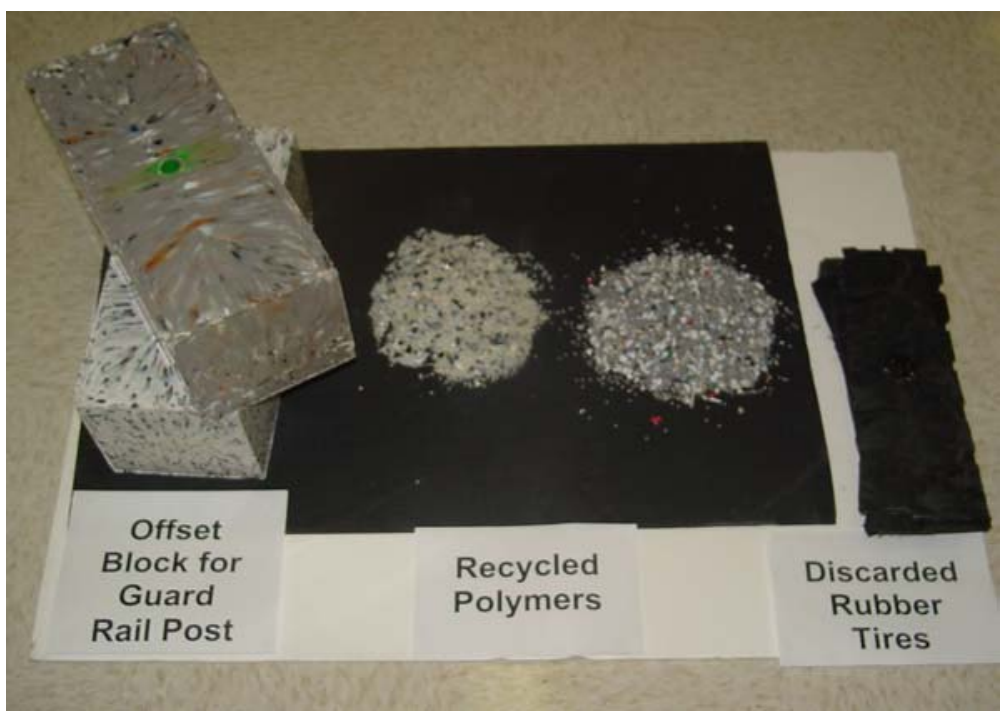

Figure 4-1 Guardrail offset blocks and constituents 
Various sections in this chapter describe steps involved in arriving at the final manufacturing procedure for the guardrail-offset block including few subsequent modifications.

Descriptions of the recycled polymers, discarded tires and glass fabrics are provided in section 4.2. This is followed by description of the equipment details, i.e., about the compression press used for the manufacturing of various products during this entire research in section 4.3. Manufacturing process is discussed in section 4.4, which includes pre-molding operations to start the molding process, testing the resin compatibility by making sample plates, and using suitable resins for making blocks. Various stages involved in development of prototype guardrail offset block, along with the process outline for making blocks are also described as a part of section 4.4. After arriving at the final procedure for manufacturing guardrail offset block, procedure for making blocks with wooden and tire strips as core is described in section 4.5. Further modifications like introducing premolded pipes for product improvement/manufacturing is discussed in section 4.6. An overview of the entire process, along with few conclusions drawn from the study is provided in section 4.7 .

\subsection{Material overview}

\subsubsection{Recycled polymer resins}

Manufacturing process was carried out using ABS recovered from various recycling sources. These thermoplastics were recovered mainly from Electronic Shredder Residue and Automotive Shredder Residue. Several batches of recycled resins were obtained by CFC-WVU during this research as listed below. 
- Blend of ABS and PC with purity level above 90\% as per supplier's MSDS sheet (SDR Plastics)

- Blend consisting of ABS of two grade purity

- ABS blend with few other polymers

- Polypropylene blend

- Polycarbonate blend

Coupon specimens manufactured from recycled polypropylene had large percentage of voids and was not considered for further research. Coupon specimens manufactured from polycarbonate had uniform blending, fusing between the pellets, and good surface finish and were used to make few offset blocks. However, ABS was selected as a good source for manufacturing offset blocks based on the ease of manufacturing, availability and excellent thermo-mechanical properties.

Initially, coupon specimens were made from different batches of recycled resin that were made available by SDR plastics to characterize its processability and manufacturability. Depending upon the degree of uniformity and blending observed from the coupon specimens, the resins were either accepted or rejected for making offset blocks. Compression molding process was used to verify the suitability of a given polymer stream for processability and usability as a structural component. Different recycled polymer blends consisted of ABS of two grades (purity) and ABS with few other polymers. Polypropylene was also tested as a possible resin for manufacturing structural products. However, it was not used due to its incompatibility in resin-blending (melting) and voids formation. 


\subsubsection{Glass fabric}

Woven glass fabric was used to reinforce the recycled polymer shell encasing the rubber tire core. Glass fabric consisted of fibers in $90^{\circ}, 0^{\circ}, \pm 45^{\circ}$.

\subsubsection{Rubber tires}

Rubber used for the offset blocks was recovered from automobile tires, cut into suitable strips and stacked to constitute the core. Tire strips were cut from discarded automobile tires, with a reciprocating handsaw. Tire strips were used to form the offset block core for their energy absorption property and inherent strength/stiffness due to the presence of steel strands.

Scrap tires: Despite the fact that the scrap tires represent about $1.2 \%$ of all solid wastes, they present special disposal and reuse challenge because of their size, shape, and physicochemical nature. Since 1983, all new car and light truck tires, as well as replacement tires sold for passenger cars or light trucks, have been steel belted radials. Steel-belted radial heavy truck tires are beginning to replace bias ply heavy truck tires, which have been the norm in the trucking industry. The composition of a typical tire casting is given in Figure 4-2.

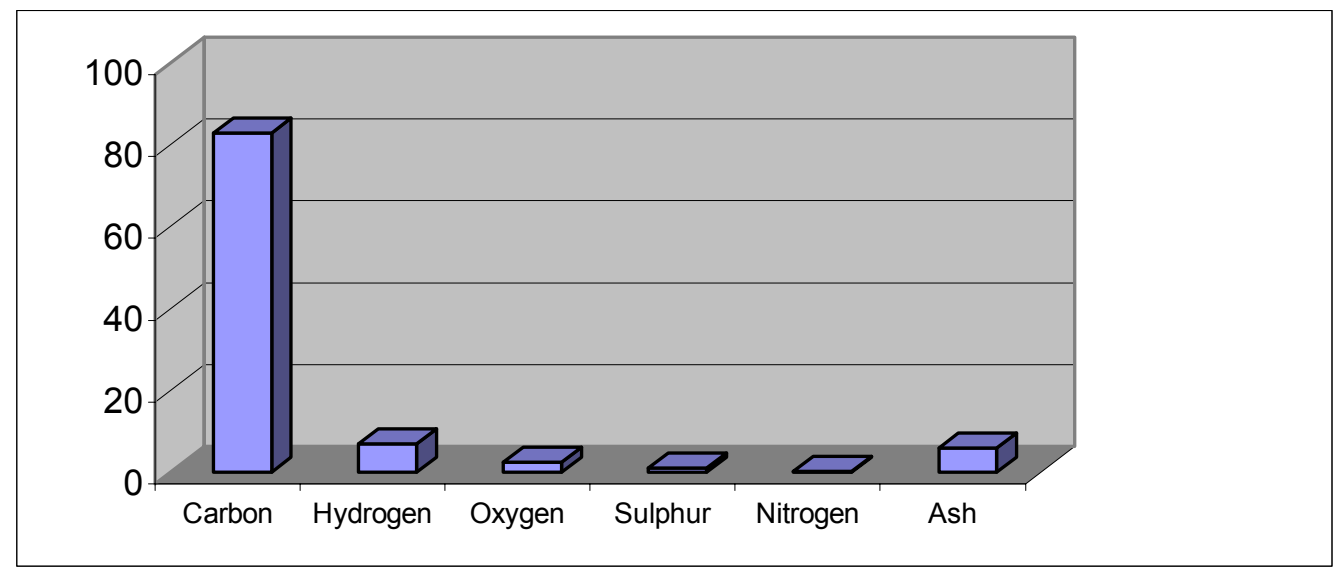

Figure 4-2 Percentage composition of typical tire casting 
Nationally, recycling, reuse, and recovery practices for scrap tires currently consume about $34.5 \%$ of the tires discarded annually. The remaining $65.5 \%$ are land filled or stockpiled.

Size reduction of a scrapped tire is achieved through the process of chopping, shredding, grinding, or cutting. Cutting the tire into strips can be automated or done by running it through the cutting machine.

\subsection{Equipment and accessories}

Various equipment needed to carry out the manufacturing using compression molding process were:

Compression press: A schematic representation of pressure application in compression molding press is shown in Figure 4-3. PHI compression-molding machine (Figure 4-4) with a maximum load capacity of 50 tons and safe operable temperature up to a maximum of $600^{\circ} \mathrm{F}$ was used. The compression machine had platens of $18.5 \mathrm{in} \times 12.5 \mathrm{in}$ size adequate to produce offset blocks of dimensions 14 in $\times 8$ in $\times 6$ in in a single stage. Machine has an air purge and cooling water supply. Cooling water enables a uniform and faster cooling when compared to the air-cooling provided by a fan. Air purge was used to let off any remaining moisture/water content in the platens before heating for the next cycle. Molds designed to produce products ranging from small coupon plates to full size offset blocks. 


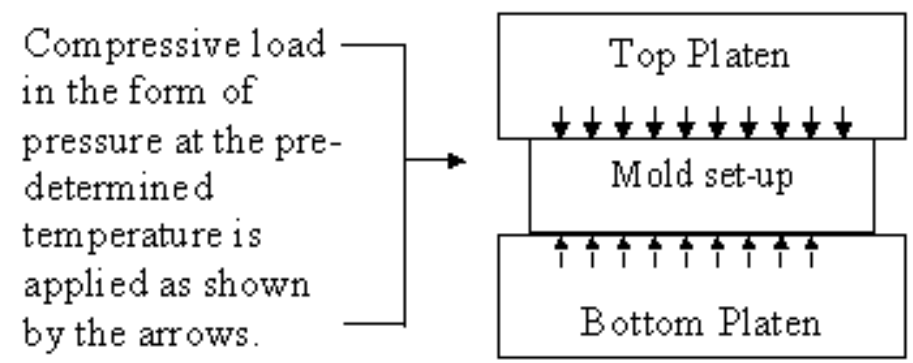

Figure 4-3 Representation of compression molding process

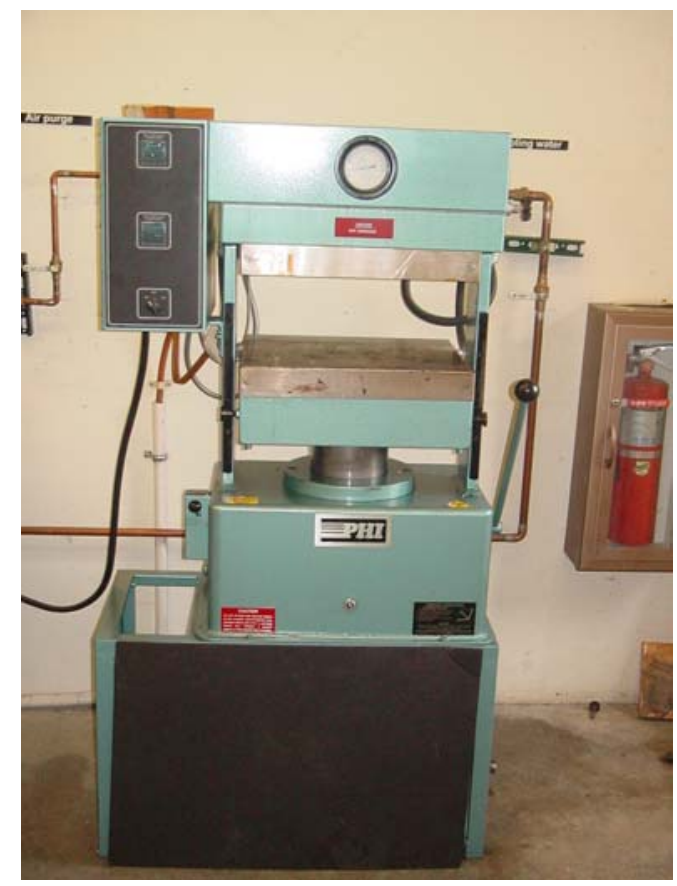

Figure 4-4 PHI Compression molding press with thermostat controls and temperature displays

\subsection{Manufacturing process}

Manufacturing sequence of the offset block consisted of following steps:

- Molding small plates (tabs) out of resin received from recycling plant and use of compatible resins for further research.

- Manufacturing core blocks using tire strips/wood and polymer resin. 
- Manufacturing prototype size block.

- Refining processing parameters by varying magnitude of applied temperature, time and pressure.

\subsubsection{Pre-molding operations}

The platens were cleaned to ensure that there were no surface impurities, dust particles or oil. Aluminum foil (heavy duty) was wrapped over the platens to avoid possible deposition of the excess polymer oozing out of the mold during manufacturing. After ensuring that the cooling water supply was closed, air purge was applied until any moisture in the platen was driven out through the exit. Process temperature was set using thermostat controls before switching the heaters on.

The molds were cleaned to remove surface impurities. Aluminum flash was cut in the shape of the mold interior, and placed in the mold with a generous coating of demolding agent (Tech Lube 25, Technick Products). The mold was then filled with its constituents and then compression molding was carried out.

\subsubsection{Testing the compatibility of resins}

Different polymer blends obtained were tested for mutual compatibility through compression molding process. Small plates (Figures 4-6 (a) to (h)) of 0.25 in thickness were made with a rectangular steel frame (Figure 4-5) using compression-molding process. 


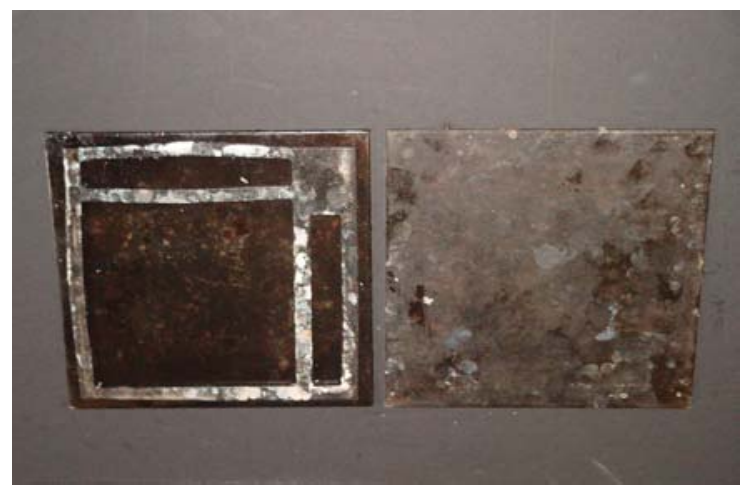

Figure 4-5 Steel frame for molding resin plates using compression molding

Process parameters like temperature and pressure were determined through trial and error technique by altering them during each molding cycle until desired degree of blending and uniformity was obtained. Temperatures from $400^{\circ} \mathrm{F}$ to $500^{\circ} \mathrm{F}$, and load of 20 tons were used for producing the plates with recycled resins.

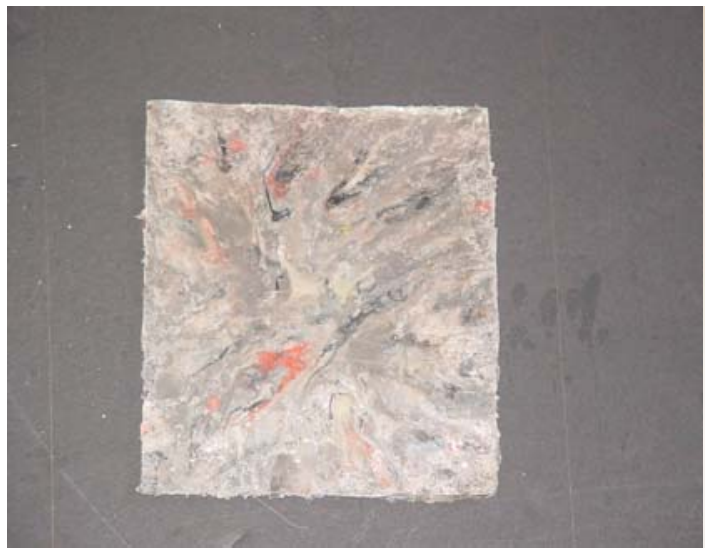

(a) $450^{\circ}$ F (4 minutes)

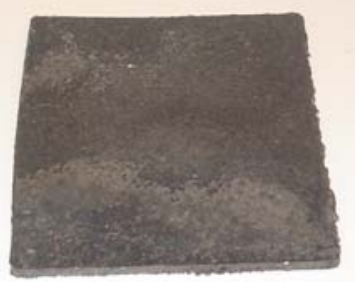

(b) $560^{\circ} \mathrm{F}(5$ minutes) 


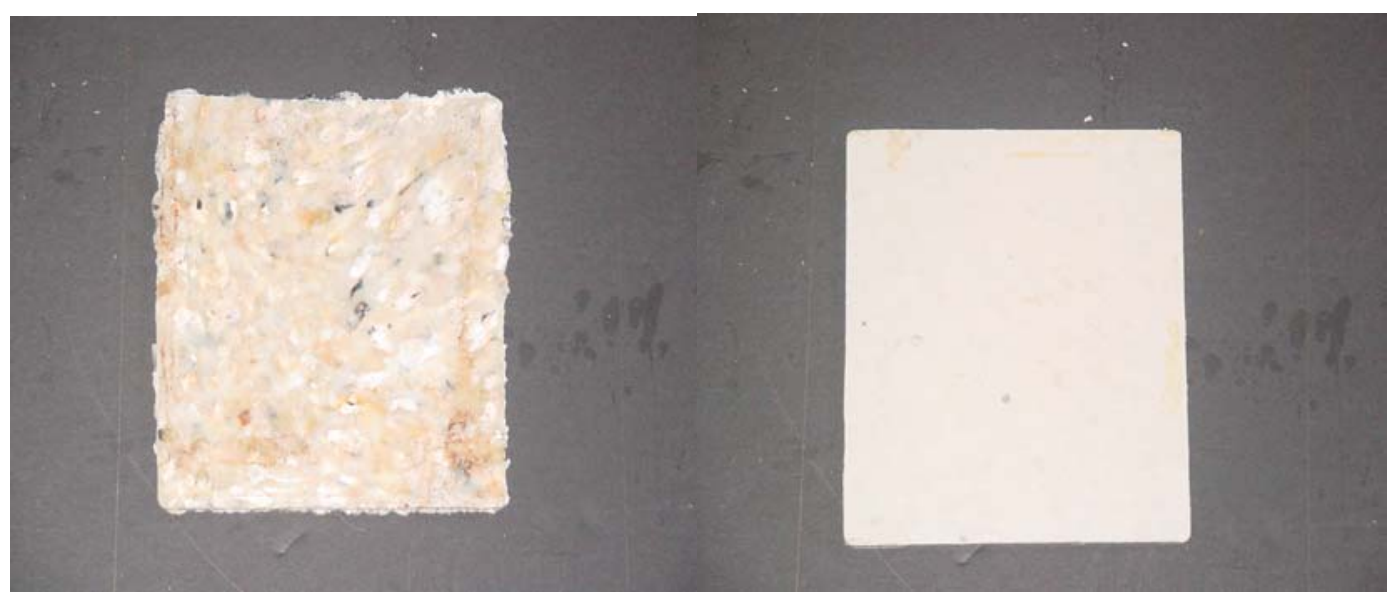

(c) $430^{\circ} \mathrm{F}$ (5 minutes)

(d) $400^{\circ} \mathrm{F}$ (4 minutes)

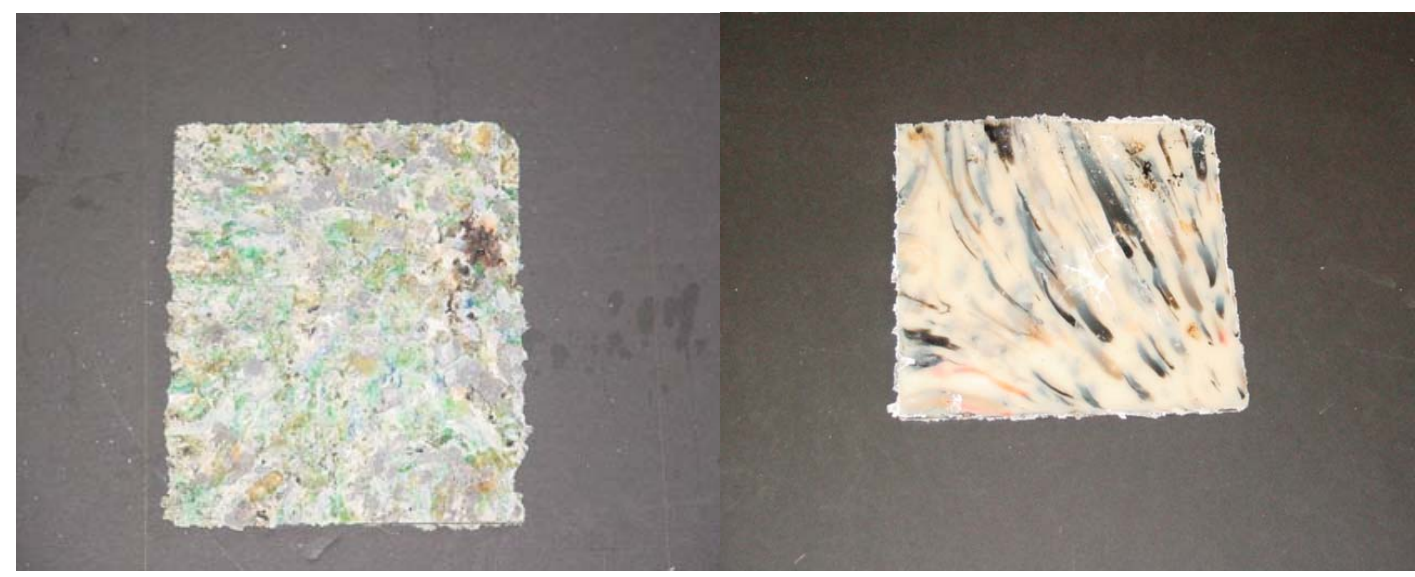

(e) $450^{\circ}$ F (6 minutes)

(f) $420^{\circ} \mathrm{F}$ (4 minutes)

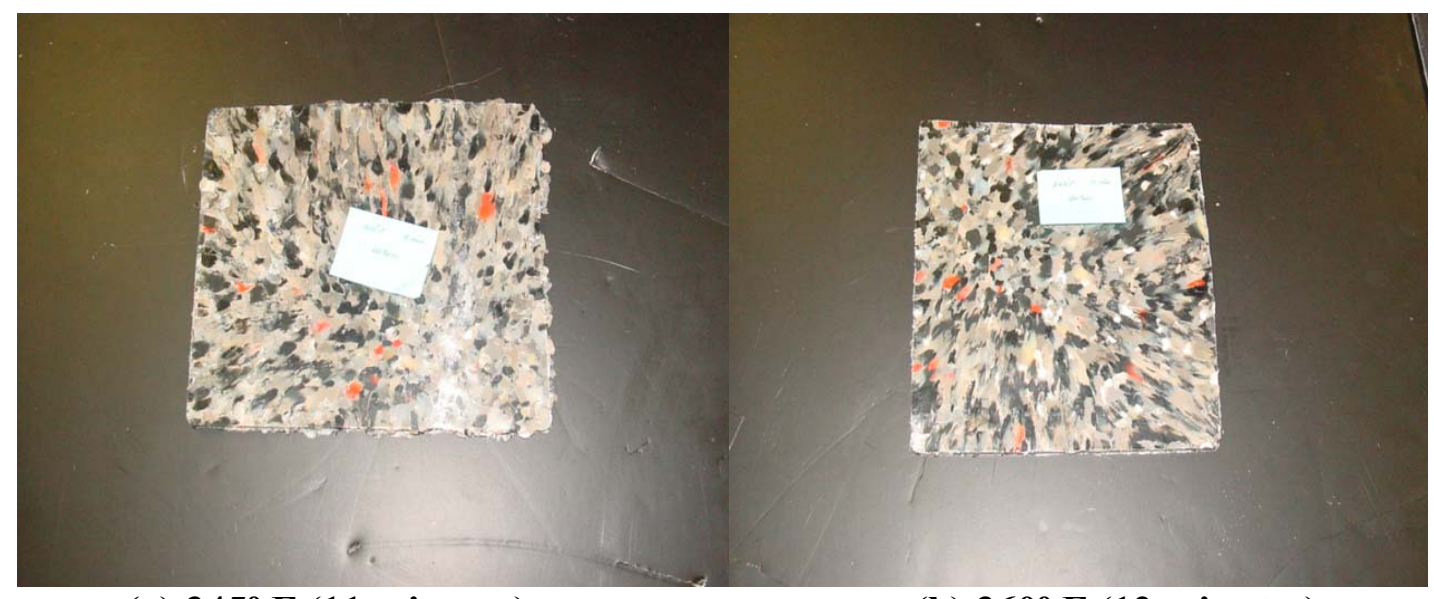

(g) $345^{\circ}$ F (11 minutes)

(h) $360^{\circ} \mathrm{F}$ (12 minutes)

Figure 4-6 Plates $(6.5 " \times 7.5 " \times 0.25 ")$ made out of different recycled blends 
Some recycled blends had significantly varying process temperatures for each polymer constituent that resulted in plates with: i) poor resin melting/blending, ii) nonuniform surface finish, and iii) void formation. Recycled blends with such incompatible polymers were found to be inefficient in terms of manufacturability. Reduction in temperature resulted in inadequate fusing of resin flakes, whereas increase in temperature resulted in burning odors and voids (Figures 4-6(a), (c) and (e)).

The recycled resins that showed better uniformity and blending were further used for manufacturing offset blocks and other composite products such as dowel bars and angle plates.

\subsubsection{Process outline for manufacturing offset blocks}

Manufacturing offset blocks consisted of four stages:

- Preheating: Preheating of the platens to desired temperature, $450^{\circ} \mathrm{F}$ (ABS).

- Load application: Twenty tons of load was applied on preheated mold consisting of resin, tire strips, and glass fabric for required duration.

- Cooling of the mold: In order to cool the mold, water was circulated through the platens until $120^{\circ} \mathrm{F}$ was attained.

- De-molding of offset block: Finally, offset block was taken out of the mold by unbolting all the mold parts.

\subsubsection{Intermediate stages in determining final manufacturing procedure for offset block}

Prior to final procedure, several modifications were made to obtain a good offset block with proper and uniform resin blending. These modifications carried out in several stages are described as follows: 
In stage 1, four individual modules (blocks) each molded with recycled ABS and rubbers from discarded tires were combined using bolts to form final offset block. In stage 2 the number of modules were decreased from 4 to 2 , by increasing their thickness and combining the two premolded modules by center bolt during on-site installation. In stage 3, manufacturing the final block in a single process cycle was attempted with partial success. In stage 4, a two-step process was followed to obtain a good product with uniformity and blending of resin pellets within the offset block.

\subsubsection{Stage 1}

Initially, four individual modules each measuring $14 " \times 6 " \times 2$ " were manufactured and joined using bolts to form final offset block. Several changes were proposed with regards to this process of forming the prototype offset block due to following reasons.

- A method was to be devised that would facilitate locking the individual units. To avoid no twisting or misalignment of four units, either 2 diagonal corners or 4 corners of the block modules had to be bolted in addition to using a central bolt to connect it to the post.

- Bolting the units on the 4 corners to form the complete block was an inefficient method of joining. On-site functioning of the prototype-offset block depended on effective alignment of these modules with respect to guardrail beam and post.

- Manufacturing 4 modules to make a single offset block was uneconomical and had to be modified.

- Process had to be modified for blocks of higher thickness since heat distribution within the mold was reduced and was non-uniform with increasing thickness. 
Non-uniform heat distribution problem within the mold, mentioned above, as one of the problems was remedied to considerable extent by placing pre-molded tabs in the mold during manufacturing leading to better quality in the final product in subsequent stages.

\subsubsection{Stage 2}

A new mold was designed to reduce the number of individual units to form a complete offset block from 4 to 2, by increasing thickness of each unit to twice that of the original. The modification consisted of a rectangular recess along the length of one of the units at its center, 4 inch wide and 0.125 inch deep, and a corresponding projection with the same profile on the other unit, thus facilitating locking of two units (Figure 4-7). Additional details of stage 2 are as follows:

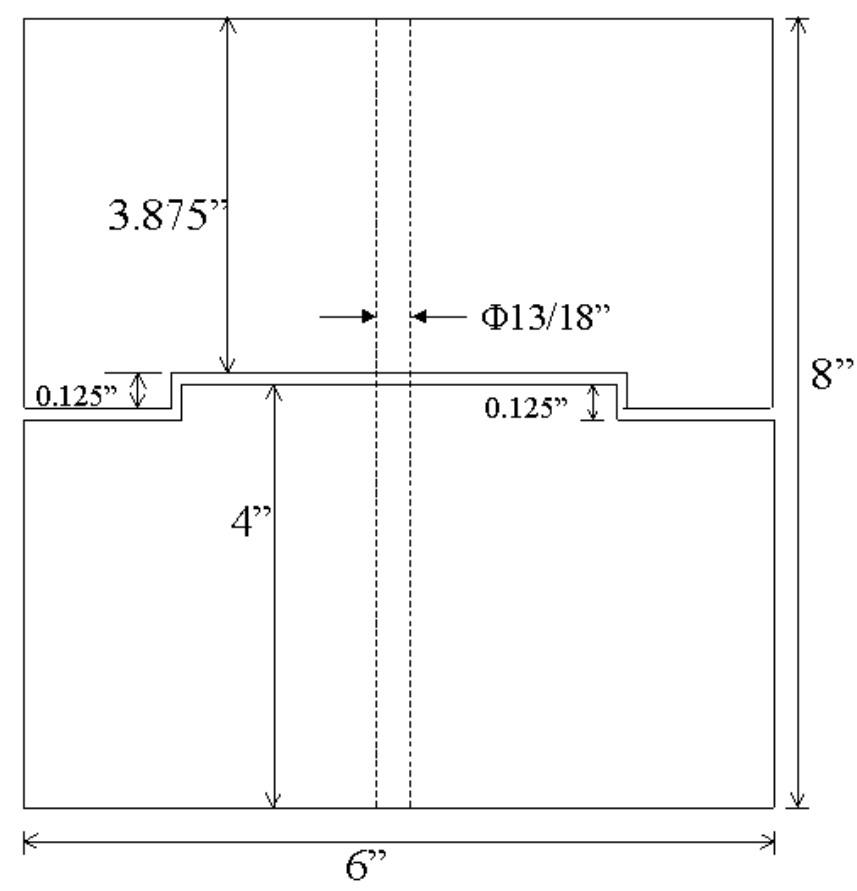

Figure 4-7 Offset block formed by bolting half blocks 
- The core portions of the blocks were pre-molded half-inch thick plates, which were molded and placed on bottom and topsides of the tire strips and positioned in the mold. Thus, the tire strips were encased with glass fabric reinforced recycled ABS shell and molded to a thickness of $1.75 \mathrm{in}$. Process parameters for the core modules were 15 minutes of preheating followed by application of 15 tons load for 15 minutes.

- Two such core modules were reinforced with glass fabric, and placed in the mold along with premolded resin end plates and additional resin pellets were heaped on the top, to manufacture the final offset block.

- Process parameters were 45 minutes of preheat followed by application of 20 tons of load for 45 minutes.

Heaters were switched off and mold was cooled under reduced load (20 tons reduced to 5 tons), with air-water circulation through the platens. Process was repeated to obtain the other half module using the designed mold. A center bolt was used to hold the two units together during on-site installation.

This design process was further modified to manufacture offset block as a single block to eliminate joining of independent modules described in stage 3 .

The thickness of the block was changed from 8 inches to 6 inches to suit WVDOT requirements. The following options were considered in mold design for manufacture of final offset block:

- Mold for manufacturing the $14 " \times 6 " \times 6$ " block in single stage by accommodating additional heaters for the side plates 
- Mold for manufacturing the $14 " \times 6 " \times 3$ " block, and bonding two such blocks with suitable adhesive such as Pliogrip

- Mold for manufacturing to produce the $14 " \times 6 " \times 2.75$ " core blocks, and then fusing two such blocks by a additional layer of the resin, thus making it a twostage process to manufacture $14 " \times 6 " \times 6 "$ block.

\subsubsection{Stage 3}

Compression molding trials were carried out to manufacture the final offset block in a single stage by placing all constituents in the mold and processing it at $450^{\circ} \mathrm{F}$ and less than 30 tons load. Improper heat propagation within the mold and irregular blending of resin pellets resulted in a product with unblended and unfinished surface as shown in Figures 4-8 and 4-9.

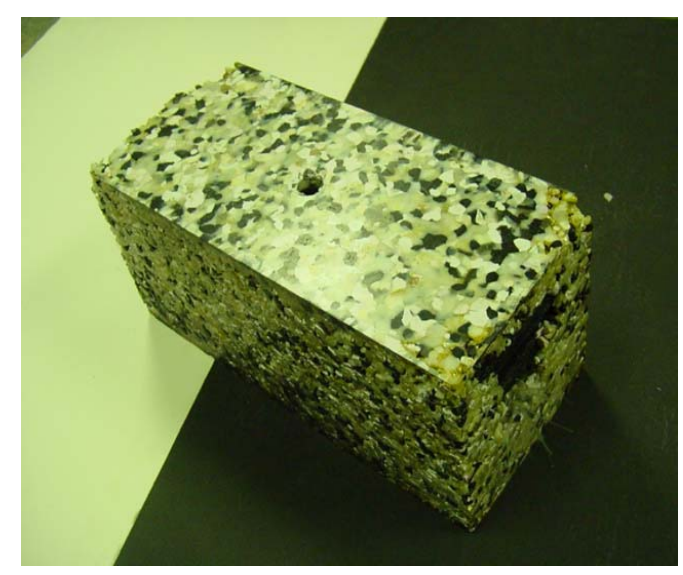

Figure 4-8 Unblended pellets on the block surface 


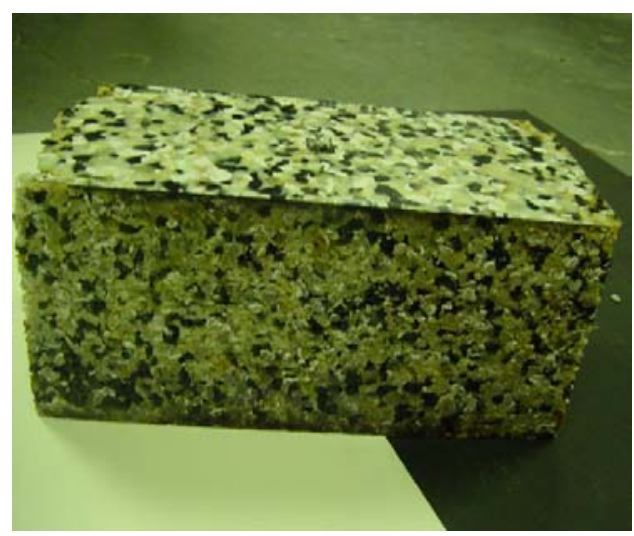

Figure 4-9 Inadequate amount of resin at sides creates voids and gaps

Therefore, two- stage process was attempted by molding core modules in the first stage and molding two such modules reinforced with glass fabric with additional resin to obtain the final offset block. The details are described in stage 4 .

\subsubsection{Stage 4}

A new mold was designed to produce core modules of size $12.5 " \times 4.5 " \times 2$ ". Two such core modules were joined using a stapling hammer and reinforced with glass fabric. This setup was placed in the 6" mold with resin pellets on all sides. Resin pellets were also heaped on the top to achieve maximum density in the final product.

Process parameters were $450^{\circ} \mathrm{F}$ temperature for recycled ABS $\left(520^{\circ} \mathrm{F}\right.$ for recycled $\left.\mathrm{PC}\right)$, with preheating time of 30 minutes followed by application of 30 tons of load for 30 minutes.

The mold was left in the compression machine under $20 \%$ of the maximum applied load for cooling, and the final offset block was demolded after about 2 hrs. Figures 4-10 and 4-11 show final offset blocks made of recycled ABS and recycled PC, respectively. These blocks with good blending and uniform melting of the resins show 
that desired quality was attained using this manufacturing process and right process parameters were achieved.

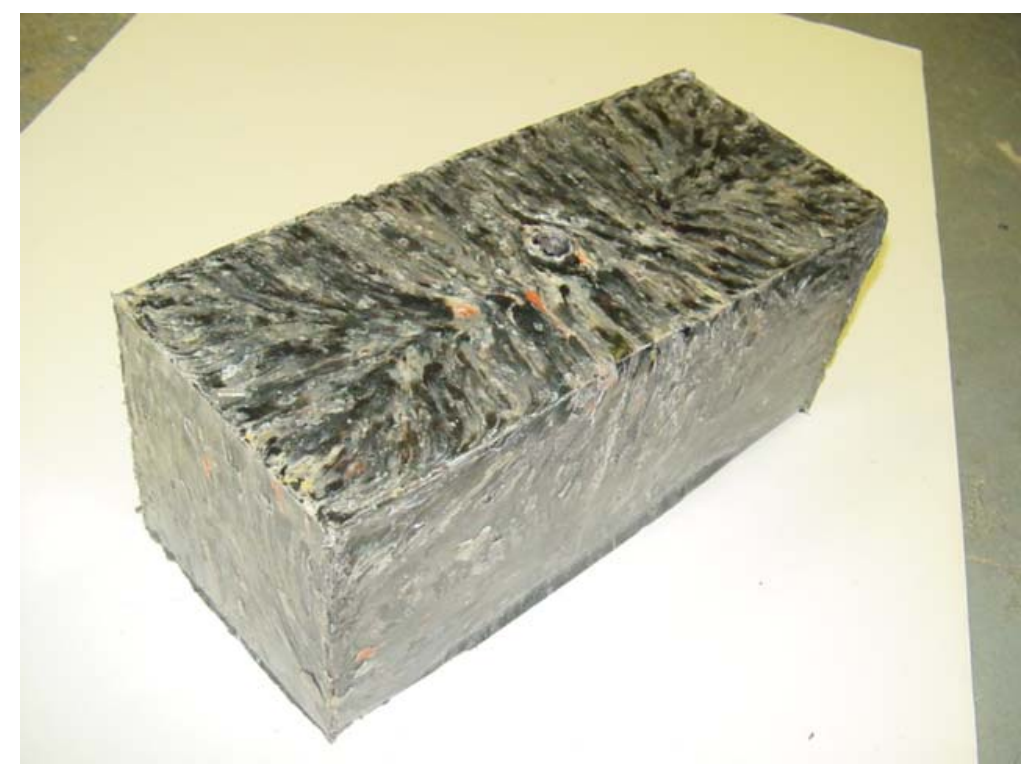

Figure 4-10 Final offset block with recycled ABS blends

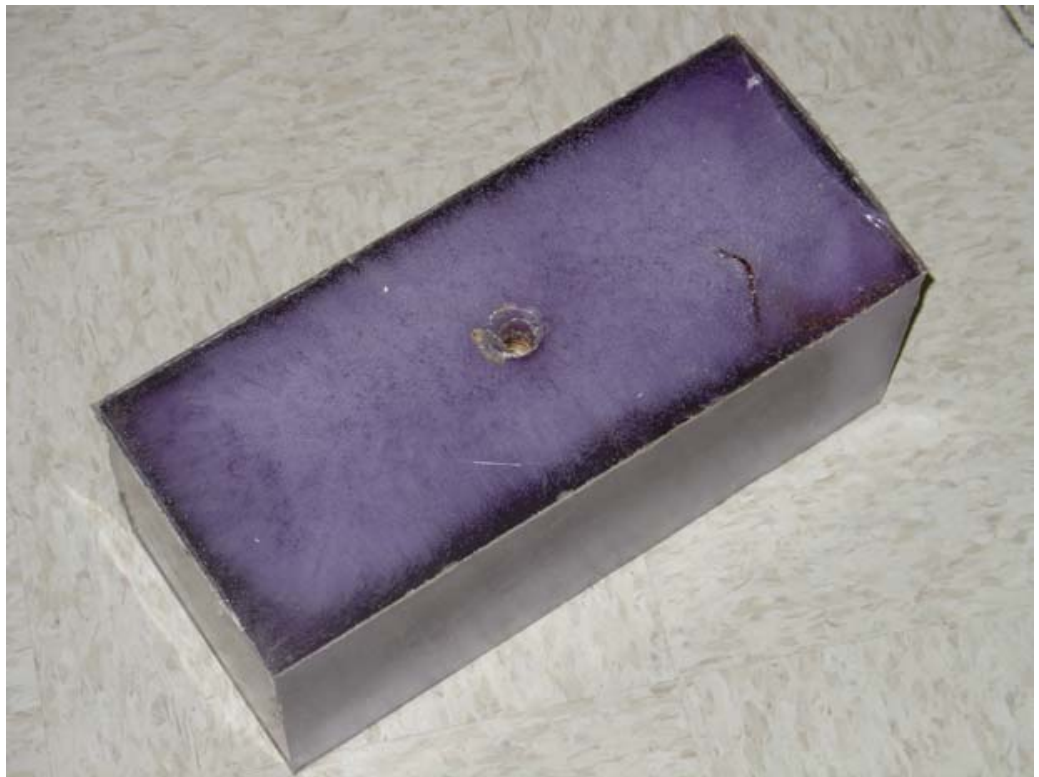

Figure 4-11 Final offset block with recycled PC blends 


\subsection{Blocks with wood/tire strips as core}

Several blocks were manufactured using recycled ABS and PC resins with rubber strips from discarded tires or wood. Various steps involved in manufacturing final offset blocks with rubber and wood cores are explained in following sections.

\subsubsection{Wood core}

Wood blocks cut to the required dimension $(12.5 " \times 4.5 " \times 1.5 ")$, were surrounded with pre-molded plastic side plates, wrapped with glass fabric and then stapled to hold them in position as shown in Figures 4-12 and 4-13.

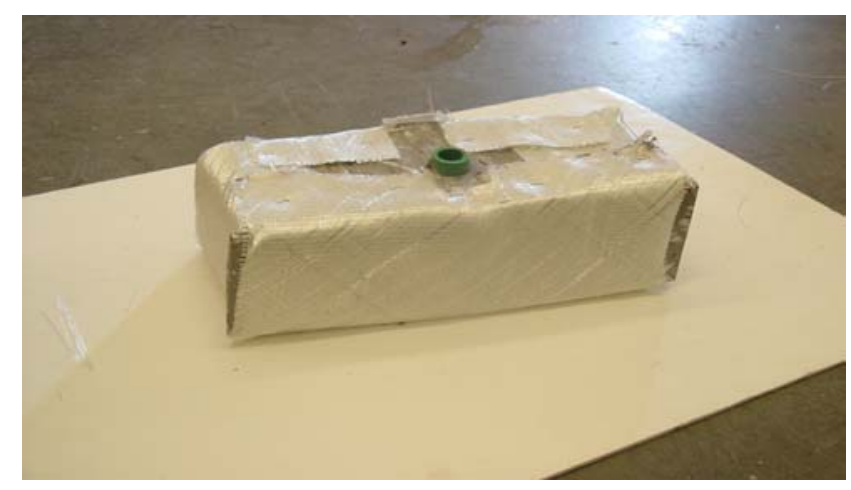

Figure 4-12 Core module wrapped with glass fabric

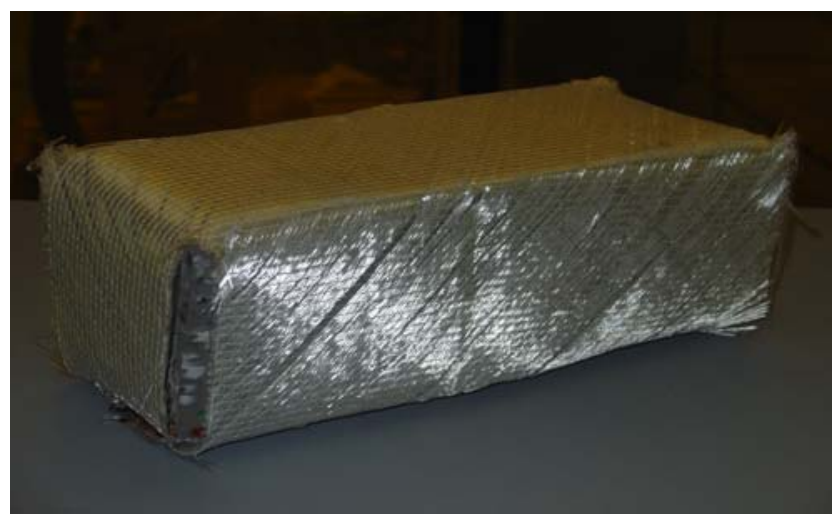

Figure 4-13 Glass fabric wrapped around wooden core with premolded polymer plates 
Small amount of resin pellets were uniformly spread on bottom of the 6" mold and wood core wrapped in glass fiber mat was positioned in the mold with central circular shaft of the mold passing through its circular hole. The size of the circular hole in the wooden blocks was 0.8 ", leaving very small clearance for plastic pellets between mold shaft and circular hole in the wood at the center. It was observed that absence of a heated central shaft resulted in no pellet fusing and exposure of wood that would be subjected to moisture ingress under field exposure.

The mold was heaped with excess amount of resin, about an inch and a half higher than the surface level of the mold edge to achieve maximum density. Figures 4-14 (a), (b), and (c) depict the resin filling process in the mold with the core module. This set up was placed in the compression molding machine. Process parameters were $450^{\circ} \mathrm{F}$, preheating for about 30 minutes followed by application of 30 tons load for about 30 minutes. The product was demolded after cooling the mold in the press under load for about 3 hours.

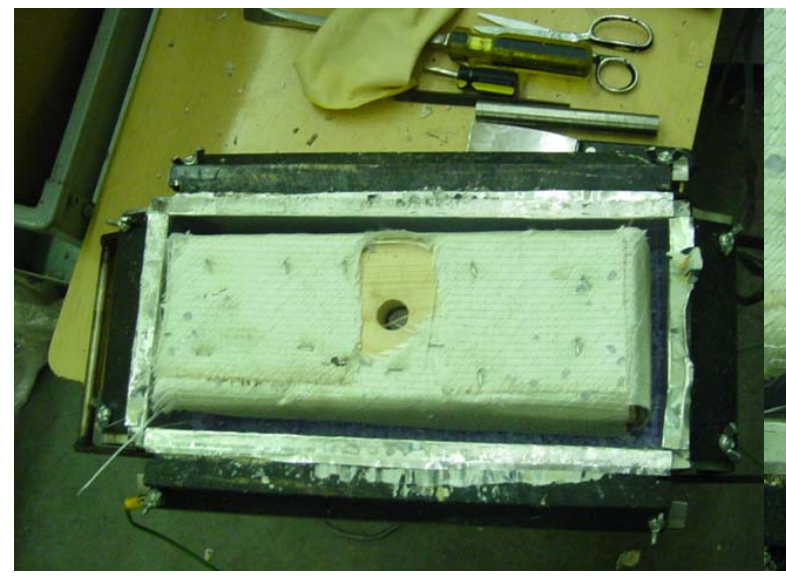

(a) Core modules in 6" mold

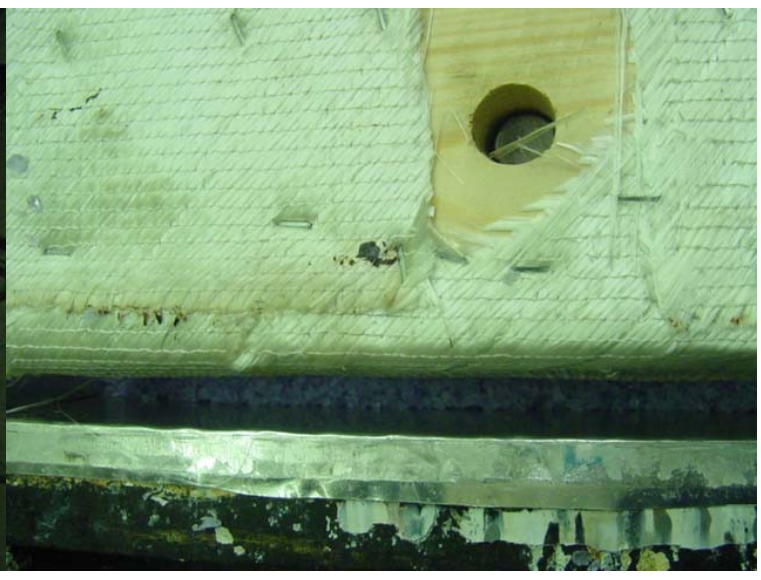

(b) Close up view 


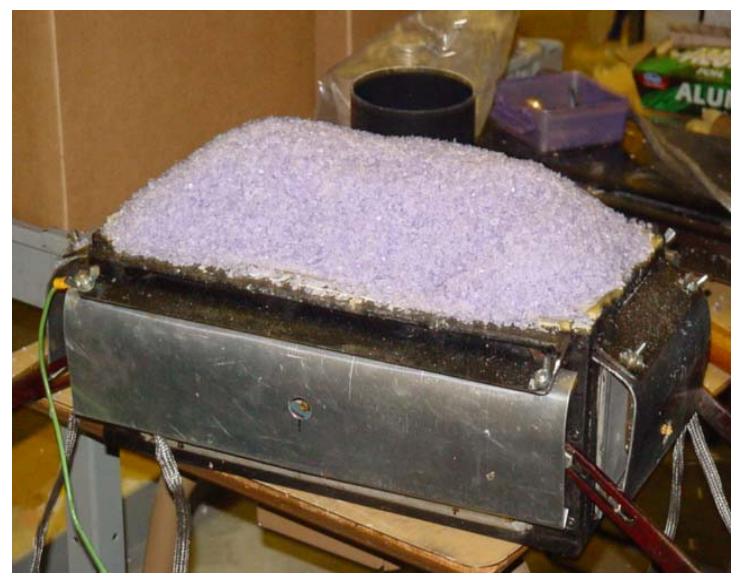

(c) Resin heaped on the core modules

Figure 4-14 Positioning the core modules in the 6" mold with additional resins on all sides and heaped on top

\subsubsection{Rubber tire core}

Tire strips that were cut from the discarded tires were resized to obtain a regular and uniform shape with square edges to make their placement in the mold easier. The tire strips were then placed in a smaller mold with inner dimensions $12.5 " \times 4.5 " \times 2 "$.

Resin layer spread on bottom of the mold was covered with tire strips and additional resin was heaped on the top. This set-up was preheated for about 15 minutes at process temperature of the resin $\left(450^{\circ} \mathrm{F}\right.$ for $\mathrm{ABS}, 520^{\circ} \mathrm{F}$ for $\left.\mathrm{PC}\right)$ and 15 tons load was applied for about 15 minutes. It was air cooled at ambient conditions and demolded to get the inner core block.

Two such core blocks were aligned one above the other and wrapped with glass fiber mat with circular holes cut in the fabric to match the mold shaft at the center. A hammer stapler was used to attach the glass fabric to the core and at FRP fabric folds. The set up was placed in the 6" mold with resin on all sides and top followed by placing the mold in the compression press. Process parameters were $450^{\circ} \mathrm{F}$, preheating for about 
30 minutes followed by application of 30 tons load for about 30 minutes. The product was demolded after cooling the mold in the press under load for about 3 hours.

\subsection{Introducing new features in offset block production}

Some problems observed despite achieving good degree of resin uniformity and blending in the final guardrail-offset block were solved as described below.

- Larger hole ( $\Phi$ 1.5”) was drilled in core modules to fill resin pellets at their center in the second stage. These pellets were found to be unblended even after completion of 2-stage manufacturing process due to inadequate heat propagation through polymer resins and rubber tire strips.

- To avoid the above-mentioned problem, the holes in the core modules were resized ( $\Phi 0.75$ ”) so that no plastic was present in the center. It was resized with a little clearance with respect to the bolt size ( $\Phi$ 13/18”) used in the field to secure it to the post during the installation. This resulted in the exposure of the core (steel stranded rubber strips/wood) to environmental conditions that may lead to corrosion of steel strands and other problems.

The problems described above were mainly because of unblended resin pellets at the center of the block, which is due to inadequate heat propagation. If the resin pellets were to be melted, it would result in sealing the exposed core material thereby preventing corrosion. Three probable solutions were considered for this purpose:

- A pre-molded hollow circular cylinder made of a resin-compatible material was to be placed at the center of the block during manufacturing so that it would melt and fuse with resin at the top and bottom portions thus sealing the center portion of the block. 
- A heater was to be incorporated at the center, into the cylindrical shaft in the mold such that heat transfer is initiated not only on the six faces of the mold but also at the center, thereby melting and fusing the plastic pellets at the center.

- Use a "dough" (charge-premelted resin) machine that would avoid preheating stage in the manufacturing process.

In order to place an additional heater at the center, a new mold had to be designed with a provision to let out its lead wires without touching the hot surfaces. Hence, placement of premolded pipes at the center was selected in this research.

\subsubsection{Pre-molded pipes}

Pre-molded plastic pipes were placed at the center of the mold along with the other constituents. PVC-pipes with internal diameter 0.75 " were initially used for trial moldings. Blending of the PVC pipe with the resin at top and bottom of the block were uniform. However, PVC material due to its lower process temperature and incompatibility with ABS resin (Table 4-1) showed burn marks at the bottom face of the block. The PVC pipe was softened, buckled, burnt out, and collapsed within the hole in addition to being covered by a top layer of resin pellets. In the next batch of manufacturing, ABS pre-molded unthreaded compressed air pipes with internal diameter 0.8 " and external diameter 1.05 " were used. ABS pipes were cut to a length of 6.5 ", a little higher than the 6" size of the final block to leave enough height for the ABS pipe to melt and fuse into the ABS resin at top and bottom in the mold. The following chart displays compatibility between various polymer resins. 
Table 4-1 Compatibility of Polymers-Recycling Electronic and Electrical equipment Industry Council for Electronic Equipment Recycling, UK, 1997

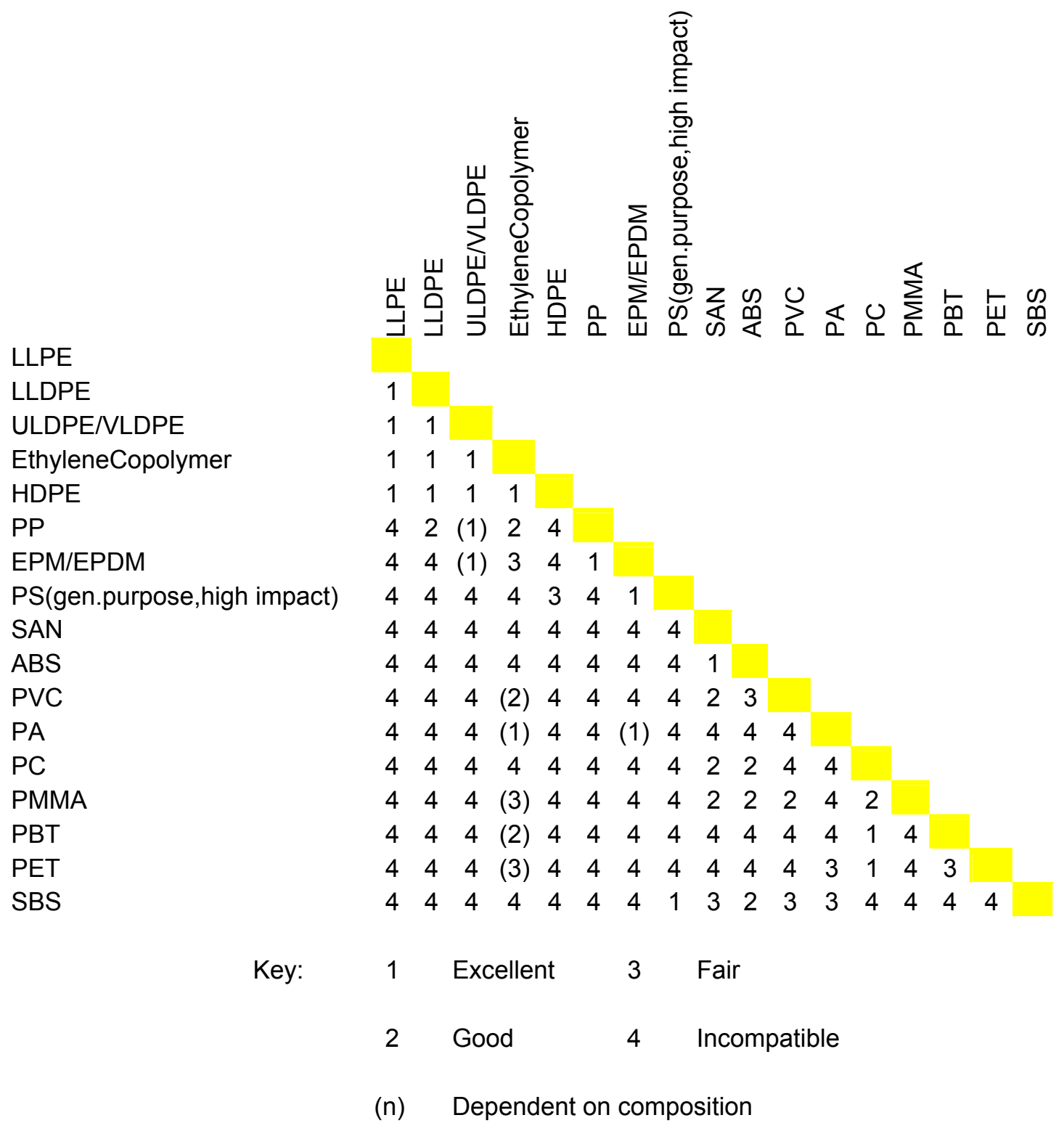




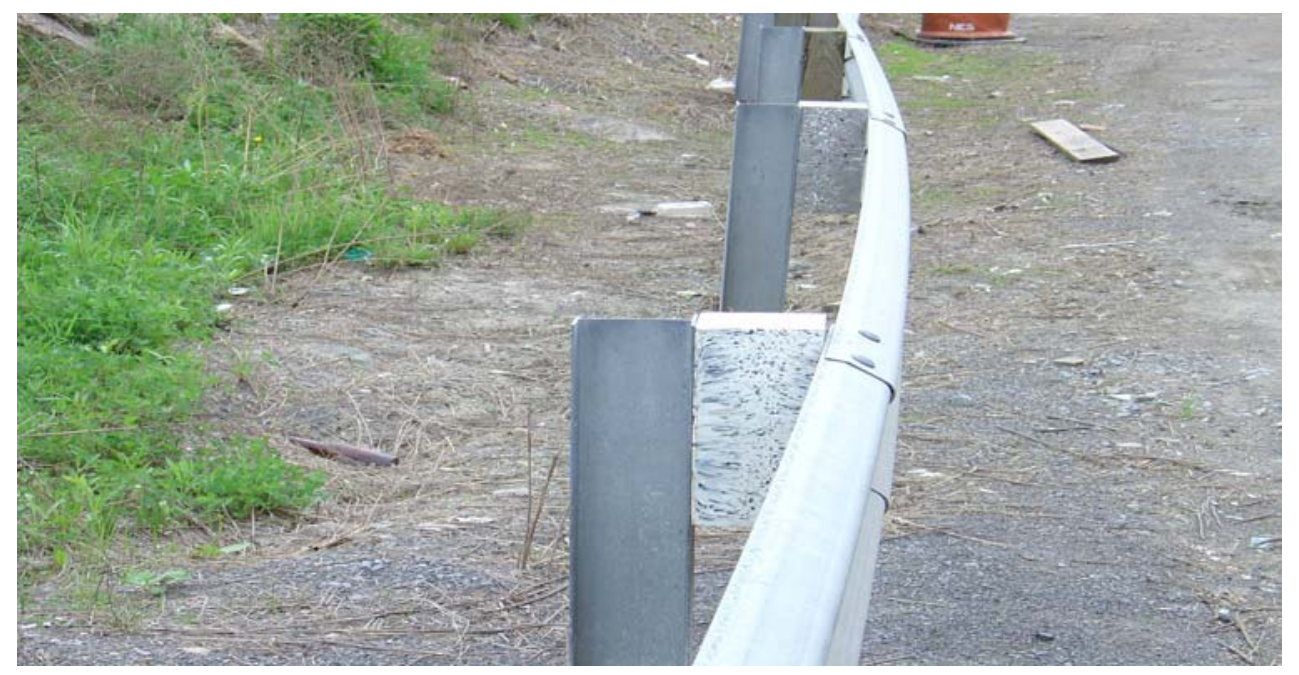

Figure 4-15 Guardrail system with polymer offset block

\subsection{Field Installation}

Figure 4-15 shows the guardrail offset block made of recycled polymer shell reinforced with glass fabric and with discarded rubber tire core, installed successfully near Star City Bridge, Star City, WV. Previously, wood blocks were used as offset blocks for the guardrail system on the bridge, and were replaced by few blocks manufactured using recycled $\mathrm{ABS}$ reinforced with glass fabric and discarded tire strips.

\subsection{Summary}

Procedure for manufacturing guardrail-offset blocks in the laboratory with rubber or wood cores encased in fiber reinforced recycled thermoplastic shell, were determined for manufacturing offset blocks. Guardrail offset blocks manufactured using this procedure were installed near Star City Bridge, Star City, WV.

- The process parameters like temperature, pressure, and time for the manufacturing process of these blocks were determined after several trials. 
- Core modules of size $12.5 " \times 4.5 " \times 2$ were manufactured using 20 minutes of preheating followed by 15 minutes of load application at $450^{\circ} \mathrm{F}$ for recycled ABS $\left(520^{\circ} \mathrm{F}\right.$ for $\left.\mathrm{PC}\right)$.

- Lowering load or time resulted in insufficient compacting and blending of the resins. Increasing in load or time resulted in burn marks on the product surface including blisters and holes.

- The process could be improved by introducing preheated resin into the mold. Use of preheated resin (charge) would eliminate problems of non-uniform heat distribution, inadequate resin flow and blending of pellets within the mold and result in shorter manufacturing duration of few minutes.

- By introducing required amount of preheated resin into the mold, number of blocks manufactured per unit time would increase, which is a major consideration for large-scale production.

- Processing of discarded tires could be modified before using them in manufacturing offset blocks. Reducing the curvature of the tires strips by "shear crimping" along the length at several sections would reduce voids/gaps in the final product.

This information could be used for mass manufacturing recycled composite offset blocks with suitable modifications knowledge gained in manufacturing offset block was used to develop recycled resin composite products such as angle plates and dowel bars described in Chapter 6. 


\section{CHAPTER 5}

\section{TEST RESULTS OF COUPON SPECIMENS}

\subsection{Introduction}

Results from various tests performed on the coupon specimens described in chapter 3 made from recycled thermoplastic (ABS), and thermoset resins (vinyl ester), with and without glass fabric are presented and analyzed in this chapter. Recycled ABS thermoplastic resins were provided by SDR recycling plant, Ravenswood, WV and glass fabrics (GFRP) were provided by BGF industries, Greensboro, NC. Glass fabric provided by BGF industries is 0.0046 in thick, and weighs $3.12 \mathrm{oz} / \mathrm{yd}^{2}$.

Strength and stiffness values of ABS and vinyl ester specimens both with and without fabric under compression, tension, bending, and impact tests are shown in Tables 5-1 to 5-24. Specimen notation indicates the type of test, material and presence of reinforcing fabric followed by specimen number. For example, specimen TA-1 indicates T for tension test, A for ABS material. Similarly, F in specimen TAF-1 indicates fabric. Similarly other notations indicate B for bending test, C for compression test and I for impact test.

\subsection{Compression test}

\subsubsection{Results of ABS specimens}

Table 5-1 shows compressive strength and stiffness results for recycled ABS specimens with and without fabric. Average compressive strength and stiffness results for each type of ABS specimens are presented in Table 5-2. 
Table 5-1 Compression test results of ABS specimens $(0.5 \% \times 0.5 " \times 1$ ") with and without glass fabric

\begin{tabular}{|c|c|c|c|c|c|}
\hline $\begin{array}{c}\text { Specimen } \\
\text { type }\end{array}$ & $\begin{array}{c}\text { Max. } \\
\text { Compressive } \\
\text { Stress (psi) }\end{array}$ & $\begin{array}{c}\text { Compressive } \\
\text { stiffness }\left(\times \mathbf{1 0}^{\mathbf{6}}\right. \\
\text { psi) }\end{array}$ & $\begin{array}{c}\text { Specimen } \\
\text { type }\end{array}$ & $\begin{array}{c}\text { Max. } \\
\text { Compressive } \\
\text { Stress (psi) }\end{array}$ & $\begin{array}{c}\text { Compressive } \\
\text { stiffness }\left(\times \mathbf{1 0}^{\mathbf{6}}\right. \\
\mathbf{p s i})\end{array}$ \\
\hline \multicolumn{7}{|c|}{ Without fabric } & & With fabric \\
\hline CA-1 & 5489.38 & 0.1374 & CAF-1 & 8445.93 & 0.1956 \\
\hline CA-2 & 7222.15 & 0.1663 & CAF-2 & 8697.76 & 0.2217 \\
\hline CA-3 & 6992.14 & 0.1850 & CAF-3 & 8531.11 & 0.2194 \\
\hline CA-4 & 6760.56 & 0.1790 & CAF-4 & 8244.82 & 0.2247 \\
\hline Average & 6616.06 & 0.1669 & Average & 8479.80 & 0.2153 \\
\hline Std dev. & $13.16 \%$ & $14.09 \%$ & Std dev. & $2.23 \%$ & $6.59 \%$ \\
\hline
\end{tabular}

Table 5-2 Average compressive stiffness and strength values of ABS specimens with and without glass fabric

\begin{tabular}{|c|c|c|c|}
\hline \multicolumn{4}{|c|}{ ABS Compression test specimens } \\
\hline Average values & Without glass fabric & With glass fabric & \% Increase \\
\hline Compressive Strength $(\mathbf{p s i})$ & $6616.06 \pm 13.16 \%$ & $8479.8 \pm 2.23 \%$ & 28.16 \\
\hline Compressive Stiffness $\left(\times \mathbf{1 0}^{\mathbf{6}} \mathbf{p s i}\right)$ & $0.1669 \pm 14.09 \%$ & $0.2153 \pm 6.59 \%$ & 28.98 \\
\hline
\end{tabular}

\subsubsection{Analysis and discussion on ABS specimens}

The following conclusions can be drawn from the results presented in Tables 5-1 and 5-2.

- Average compressive strength and stiffness increase of $28.16 \%$ and $28.98 \%$ respectively were observed for glass fabric reinforced ABS specimens.

\subsubsection{Results of vinyl ester specimens}

Table 5-3 shows compression strength and stiffness results for vinyl ester specimens with and without fabric. Average compressive strength and stiffness results for vinyl ester specimens are presented in Table 5-4. 
Table 5-3 Compression test results of vinyl ester specimens $(0.5 " \times 0.5 " \times 1$ ") with and without glass fabric

\begin{tabular}{|c|c|c|c|c|c|}
\hline $\begin{array}{c}\text { Specimen } \\
\text { type }\end{array}$ & $\begin{array}{c}\text { Max. } \\
\text { Compressive } \\
\text { Stress (psi) }\end{array}$ & $\begin{array}{c}\text { Compressive } \\
\text { stiffness }\left(\times \mathbf{1 0}^{\mathbf{6}}\right. \\
\mathbf{p s s i})\end{array}$ & $\begin{array}{c}\text { Specimen } \\
\text { type }\end{array}$ & $\begin{array}{c}\text { Max. } \\
\text { Compressive } \\
\text { Stress (psi) }\end{array}$ & $\begin{array}{c}\text { Compressive } \\
\text { stiffness }\left(\times \mathbf{1 0}^{\mathbf{6}}\right. \\
\mathbf{p s i})\end{array}$ \\
\hline CV-1 & 11187.85 & 0.2278 & CVF-1 & 13675.95 & 0.2820 \\
\hline CV-2 & 11754.93 & 0.2497 & CVF-2 & 13947.92 & 0.2954 \\
\hline CV-3 & 10927.92 & 0.2327 & CVF-3 & 15451.38 & 0.2969 \\
\hline CV-4 & 9343.599 & 0.2342 & CVF-4 & 14618.86 & 0.2946 \\
\hline Average & 10803.57 & 0.2361 & Average & 14423.52 & 0.2922 \\
\hline Std dev. & $10.33 \%$ & $3.9 \%$ & Std dev. & $5.39 \%$ & $2.41 \%$ \\
\hline
\end{tabular}

Table 5-4 Average compressive stiffness and strength values of vinyl ester specimens with and without glass fabric

\begin{tabular}{|c|c|c|c|}
\hline \multicolumn{4}{|c|}{ Vinyl ester specimens } \\
\hline Average values & Without glass fabric & With glass fabric & \% Increase \\
\hline Compressive Strength $(\mathbf{p s i})$ & $10803.57 \pm 10.33 \%$ & $14423.52 \pm 5.39 \%$ & 23.75 \\
\hline Compressive Stiffness $\left(\times \mathbf{1 0}^{\mathbf{6}} \mathbf{p s i}\right)$ & $0.2361 \pm 3.9 \%$ & $0.2922 \pm 2.41 \%$ & 33.5 \\
\hline
\end{tabular}

\subsubsection{Analysis and discussion on vinyl ester specimens}

Following conclusions are drawn from the results presented in Table 5-3 and 5-4.

- Average compressive strength and stiffness increase of $23.75 \%$ and $33.50 \%$ were observed, respectively for glass fabric reinforced vinyl ester specimens.

\subsubsection{Summary of results}

Table 5-5 Comparison of average compressive strength and stiffness values of ABS and vinyl ester samples with and without glass fabric respectively

\begin{tabular}{|c|c|c|c|c|c|c|}
\hline \multirow{2}{*}{$\begin{array}{c}\text { Parameter from } \\
\text { experimental results }\end{array}$} & \multicolumn{2}{|c|}{ ABS } & \multicolumn{2}{c|}{ Vinyl ester } & \multicolumn{2}{c|}{$\begin{array}{c}\text { Increase ABS and } \\
\text { Vinyl ester }\end{array}$} \\
\cline { 2 - 7 } & $\begin{array}{c}\text { Without } \\
\text { flass }\end{array}$ & $\begin{array}{c}\text { With } \\
\text { glass } \\
\text { fabric }\end{array}$ & $\begin{array}{c}\text { Without } \\
\text { glass fabric }\end{array}$ & $\begin{array}{c}\text { With glass } \\
\text { fabric }\end{array}$ & $\begin{array}{c}\text { Without } \\
\text { glass } \\
\text { fabric }\end{array}$ & $\begin{array}{c}\text { With glass } \\
\text { fabric }\end{array}$ \\
\hline $\begin{array}{c}\text { Avg. Compressive } \\
\text { strength (psi) }\end{array}$ & 6616.06 & 8479.80 & 10803.57 & 14423.52 & 63.29 & 70.09 \\
\hline $\begin{array}{c}\text { Avg. Compressive } \\
\text { stiffness }\left(\times \mathbf{1 0}^{\mathbf{6}} \text { psi) }\right.\end{array}$ & 0.1669 & 0.2153 & 0.2361 & 0.2922 & 41.43 & 35.70 \\
\hline
\end{tabular}


- Average strength and stiffness increase of $63.29 \%$ and $41.43 \%$ were observed for ABS and vinyl ester without glass fabric respectively.

- Average strength and stiffness increase of $70.09 \%$ and $35.70 \%$ were observed for ABS and vinyl ester with glass fabric respectively.

\subsubsection{Results of compression test specimens cut from wood guardrail offset block}

Compression test specimens measuring $0.5 " \times 0.5 " \times 1$ " were cut from a field installed wooden guardrail offset block. Results are presented in Table 5-6.

Table 5-6 Compressive stiffness and strength values of wood specimens

\begin{tabular}{|c|c|c|}
\hline Specimen type & Compressive Stress (psi) & Compressive Stiffness $\left(\times \mathbf{1 0}^{\mathbf{6}} \mathbf{p s i}\right)$ \\
\hline $\mathbf{C W}-\mathbf{1}$ & 5407.26 & 0.1399 \\
\hline $\mathbf{C W}-\mathbf{2}$ & 5163.99 & 0.1557 \\
\hline $\mathbf{C W}-3$ & 5098.75 & 0.1483 \\
\hline $\mathbf{C W}-\mathbf{4}$ & 5210.34 & 0.1529 \\
\hline $\mathbf{C W}-\mathbf{5}$ & 5708.36 & 0.1500 \\
\hline Average & 5317.74 & 0.1494 \\
\hline Std dev. & $4.49 \%$ & $4.13 \%$ \\
\hline
\end{tabular}

Average compressive strength and stiffness values of 5317.74 psi and 0.1491 $\times 10^{6}$ psi respectively were observed in case of wooden specimens cut (parallel to grain direction) from a field installed wooden guardrail offset block.

\subsubsection{Conclusions}

- Average compressive strength of ABS with glass fabric (8479.80 psi) is about 1.59 times higher than that of wood (5317.4 psi).

- Average compressive stiffness value of ABS with glass fabric specimens $\left(0.2153 \times 10^{6} \mathrm{psi}\right)$ is about 1.44 times higher than that of wooden specimens 
$\left(0.1491 \times 10^{6} \mathrm{psi}\right)$. This gives an idea on efficient use of recycled polymer composites for guardrail systems.

- Average compressive strength and stiffness values for recycled ABS with glass fabric vs. wood from previous study are 14891 psi vs. 8399 psi and $0.92 \times 10^{6}$ psi vs. $1.63 \times 10^{6}$ psi respectively.

- Test specimens from previous study were injection molded and they showed about $15 \%$ higher strength and stiffness values.

\subsection{Tension test}

\subsubsection{Results of ABS specimens}

Maximum tensile strength and stiffness results for recycled ABS specimens with and without fabric are shown in Table 5-7. The average tensile stress and stiffness results and their variations for ABS specimens are shown in Table 5-8.

Table 5-7 Tension test results of ABS specimens with and without glass fabric

\begin{tabular}{|c|c|c|c|c|c|}
\hline $\begin{array}{c}\text { Specimen } \\
\text { type }\end{array}$ & $\begin{array}{c}\text { Max.Tensile } \\
\text { Stress (psi) }\end{array}$ & $\begin{array}{c}\text { Tensile stiffness } \\
\left(\times \mathbf{1 0}^{\mathbf{6}} \mathbf{p s i}\right)\end{array}$ & $\begin{array}{c}\text { Specimen } \\
\text { type }\end{array}$ & $\begin{array}{c}\text { Max.Tensile } \\
\text { Stress (psi) }\end{array}$ & $\begin{array}{c}\text { Tensile stiffness } \\
\left(\times \mathbf{1 0}^{\mathbf{6}} \mathbf{p s i}\right)\end{array}$ \\
\hline \multicolumn{7}{|c|}{ Without fabric } & \multicolumn{3}{|c|}{ With fabric } \\
\hline TA-1 & 4347.06 & 0.3120 & TAF-1 & 4123.43 & 0.3262 \\
\hline TA-2 & 4332.75 & 0.3126 & TAF-2 & 4305.76 & 0.3856 \\
\hline TA-3 & 4495.03 & 0.3680 & TAF-3 & 5135.76 & 0.3949 \\
\hline TA-4 & 4360.84 & 0.3156 & TAF-4 & 4755.66 & 0.3833 \\
\hline TA-5 & 4532.39 & 0.2766 & TAF-5 & 4378.01 & 0.3508 \\
\hline Average & 4413.61 & 0.3170 & Average & 4643.80 & 0.3756 \\
\hline Std dev. & $2.08 \%$ & $10.08 \%$ & Std dev. & $8.63 \%$ & $8.22 \%$ \\
\hline
\end{tabular}

(Note: Specimens were 0.5 " wide and 0.25 " thick)

Table 5-8 Average tensile stiffness and strength values of ABS specimens with and without glass fabric

\begin{tabular}{|c|c|c|c|}
\hline Average values & Without glass fabric & With glass fabric & \% Increase \\
\hline Tensile Strength $(\mathbf{p s i})$ & $4413.61 \pm 2.08 \%$ & $4643.80 \pm 8.63 \%$ & 5.21 \\
\hline Tensile Stiffness $\left(\times \mathbf{1 0}^{\mathbf{6}} \mathbf{~ p s i )}\right.$ & $0.3170 \pm 10.08 \%$ & $0.3756 \pm 8.22 \%$ & 18.49 \\
\hline
\end{tabular}




\subsubsection{Analysis and discussion on ABS specimens}

Increase in tensile stiffness and strength values of ABS specimens due to glass fabric can be observed in Tables 5-7 and 5-8.

- Average tensile strength and stiffness increase of $5.21 \%$ and $18.49 \%$ were observed for glass fabric reinforced ABS specimens respectively.

\subsubsection{Results of vinyl ester specimens}

Table 5-9 shows the tensile strength and stiffness results for vinyl ester specimens with and without fabric. Average tensile strength and stiffness results for vinyl ester specimens are presented in Table 5-10.

Table 5-9 Tension test results of vinyl ester specimens with and without glass fabric

\begin{tabular}{|c|c|c|c|c|c|}
\hline $\begin{array}{c}\text { Specimen } \\
\text { type }\end{array}$ & $\begin{array}{c}\text { Max.Tensile } \\
\text { Stress (psi) }\end{array}$ & $\begin{array}{c}\text { Tensile stiffness } \\
\left(\times \mathbf{1 0}^{\mathbf{6}} \mathbf{p s i}\right)\end{array}$ & $\begin{array}{c}\text { Specimen } \\
\text { type }\end{array}$ & $\begin{array}{c}\text { Max.Tensile } \\
\text { Stress (psi) }\end{array}$ & $\begin{array}{c}\text { Tensile stiffness } \\
\left(\times \mathbf{1 0}^{\mathbf{6}} \mathbf{p s i}\right)\end{array}$ \\
\hline \multicolumn{7}{|c|}{ Without fabric } & \multicolumn{3}{|c|}{ With fabric } \\
\hline TV-1 & 4780.10 & 0.4674 & TVF-1 & 7555.16 & 0.4731 \\
\hline TV-2 & 5795.66 & 0.3283 & TVF-2 & 4503.75 & 0.5128 \\
\hline TV-3 & 5328.14 & 0.3413 & TVF-3 & 6056.56 & 0.3186 \\
\hline TV-4 & 5153.11 & 0.3649 & TVF-4 & - & - \\
\hline Average & 5264.25 & 0.3755 & Average & 6038.49 & 0.4348 \\
\hline Std dev. & $7.99 \%$ & $15.13 \%$ & Std dev. & $27.4 \%$ & $28.01 \%$ \\
\hline
\end{tabular}

(Note: Specimens were 0.5 " wide and 0.25 " thick)

Table 5-10 Average tensile stiffness and strength values of vinyl ester specimens with and without glass fabric

\begin{tabular}{|c|c|c|c|}
\hline \multicolumn{4}{|c|}{ Vinyl ester tension specimens } \\
\hline Average values & Without glass fabric & With glass fabric & \% Increase \\
\hline Tensile Strength $(\mathbf{p s i})$ & $5264.25 \pm 7.99 \%$ & $6038.49 \pm 27.4 \%$ & 14.7 \\
\hline Tensile Stiffness $\left(\times \mathbf{1 0}^{\mathbf{6}} \mathbf{\text { psi) }}\right.$ & $0.3755 \pm 15.13 \%$ & $0.4348 \pm 28.01 \%$ & 15.8 \\
\hline
\end{tabular}

\subsubsection{Analysis and discussion on vinyl ester specimens}

Following conclusions can be drawn from the results presented in Tables 5-9 and $5-10$. 
- Average tensile strength and stiffness increase of $14.7 \%$ and $15.8 \%$ were observed, respectively for vinyl ester specimens reinforced with glass fabric.

\subsubsection{Results of tension test specimens cut from the wood guardrail offset block}

Specimens 0.5 " wide and 0.25 " thick were cut from a field installed wood guardrail offset block and tested for tension. Results of the tests are presented in Table 5-

11.

Table 5-11 Tensile stiffness and strength of wood test specimens

\begin{tabular}{|c|c|c|}
\hline Specimen type & Max.Tensile Stress (psi) & Tensile stiffness $\left(\times \mathbf{1 0}^{\mathbf{6}} \mathbf{p s i}\right)$ \\
\hline TW-1 & 6258.74 & 0.6120 \\
\hline TW-2 & $2700.36^{*}$ & 0.5462 \\
\hline
\end{tabular}

* Presence of a knot in sample TW-2 (*) induced higher stress concentration resulting in a premature failure.

\subsubsection{Summary of results}

Table 5-12 Comparison of average tensile strength and stiffness values of ABS and vinyl ester samples with and without glass fabric respectively

\begin{tabular}{|c|c|c|c|c|c|c|}
\hline \multirow{2}{*}{$\begin{array}{c}\text { Parameter from } \\
\text { experimental results }\end{array}$} & \multicolumn{2}{|c|}{ ABS } & \multicolumn{2}{c|}{ Vinyl ester } & \multicolumn{2}{c|}{$\begin{array}{c}\text { Increase ABS and } \\
\text { Vinyl ester }\end{array}$} \\
\cline { 2 - 7 } & $\begin{array}{c}\text { Without } \\
\text { glass } \\
\text { fabric }\end{array}$ & $\begin{array}{c}\text { With } \\
\text { glass } \\
\text { fabric }\end{array}$ & $\begin{array}{c}\text { Without } \\
\text { glass } \\
\text { fabric }\end{array}$ & $\begin{array}{c}\text { With glass } \\
\text { fabric }\end{array}$ & $\begin{array}{c}\text { Without } \\
\text { glass } \\
\text { fabric }\end{array}$ & $\begin{array}{c}\text { With } \\
\text { glass } \\
\text { fabric }\end{array}$ \\
\hline $\begin{array}{c}\text { Avg. Tensile } \\
\text { strength (psi) }\end{array}$ & 4413.61 & 4643.80 & 5264.25 & 6038.49 & 19.27 & 30.03 \\
\hline $\begin{array}{c}\text { Avg. Tensile } \\
\text { stiffness }\left(\times \mathbf{1 0}^{\mathbf{6}} \text { psi) }\right.\end{array}$ & 0.3170 & 0.3756 & 0.3755 & 0.4348 & 18.45 & 15.77 \\
\hline
\end{tabular}

- There is $19.27 \%$ variation in average tensile strength and $18.45 \%$ variation in average tensile stiffness between ABS and vinyl ester without glass fabric.

- There is $30.03 \%$ variation in average tensile strength and $15.77 \%$ variation in average tensile stiffness between ABS and vinyl ester with glass fabric. 
- The glass fabric was obtained from BGF industries. Manufacturer suggested ABS thermoplastic to be compatible with glass fabric, however no increase in tension strength was observed. Further tests need to be done using a glass fabric that is compatible with thermoplastic ABS.

\subsection{Bending test}

\subsubsection{Results of ABS specimens}

Table 5-13 shows bending strength and stiffness results for recycled ABS specimens with and without fabric. Average bending strength and stiffness results for ABS specimens are presented in Table 5-14.

Table 5-13 Bending test results of ABS specimens $(0.5$ " $\times 0.25$ ") with and without glass fabric

\begin{tabular}{|c|c|c|c|c|c|}
\hline $\begin{array}{c}\text { Specimen } \\
\text { type }\end{array}$ & $\begin{array}{c}\text { Max. Bending } \\
\text { Stress (psi) }\end{array}$ & $\begin{array}{c}\text { Bending stiffness } \\
\left(\times \mathbf{1 0}^{\mathbf{6}} \mathbf{p s i}\right)\end{array}$ & $\begin{array}{c}\text { Specimen } \\
\text { type }\end{array}$ & $\begin{array}{c}\text { Max. Bending } \\
\text { Stress (psi) }\end{array}$ & $\begin{array}{c}\text { Bending stiffness } \\
\left(\times \mathbf{1 0}^{\mathbf{6}} \mathbf{\text { psi }}\right)\end{array}$ \\
\hline \multicolumn{7}{|c|}{ Without fabric } & \multicolumn{3}{|c|}{ With fabric } \\
\hline BA-1 & 12249.64 & 0.4129 & BAF-1 & 19650.05 & 0.4866 \\
\hline BA-2 & 11928.60 & 0.3413 & BAF-2 & 14042.71 & 0.4946 \\
\hline BA-3 & 11418.70 & 0.3922 & BAF-3 & 17964.98 & 0.4734 \\
\hline Average & 11865.64 & 0.3822 & Average & 17219.24 & 0.4849 \\
\hline Std dev. & $3.56 \%$ & $10.09 \%$ & Std dev. & $18.29 \%$ & $2.22 \%$ \\
\hline
\end{tabular}

Note: Support span of 7.5" was used for bending tests conducted on all specimens

Table 5-14 Average bending stiffness and strength values of ABS specimens with and without glass fabric

\begin{tabular}{|c|c|c|c|}
\hline \multicolumn{4}{|c|}{ ABS bending test specimens } \\
\hline Average values & Without glass fabric & With glass fabric & \% Increase \\
\hline Bending Strength $(\mathbf{p s i})$ & $11865.64 \pm 3.56 \%$ & $17219.24 \pm 18.29 \%$ & 45.11 \\
\hline Bending Stiffness $\left(\times \mathbf{1 0}^{\mathbf{6}} \mathbf{\text { psi) }}\right.$ & $0.3822 \pm 10.09 \%$ & $0.4849 \pm 2.22 \%$ & 26.87 \\
\hline
\end{tabular}

\subsubsection{Analysis and discussion on ABS specimens}

Following conclusions can be drawn from the results presented in Tables 5-13 and 514. 
- Average bending strength, and stiffness increase of $45.11 \%$ and $26.87 \%$ were observed for glass fabric reinforced ABS specimens respectively.

\subsubsection{Results of vinyl ester specimens}

Table 5-15 shows bending strength and stiffness results for vinyl ester specimens with and without fabric. Support span of 7.5 " was used for bending tests conducted on all specimens. Average bending strength and stiffness results for vinyl ester specimens are presented in Table 5-16.

Table 5-15 Bending test results of vinyl ester specimens $(0.5$ " $\times 0.25$ ”) with and without glass fabric

\begin{tabular}{|c|c|c|c|c|c|}
\hline $\begin{array}{c}\text { Specimen } \\
\text { type }\end{array}$ & $\begin{array}{l}\text { Max. Bending } \\
\text { Stress (psi) }\end{array}$ & $\begin{array}{c}\text { Bending stiffness } \\
\left(\times 10^{6} \mathrm{psi}\right)\end{array}$ & $\begin{array}{c}\text { Specimen } \\
\text { type }\end{array}$ & $\begin{array}{l}\text { Max. Bending } \\
\text { Stress (psi) }\end{array}$ & $\begin{array}{c}\text { Bending stiffness } \\
\left(\times 10^{6} \mathrm{psi}\right)\end{array}$ \\
\hline \multicolumn{3}{|c|}{ Without fabric } & \multicolumn{3}{|c|}{ With fabric } \\
\hline BV-1 & 16292.87 & 0.5710 & BVF-1 & 19556.08 & 0.7973 \\
\hline BV-2 & 16025.02 & 0.7750 & BVF-2 & 24669.96 & 0.8657 \\
\hline BV-3 & 17250.9 & 0.7550 & BVF-3 & 26457.84 & 0.8643 \\
\hline Average & 16522.93 & 0.7003 & Average & 23561.29 & 0.8425 \\
\hline Std dev. & $3.83 \%$ & $17.98 \%$ & Std dev. & $16.59 \%$ & $4.77 \%$ \\
\hline
\end{tabular}

Table 5-16 Average bending stiffness and strength values of vinyl ester specimens with and without glass fabric

\begin{tabular}{|c|c|c|c|}
\hline \multicolumn{4}{|c|}{ Vinyl ester bending test specimens } \\
\hline Average values & Without glass fabric & With glass fabric & \% Increase \\
\hline Bending Strength $(\mathbf{p s i})$ & $16522.93 \pm 3.83 \%$ & $23561.29 \pm 16.59 \%$ & 42.59 \\
\hline Bending Stiffness $\left(\times \mathbf{1 0}^{\mathbf{6}} \mathbf{\text { psi) }}\right.$ & $0.7003 \pm 17.98 \%$ & $0.8425 \pm 4.77 \%$ & 20.29 \\
\hline
\end{tabular}

\subsubsection{Analysis and discussion on vinyl ester specimens}

Following conclusions can be drawn from the results presented in Tables 5-15 and 5-16.

- Average bending strength and stiffness increase of $42.59 \%$ and $20.29 \%$ were observed for glass fabric reinforced vinyl ester specimens respectively. 


\subsubsection{Results of bending test specimens cut from wood guardrail offset block}

Specimens 0.5 " wide and 0.25 " thick were cut from a field wood guardrail offset block and tested for bending. A support span of 7.5 " was maintained during the test. Results of the tests are presented in Table 5-17. Presence of a knot in sample BW-2 induced higher stress concentration resulting in premature failure.

Table 5-17 Bending strength and stiffness values for wooden specimens $(0.5$ " $\times 0.25$ ")

\begin{tabular}{|c|c|c|}
\hline Specimen type & Max. Bending Stress (psi) & Bending stiffness $\left(\times \mathbf{1 0}^{\mathbf{6}} \mathbf{p s i}\right)$ \\
\hline BW-1 & 14791.91 & 0.5366 \\
\hline BW-2 & $4347.90^{*}$ & 0.7934 \\
\hline
\end{tabular}

Note: * indicates premature failure of specimen due to presence of knot.

\subsubsection{Summary of results}

Table 5-18 Comparison of average bending strength and stiffness values of ABS and vinyl ester samples with and without glass fabric respectively

\begin{tabular}{|c|c|c|c|c|c|c|}
\hline \multirow{2}{*}{$\begin{array}{c}\text { Parameter from } \\
\text { experimental results }\end{array}$} & \multicolumn{2}{|c|}{ ABS } & \multicolumn{2}{c|}{ Vinyl ester } & \multicolumn{2}{c|}{$\begin{array}{c}\text { \% Increase between } \\
\text { ABS and Vinyl ester }\end{array}$} \\
\cline { 2 - 7 } & $\begin{array}{c}\text { Without } \\
\text { glass } \\
\text { fabric }\end{array}$ & $\begin{array}{c}\text { With glass } \\
\text { fabric }\end{array}$ & $\begin{array}{c}\text { Without } \\
\text { glass } \\
\text { fabric }\end{array}$ & $\begin{array}{c}\text { With glass } \\
\text { fabric }\end{array}$ & $\begin{array}{c}\text { Without } \\
\text { glass } \\
\text { fabric }\end{array}$ & $\begin{array}{c}\text { With } \\
\text { glass } \\
\text { fabric }\end{array}$ \\
\hline $\begin{array}{c}\text { Avg. Bending } \\
\text { strength (psi) }\end{array}$ & 11865.64 & 17219.24 & 16522.93 & 23561.29 & 39.25 & 36.83 \\
\hline $\begin{array}{c}\text { Avg. Bending } \\
\text { stiffness }\left(\times \mathbf{1 0}^{\mathbf{6}} \text { psi) }\right.\end{array}$ & 0.3822 & 0.4849 & 0.7003 & 0.8425 & 83.24 & 73.74 \\
\hline
\end{tabular}

- Average bending strength and stiffness increase of $39.25 \%$ and $83.24 \%$ were observed for ABS and vinyl ester specimens without glass fabric.

- Average bending strength and stiffness increase of $36.83 \%$, and $73.74 \%$ were observed for ABS and vinyl ester samples with glass fabric. 


\subsection{Impact test}

\subsubsection{Results of ABS specimens}

Tables 5-19, and 5-20 show the impact strength results for recycled ABS specimens with and without fabric. Maximum impact strength results for ABS specimens are tabulated.

Table 5-19 Impact test results of ABS specimens (2.5” $\times 0.5$ " $\times$ '0.25") without glass fabric

\begin{tabular}{|c|c|}
\hline Specimen type & Impact strength (lbf/in) \\
\hline IA-1 & 2.64 \\
\hline IA-2 & 2.24 \\
\hline IA-3 & 2.20 \\
\hline IA-4 & 2.96 \\
\hline IA-5 & 2.01 \\
\hline Average & 2.41 \\
\hline Std dev. & $15.38 \%$ \\
\hline
\end{tabular}

Table 5-20 Impact test results of ABS specimens (2.5" $\times 0.5$ " $\times 0.25$ ”) with glass fabric

\begin{tabular}{|c|c|}
\hline Specimen type & Impact strength (lbf/in) \\
\hline IAF-1 & 5.27 \\
\hline IAF-2 & 4.67 \\
\hline IAF-3 & 5.40 \\
\hline IAF-4 & 3.78 \\
\hline IAF-5 & 4.06 \\
\hline Average & 4.63 \\
\hline Std dev. & $16.123 \%$ \\
\hline
\end{tabular}

\subsubsection{Analysis and discussion on ABS specimens}

Following conclusions can be drawn from the results presented in Tables 5-19 and $5-20$.

- Average Impact strength increased by about 1.91 times for ABS specimens reinforced with continuous glass bi-directional fabric when compared to those without glass fabric. 
- Previous research results (Basto 2002) showed decrease in impact strength due to addition of chopped fibers.

- Use of continuous, particularly bi-directional fabric, has led to increase in impact strength in ABS specimens as per test results in this study.

\subsubsection{Results of vinyl ester specimens}

Tables 5-21 and 5-22 show the impact strength results for vinyl ester specimens with and without fabric. Maximum impact strength results for each type of the vinyl ester specimens are tabulated.

Table 5-21 Impact test results of vinyl ester specimens $(2.5$ ” $\times 0.5$ ” $\times 0.25$ ”) without glass fabric

\begin{tabular}{|c|c|}
\hline Specimen type & Impact strength (lbf/in) \\
\hline IV-1 & 0.27 \\
\hline IV-2 & 0.29 \\
\hline IV-3 & 0.53 \\
\hline IV-4 & 0.27 \\
\hline IV-5 & 0.31 \\
\hline Average & 0.33 \\
\hline Std. Dev. & $25.29 \%$ \\
\hline
\end{tabular}

Table 5-22 Impact test results of vinyl ester specimens $(2.5$ " $\times 0.5$ " $\times 0.25$ ") with glass fabric

\begin{tabular}{|c|c|}
\hline Specimen type & Impact strength (lbf/in) \\
\hline IVF-1 & 0.72 \\
\hline IVF-2 & 0.6 \\
\hline IVF-3 & 0.74 \\
\hline IVF-4 & 0.66 \\
\hline IVF-5 & 0.60 \\
\hline Average & 0.66 \\
\hline Std. Dev. & $9.88 \%$ \\
\hline
\end{tabular}




\subsubsection{Analysis and discussion on vinyl ester specimens}

Following conclusions can be drawn from the results presented in Tables 5-21 and $5-22$.

- Average Impact strength increased by about 1.96 times for glass fabric reinforced vinyl ester specimens when compared to those without glass fabric.

\subsubsection{Results of impact test specimens cut from wood guardrail offset block}

Table 5-23 shows the impact strength values of wood specimens cut from field installed guardrail offset block.

Table 5-23 Impact test results of wood specimens $(2.5$ " $\times 0.5$ " $\times 0.125$ ”)

\begin{tabular}{|c|c|}
\hline Specimen type & Impact strength (lbf/in) \\
\hline IW-1 & 3.98 \\
\hline IW-2 & 3.08 \\
\hline IW-3 & 3.52 \\
\hline Average & 3.19 \\
\hline Std dev. & $12.97 \%$ \\
\hline
\end{tabular}

\subsubsection{Summary of results}

Table 5-24 Comparison of impact strength values of ABS, vinyl ester with and without glass fabric and wood specimens

\begin{tabular}{|c|c|c|c|c|c|c|c|}
\hline \multirow{2}{*}{$\begin{array}{c}\text { Experimental } \\
\text { parameter }\end{array}$} & \multicolumn{3}{|c|}{ ABS } & \multicolumn{3}{c|}{ Vinyl ester } & \multirow{2}{*}{ Wood } \\
\cline { 2 - 7 } & fabric & $\begin{array}{c}\text { With } \\
\text { fabric }\end{array}$ & $\begin{array}{c}\% \\
\text { Increase }\end{array}$ & $\begin{array}{c}\text { Without } \\
\text { fabric }\end{array}$ & $\begin{array}{c}\text { With } \\
\text { fabric }\end{array}$ & $\begin{array}{c}\% \\
\text { Increase }\end{array}$ & \\
\hline $\begin{array}{c}\text { Avg. Impact } \\
\text { strength (lbf/in) }\end{array}$ & 2.41 & 4.63 & 92.1 & 0.3394 & 0.6659 & 96.20 & 3.19 \\
\hline
\end{tabular}

\subsection{Conclusions}

- From previous study (Basto, 2002) decrease in impact strength (2.17 lbf/in to 0.96 lbf/in) was observed in recycled ABS specimens due to addition of chopped glass fibers. 
- In this study, recycled ABS resin used with continuous fabric having bidirectional fibers increased the impact strength $(4.64 \mathrm{lbf} /$ in from $2.41 \mathrm{lbf} / \mathrm{in})$ due to better energy dissipation.

- Impact strength of recycled ABS specimens with continuous glass fabric was found to be 1.45 times more than specimens cut from field installed wood offset blocks.

\subsection{Bending tests on dowel bars}

Bending tests were conducted on pultruded dowel bars along with the one manufactured with ABS thermoplastic resin through compression molding process. Notation of the dowel bars tested in this research based on their color is shown in Table $5-25$.

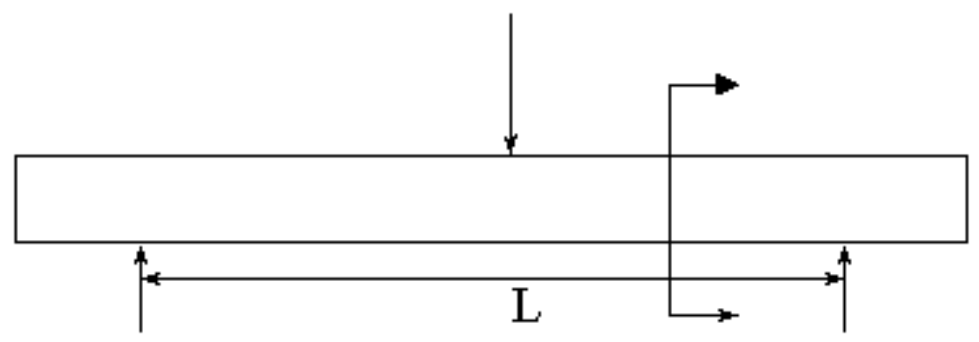

$\mathrm{D}$

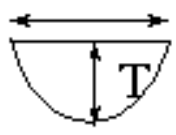

Figure 5-1 Cross-section view of dowel bar

Table 5-25 Notation of the dowel bars for bending test

\begin{tabular}{|c|c|c|}
\hline Specimen & Description & Content \\
\cline { 1 - 1 } BRD-1 & Pultruded bending test sample & Glass fibers with vinyl ester \\
\cline { 1 - 1 } BRD-2 & Pultruded bending test sample & Glass fibers with vinyl ester \\
\cline { 1 - 2 } BGD-1 & Compression molded bending test sample & Recycled ABS, no fiber \\
\hline BWD
\end{tabular}


The fiber weight fractions of these dowel bars are $77.39 \%$ for green bar (BGD) and $69.11 \%$ for red bar (BRD). The volume fractions are $63.09 \%$ and $52.80 \%$ for BGD and $\mathrm{BRD}$ respectively.

Bending tests were conducted on dowel bars with the dimensions conforming to ASTM D4476-97 and the results are presented in Table 5-26.

\subsubsection{Pultruded bending test sample-1 (BRD)}

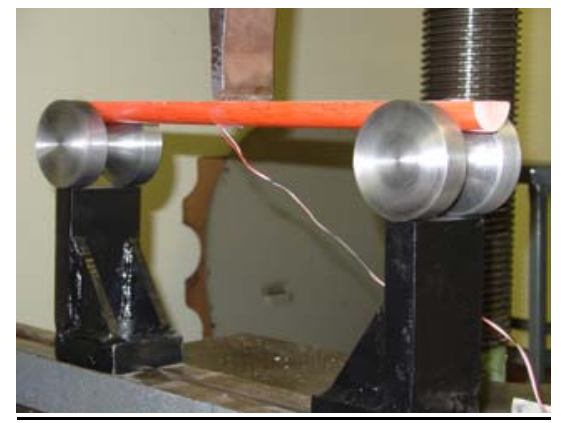

Figure 5-2 Dowel bar sample-1 (pultruded)

\section{$\underline{\text { Parameters }}$}

$\mathrm{L}=$ Length of support $\operatorname{span}=15$ in

$\mathrm{D}=$ Original diameter of the specimen $=1.5$ in

D1=Depth of the specimen taken as an average of values along the length of the

bar $=0.72$ in

$\mathrm{R}=0.5 \mathrm{D}=0.75$ in

$\gamma=\mathrm{D} 1 / \mathrm{R}=0.96$

$A=\sqrt{ }(\gamma(2-\gamma))=0.99919968$

$B=1-\gamma=0.04$

$\mathrm{G}=\operatorname{arc}$ sine $\mathrm{A}, \mathrm{rad},=1.5307$

$\mathrm{H}=2 \mathrm{~A} . \mathrm{B}=0.0799357$

$\mathrm{C}=$ Distance of centroid to extremities $=\mathrm{R}\left(1-\left(4 \mathrm{~A}^{3} /(6 \mathrm{G}-3 \mathrm{H})\right)\right)=0.41541 \mathrm{in}$ 
$\mathrm{I}=$ Moment of Inertia $=\mathrm{R}^{4}\left[0.125(2 \mathrm{G}-\mathrm{H})\left(1+2 \mathrm{~A}^{3} \mathrm{~B} /(\mathrm{G}-0.5 \mathrm{H})\right)-(8 / 9)\left(\mathrm{A}^{4} /(2 \mathrm{G}-\right.\right.$

H) $]=0.03021313 \mathrm{in}^{4}$

Maximum stress $=116699.30 \mathrm{psi}$

Stiffness $=5.6179\left(\times 10^{6}\right) \mathrm{psi}$

\subsubsection{Pultruded bending test sample-2 (BGD)}

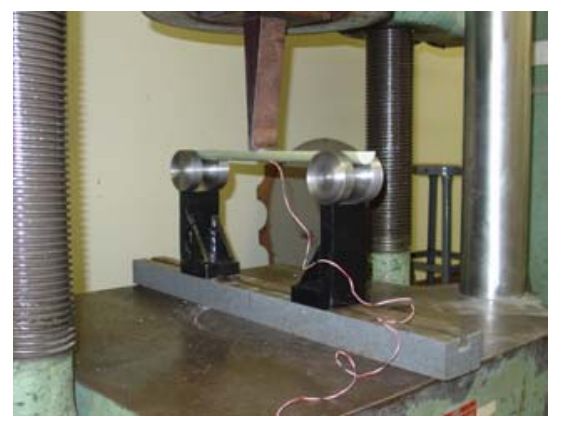

Figure 5-3 Dowel bar sample-2 (pultruded)

\section{Parameters}

$\mathrm{L}=$ Length of support span $=15$ in

$\mathrm{D}=$ Original diameter of the specimen $=1.5$ in

D1=Depth of the specimen taken as an average of values along the length of the bar $=0.73$

in

$\mathrm{R}=0.5 \mathrm{D}=0.75$ in

$\gamma=\mathrm{D} 1 / \mathrm{R}=0.97333$

$A=\sqrt{ }(\gamma(2-\gamma))=0.999644381$

$\mathrm{B}=1-\gamma=0.02666285$

$\mathrm{G}=\operatorname{arc} \operatorname{sine} \mathrm{A}, \mathrm{rad},=1.544126499$

$\mathrm{H}=2 \mathrm{~A} . \mathrm{B}=0.053314367$

$\mathrm{C}=$ Distance of centroid to extremities $=\mathrm{R}\left(1-\left(4 \mathrm{~A}^{3} /(6 \mathrm{G}-3 \mathrm{H})\right)\right)=0.420855446 \mathrm{in}$ 
$\mathrm{I}=$ Moment of Inertia $=\mathrm{R}^{4}\left[0.125(2 \mathrm{G}-\mathrm{H})\left(1+2 \mathrm{~A}^{3} \mathrm{~B} /(\mathrm{G}-0.5 \mathrm{H})\right)-(8 / 9)\left(\mathrm{A}^{4} /(2 \mathrm{G}-\right.\right.$

$\mathrm{H})]=0.03170949$ in $^{4}$

Maximum stress $=173952.65 \mathrm{psi}$

Stiffness $=6.3837\left(\times 10^{6}\right) \mathrm{psi}$

\subsubsection{Compression molded bending test sample (BWD)}

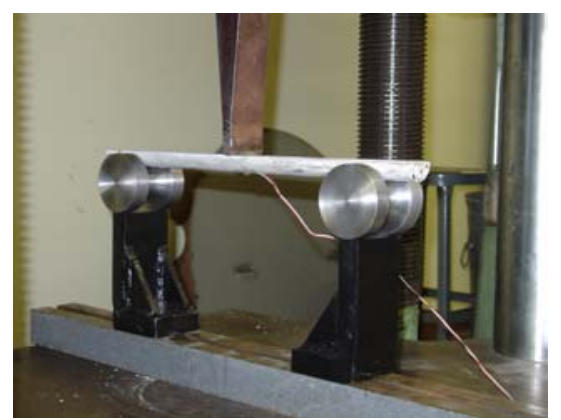

Figure 5-4 Dowel bar sample-3 (compression molded)

\section{$\underline{\text { Parameters }}$}

$\mathrm{L}=$ Length of support span $=15$ in

$\mathrm{D}=$ Original diameter of the specimen $=1.5$ in

D1=Depth of the specimen taken as an average of values along the length of the bar $=0.78133$ in

$\gamma=\mathrm{D} 1 / \mathrm{R}=1.041777$

$A=\sqrt{ }(\gamma(2-\gamma))=0.999127$

$B=1-\gamma=-0.04178$

$\mathrm{G}=\operatorname{arc}$ sine $\mathrm{A}, \mathrm{rad},=1.529007$

$\mathrm{H}=2 \mathrm{~A} \cdot \mathrm{B}=-0.08348$

$\mathrm{C}=$ Distance of centroid to extremities $=\mathrm{R}\left(1-\left(4 \mathrm{~A}^{3} /(6 \mathrm{G}-3 \mathrm{H})\right)\right)=0.4325$ in

$\mathrm{I}=$ Moment of Inertia $=\mathrm{R}^{4}\left[0.125(2 \mathrm{G}-\mathrm{H})\left(1+2 \mathrm{~A}^{3} \mathrm{~B} /(\mathrm{G}-0.5 \mathrm{H})\right)-(8 / 9)\left(\mathrm{A}^{4} /(2 \mathrm{G}-\mathrm{H})\right]=0.028441\right.$

in $^{4}$ 
Maximum stress $=10536.51 \mathrm{psi}$

Stiffness $=0.4828\left(\times 10^{6}\right) \mathrm{psi}$

Table 5-26 Bending strength and stiffness values of the dowel bars

\begin{tabular}{|c|c|c|}
\hline Specimen type & Max strength (psi) & Max stiffness $\left(\times \mathbf{1 0}^{\mathbf{6}}\right) \mathbf{p s i}$ \\
\hline BRD-1 & 116699.30 & 5.96 \\
\hline BRD-2 & 133523.92 & 6.24 \\
\hline BGD-1 & 173952.65 & 6.38 \\
\hline BGD-2 & 174706.23 & 8.15 \\
\hline BWD & 10536.51 & 0.48 \\
\hline
\end{tabular}

\subsubsection{Summary}

Dowel bar made of only recycled ABS pellets without any fiber/fabric reinforcement showed a bending strength of $10536.51 \mathrm{psi}$ and stiffness of $0.4828 \times 10^{6}$ psi. Based on the limited trials conducted in this research, dowel bars could be manufactured using recycled resins with appropriate modifications to manufacturing process and dowel bar constituents. Chopped fibers can be added to the recycled pellets to manufacture dowel bar to improve strength and stiffness. 


\section{CHAPTER 6}

\section{RECYCLED COMPOSITE PRODUCTS}

\subsection{Introduction}

The applications of composites have been widely demonstrated in construction, marine/waterfront structures, repair and rehabilitation, corrosion reduction, and structural alternative utilitie (Busel 1995). Composites are applied in various fields such as aerospace, automobiles, chemical industry, electrical, consumer and sports, and biomedical equipments.

Growing concerns about pollution of the environment and decreasing capacity of the sanitary landfill sites, has enhanced the momentum of plastics recycling in the U.S. Recycled polymers have been a cheap source of material for numerous applications and appear in the market as composites, both with and in reinforcements.

For components with complicated geometry, compression molding is more suitable. Compression molded composites are used in many automobiles, appliances, construction and industrial applications (Mallick et al., 1990).

Various products that can be manufactured from recycled polymers are:

- Civil engineering: geotextile, urethane foam, curb stops, signs, traffic-barrier cones, guardrails, offset blocks, posts, pipes, building products etc.,

- Recreational: skis, surfboards, sailboat hulls, and toys etc.,

- Industrial: carpets, fence posts, fiberfill, fuel pellets, industrial paints, strapping, paint brushes, pallets, soft drink base cups, milk bottle carriers, matting, kitchen drain boards, drums/pails, trash cans etc., 
Compression molding has number of advantages over injection molding process. It is performed with no sprues, gates, and runners, resulting in very little wastage of material, with relatively lesser molding pressure application than the injection molding. While injection molding restricts the size of the fiber length to $3 \mathrm{~mm}$ maximum and low fiber volume fractions, compression molding easily accommodates long fiber lengths and high fiber volume fractions. In general, better physical and mechanical properties can be achieved in compression-molded parts (Mallick, 1990). We have attempted to develop two products using glass reinforced recycled polymers using compression molding technique. The products are:

- Dowel bars

- Angles

\subsection{Dowel bars}

The repairs and replacements in the nation's transportation infrastructure are due to the deterioration of the concrete pavements. The performance of the pavements is largely related to the performance of the joints. As opposed to inadequate structural capacity the failure at the joints can be attributed to stresses resulting from faulting, pumping, spalling, corner breaks, blowups, and mid-panel cracking. Dowels help in transferring the load across joints between two contiguous pavement slabs is the cause that highlights the use of Dowel bars (Figures 6-1 and 6-2). 

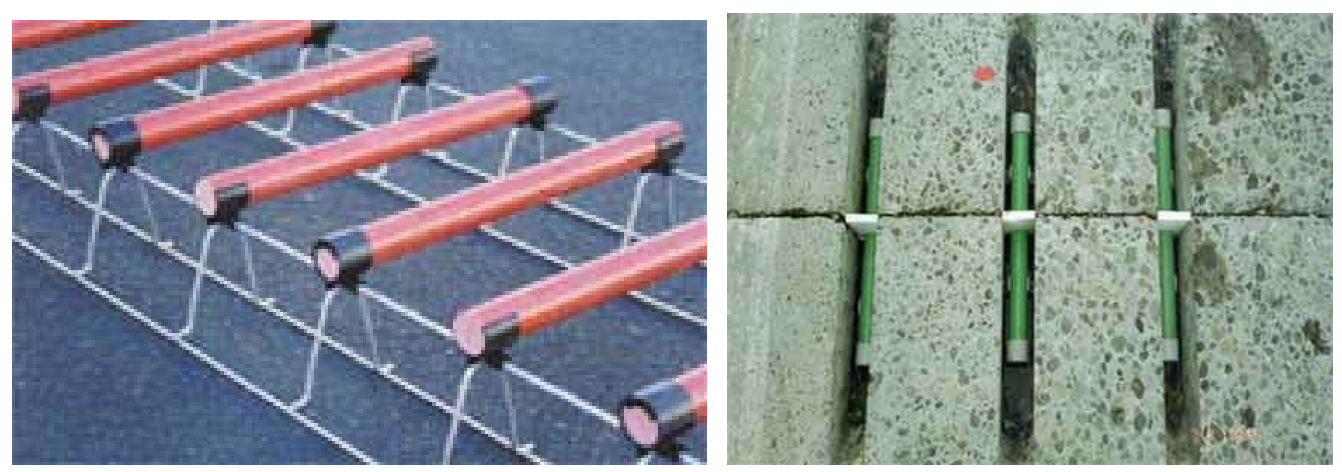

Figure 6-1 FRP dowel bars

Figure 6-2 Dowel bars in concrete slabs

Normally, the dowel bars are made of steel, which are susceptible to deterioration due to de-icing salts. Corrosion of the steel dowels binds or locks the joints resulting in undesirable pavement performance. The corrosion resistance of GFRP makes it an ideal material for use as load transfer device (dowel) in concrete highway pavement slabs.

\subsubsection{Manufacturing dowel bar with recycled ABS}

Typically, FRP dowel bars are pultruded using continuous fiber filaments and resin. The filaments are drawn through a resin bath, sized by an appropriate die, to form the dowel. Dowels are typically 1.5 " in diameter and 18 " long for pavement slabs with a thickness of about 10".

Proposed method of making Dowel: Manufacturing of dowels using recycled thermoplastics was experimented with considerably successful results. A new mold was designed to manufacture 18.5 " long dowel bars using heated rectangular split aluminum molds with semi-cylindrical grooves. The mold enabled pressure application on resin pellets fed into the mold through a piston positioned at the end plate. Mold was heated to the required processing temperature and pressure was simultaneously applied to achieve a good product with respect to uniform melting and blending of the resin. 


\subsubsection{Details of the mold}

A mold was designed to manufacture a dowel bar, 18.5" long and 1.5" in diameter, using recycled polymer reinforced with glass fibers. The mold comprised of long rectangular aluminum pieces with semi-circular grooves in each piece. A piston was positioned near the end plate for applying pressure. Initially, the mold was filled with only ABS resin pellets as a trial (Figure 6-3) and 2 heaters were used on the mold exterior for preheating the resin for about 20 minutes followed by pressure application for about 20 minutes.

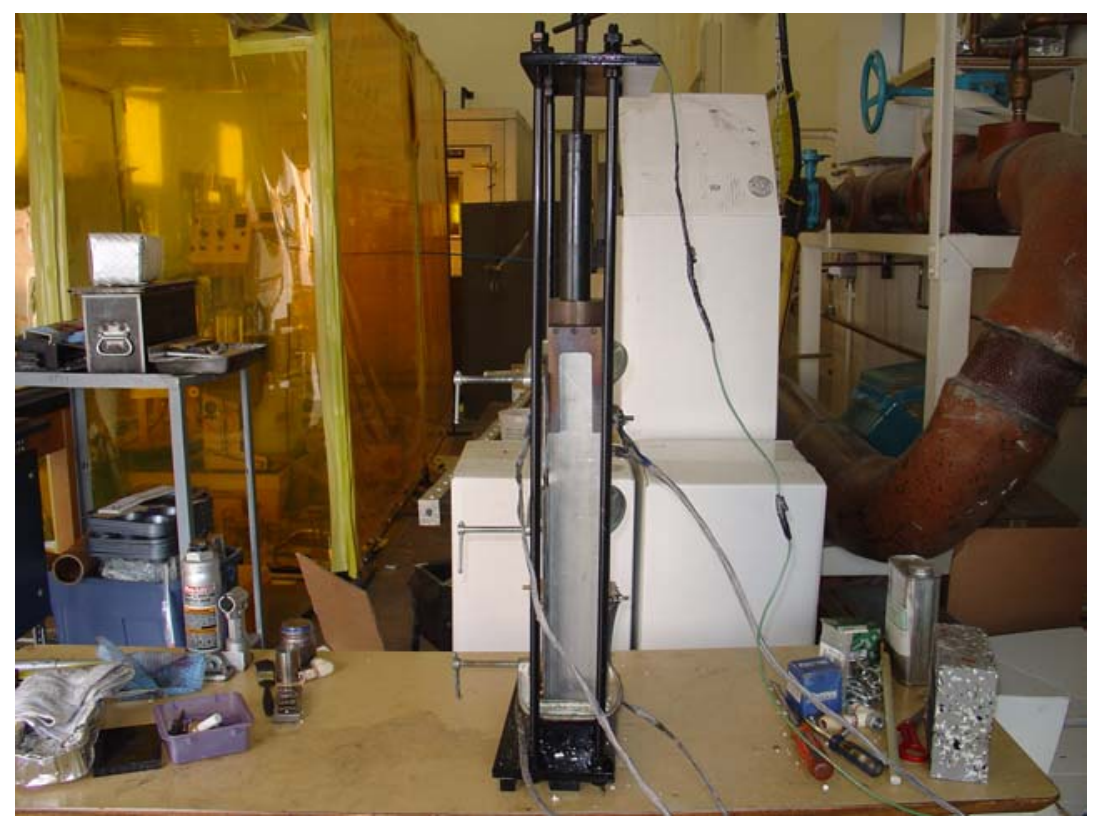

Figure 6-3 Experimental mold setup for dowel bar manufacture

Pressure was applied using a mini jack with a load rating of 4 tons. Resin pellets were added intermittently into the mold, removing the piston to maximize resin density. Though resin pellets were not adequately bonded dowel bar appeared to be well compacted (Figure 6-4). 


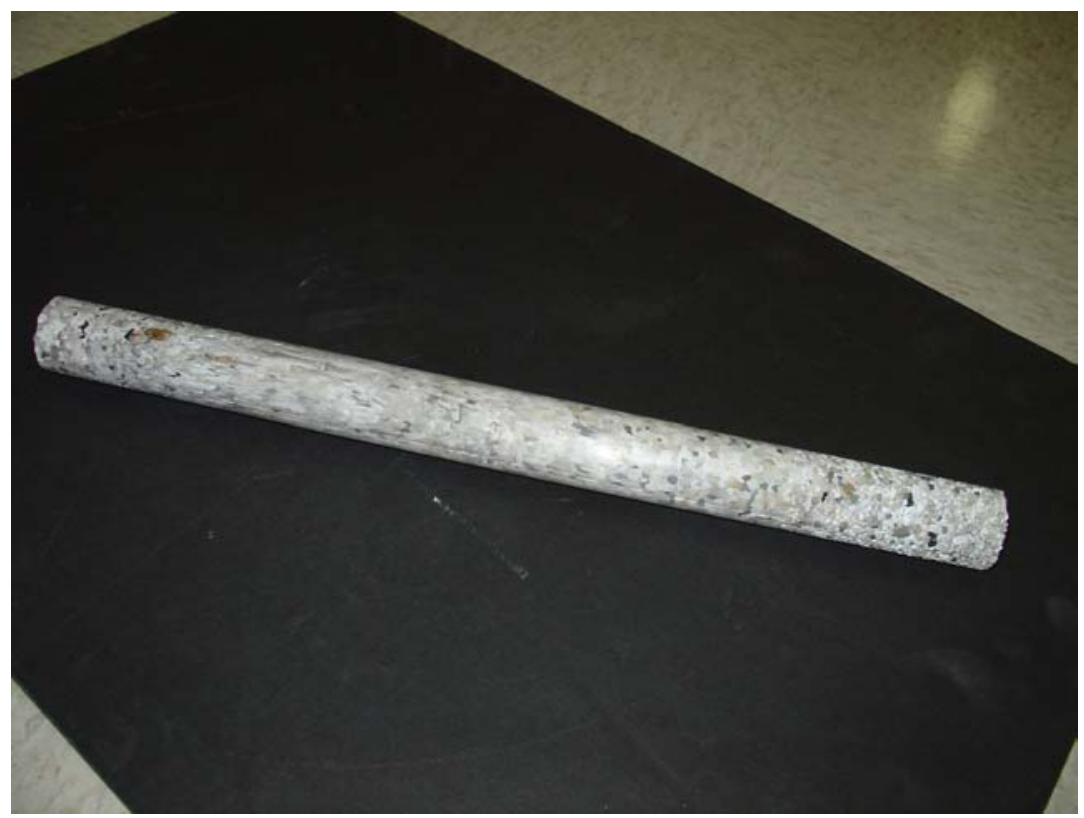

Figure 6-4 Unblended resin pellets in the dowel due to inadequate heat transfer

Then, several compression molding trials were carried out by keeping the pressure constant and varying both temperature and time. Two additional side heaters were mounted on the mold along with the two already existing on the mold to increase the heat transfer. Dowel bar with better surface finish and blending was obtained after 30 min of preheating followed by 45 minutes of pressure application, with intermittent addition of resin pellets.

\subsubsection{Dowel bar manufacturing process}

Proper compaction of the pellets and heat transfer were the keys to obtain a good dowel bar with respect to weight, surface finish and blending. Inadequate resin filling and compaction led to air voids and gaps in the dowel bar. Resin pellets were intermittently added by lifting the piston after first 10 minutes of heating. Additional pellets were added by compressing the softened resin. 
Three process cycles each of 45-minute duration, each time with additional pellets along with the bar made from the earlier cycle were used to obtain a good dowel bar. Pellets were added at the bottom of the mold in each successive cycle, along with the bar made from previous process cycle (Figure 6-5 and 6-6).

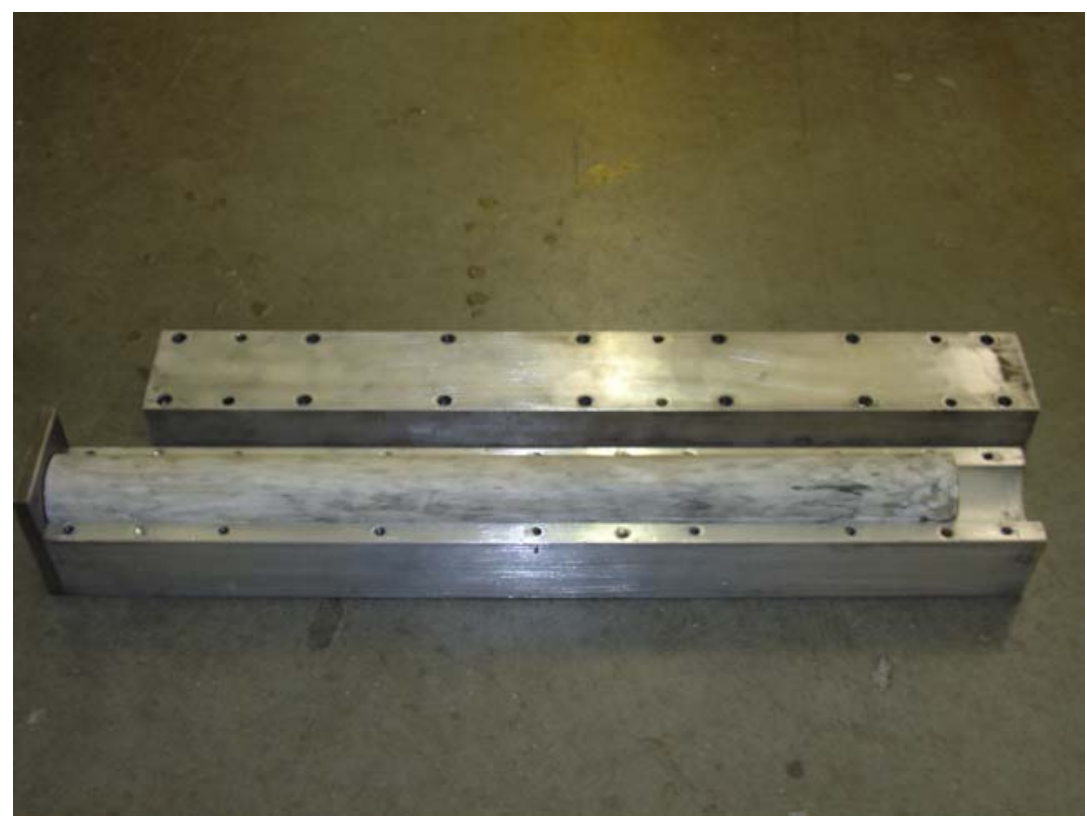

Figure 6-5 Mold with dowel bar after first process cycle

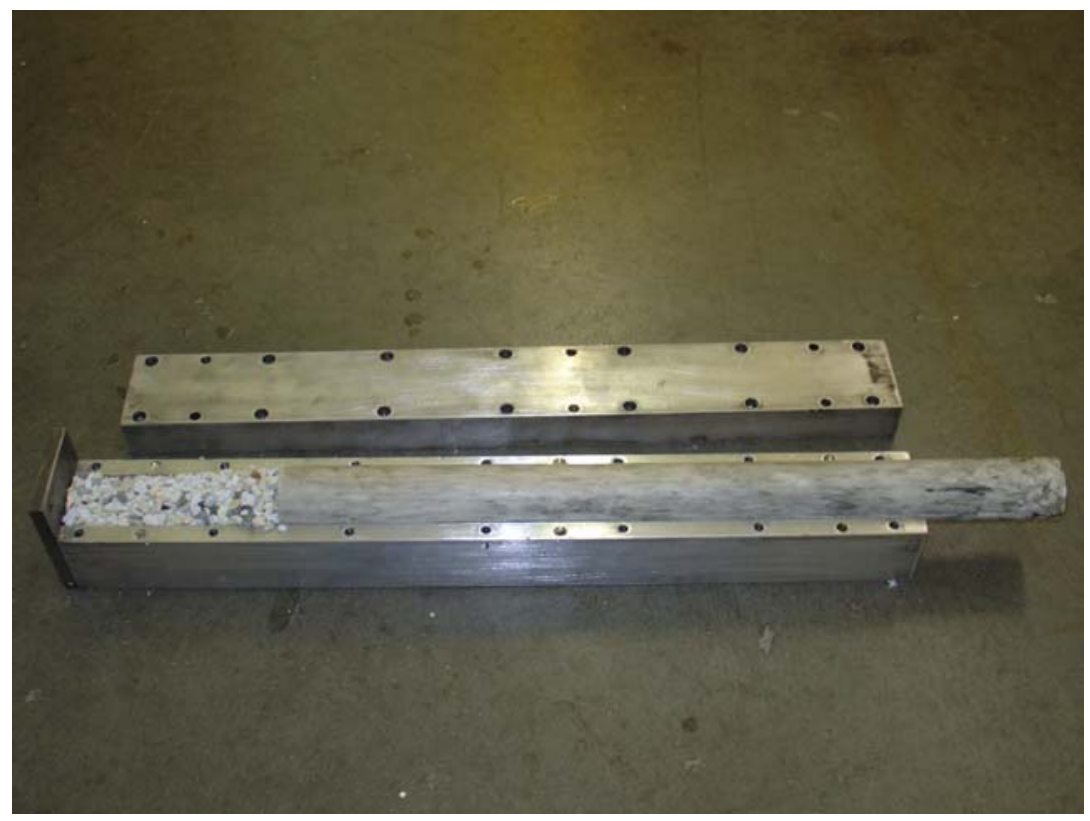

Figure 6-6 Mold with additional pellets and premolded bar for following cycles 
After 45 minutes of each cycle, the heaters were switched off and the mold was left for cooling for about 3 hours and then demolded. This process was repeated to obtain a dowel bar successfully (Figure 6-7).

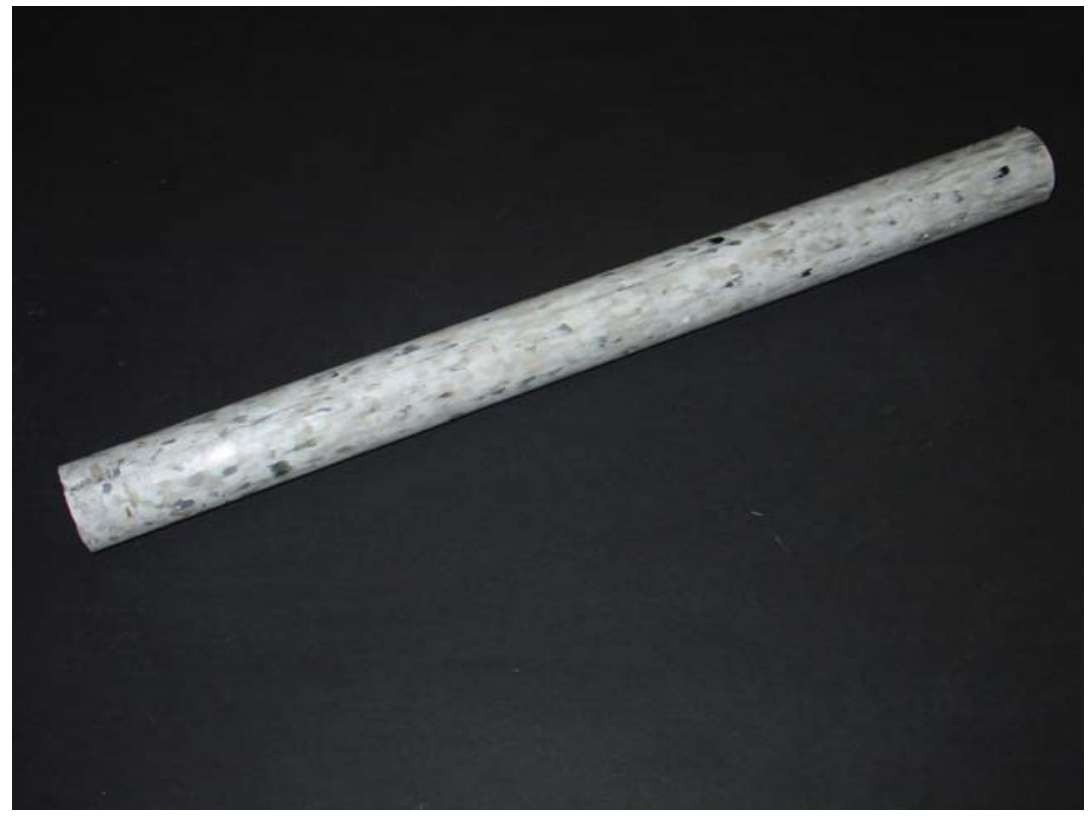

Figure 6-7 Appreciable surface finish and blending in dowel, with increase in process time

Another dowel bar was also manufactured using commercial thermoplastic-coated 1" long fibers called "Twintex." Manufacturing trials to determine its process parameters indicated higher process temperature requirement than that is available with current set of heaters. In addition, use of extruded resins in a melted state would lead to a better dowel bar with significant reductions in manufacturing time. 


\subsubsection{Summary}

Process parameters for obtaining a good dowel bar using recycled ABS were determined. These dowels were tested for strength and stiffness in bending, and the results were discussed in Chapter 5.

Introducing preheated resin into the mold would increase the uniformity and blending in the final product and the process time would decrease considerably. Resin with chopped fiber could be used to obtain products of higher strength/stiffness and tested subsequently for field installation.

\subsection{Angles}

Angles, manufactured using the glass fiber reinforced recycled polymers can be used to replace the wooden posts currently used for guardrail systems on highways and bridges. Also, creosote coated wooden guardrail posts are not favored by many environmentalists, because of the potential danger of the groundwater contamination by leached creosote. Fiber reinforced recycled polymer thus forms an alternative material for component of guardrail system, and reduce the demand for lumber supply.

\subsubsection{Details of the mold}

A new mold was designed with a v-groove cut along base plate, and closed by end plates. An inverted angle was bolted to the top plate such that the matched mold would give an angle of desired thickness as final product (Figure 6-10). Angles of different thickness could be produced by the same mold by additional inserts (plates) positioned in the bottom mold. 


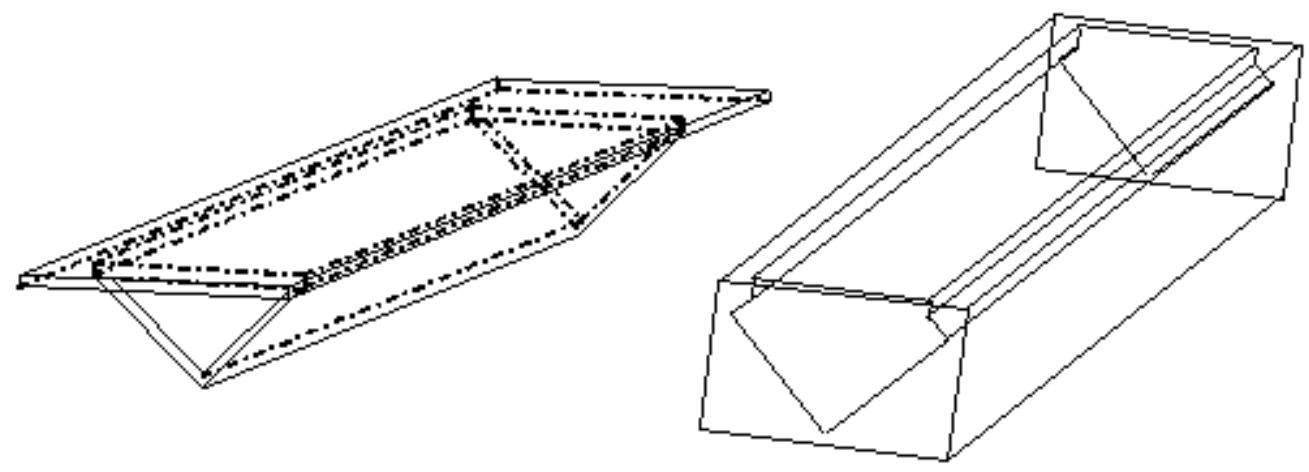

Figure 6-8 Angle mold top and bottom plates

\subsubsection{Manufacturing process of angle}

Proposed method: Angles were manufactured using compression molding with a specially designed mold (Figure 6-8). Flash was positioned between the resin and inner walls of the mold to provide better surface finish. Demolding agent (Tech Lube 25, Technick products) was coated on the flash for easier retrieval of the end product from the mold. The amount of recycled resin, initially filled in the mold was calculated keeping in view the volume of the end product and its density. The top plate was positioned on the bottom mold: whole mold was placed in the compression press preheated to the required temperature $\left(450^{\circ} \mathrm{F}\right)$. The side heaters were switched "ON" and resin was left for 25 minutes to preheat (polymer pellets after preheating becomes soft and mushy). The pressure was then applied gradually to compress the resin in the mold. Twenty tons of compression pressure was kept constant for 30 minutes and then dropped to around 5 tons for cooling.

Figures 6-9 to 6-12 show the sequential procedure in manufacturing an angle using Compression molding process. Figures 6-13 and 6-14 show the manufactured product and its cross section from a cut section. 


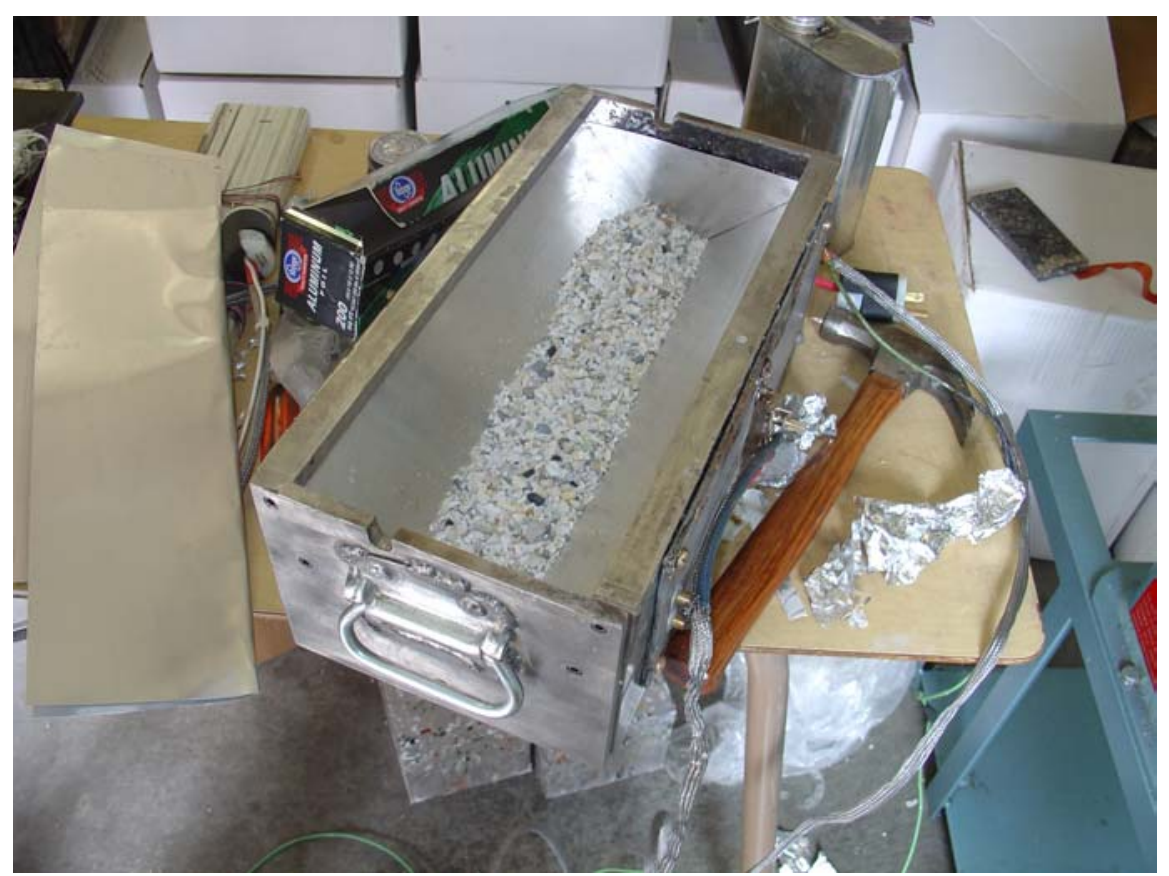

Figure 6-9 Angle mold being filled with ABS resin

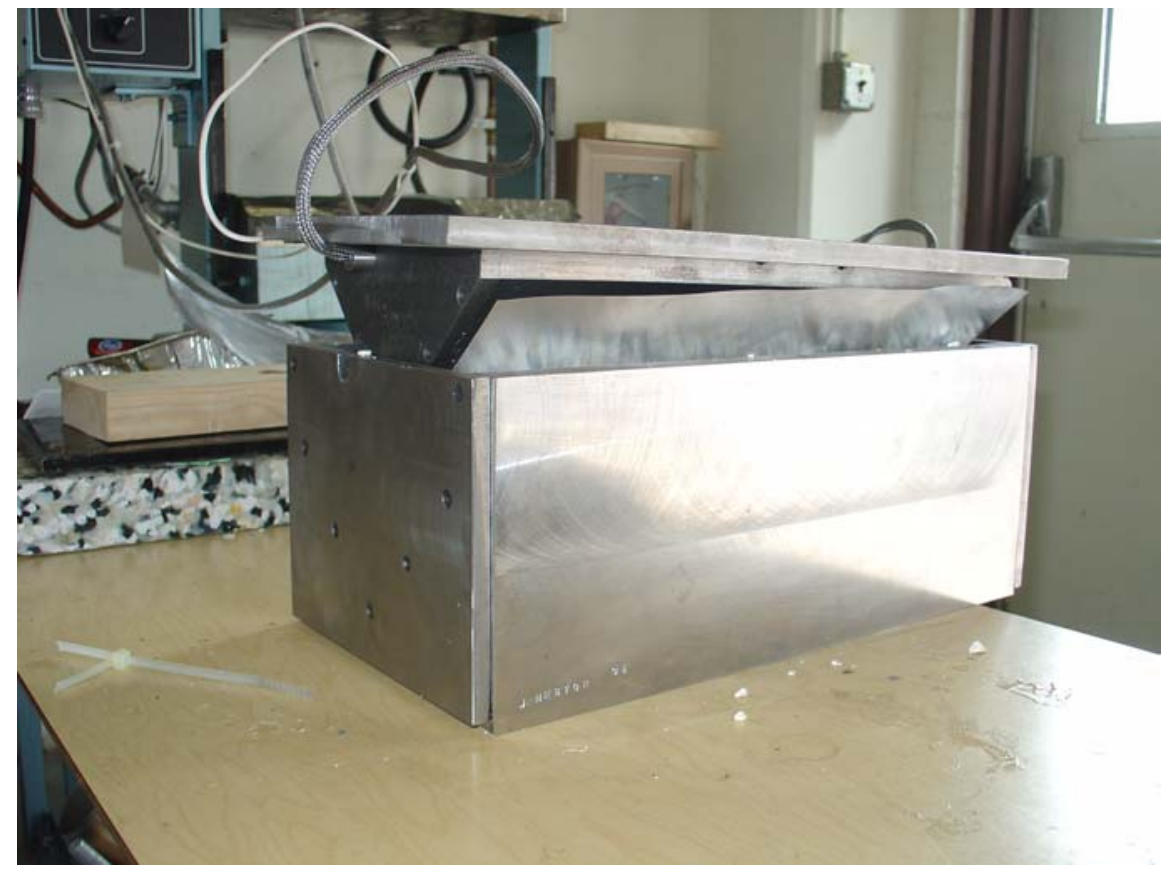

Figure 6-10 Angle mold filled with ABS resin reinforced with glass fabric 


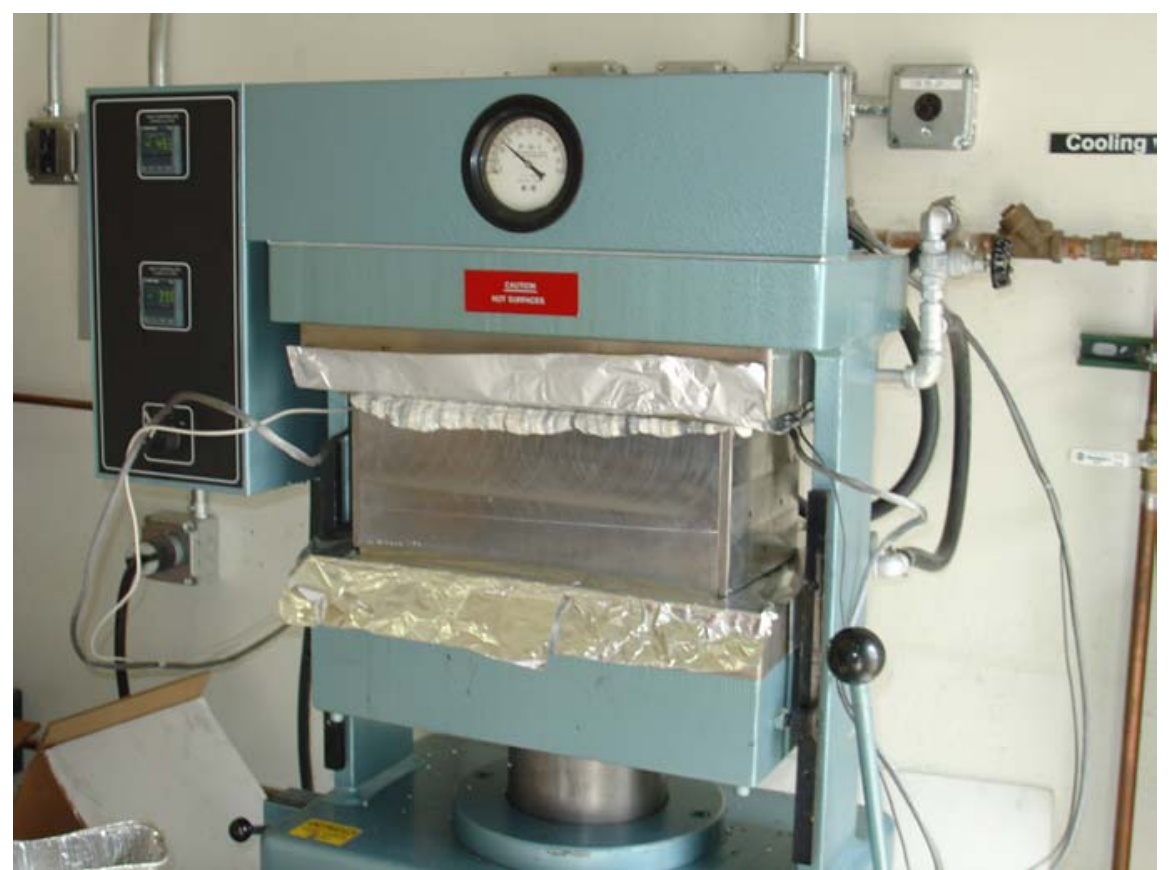

Figure 6-11 Mold compressed under pressure and temperature

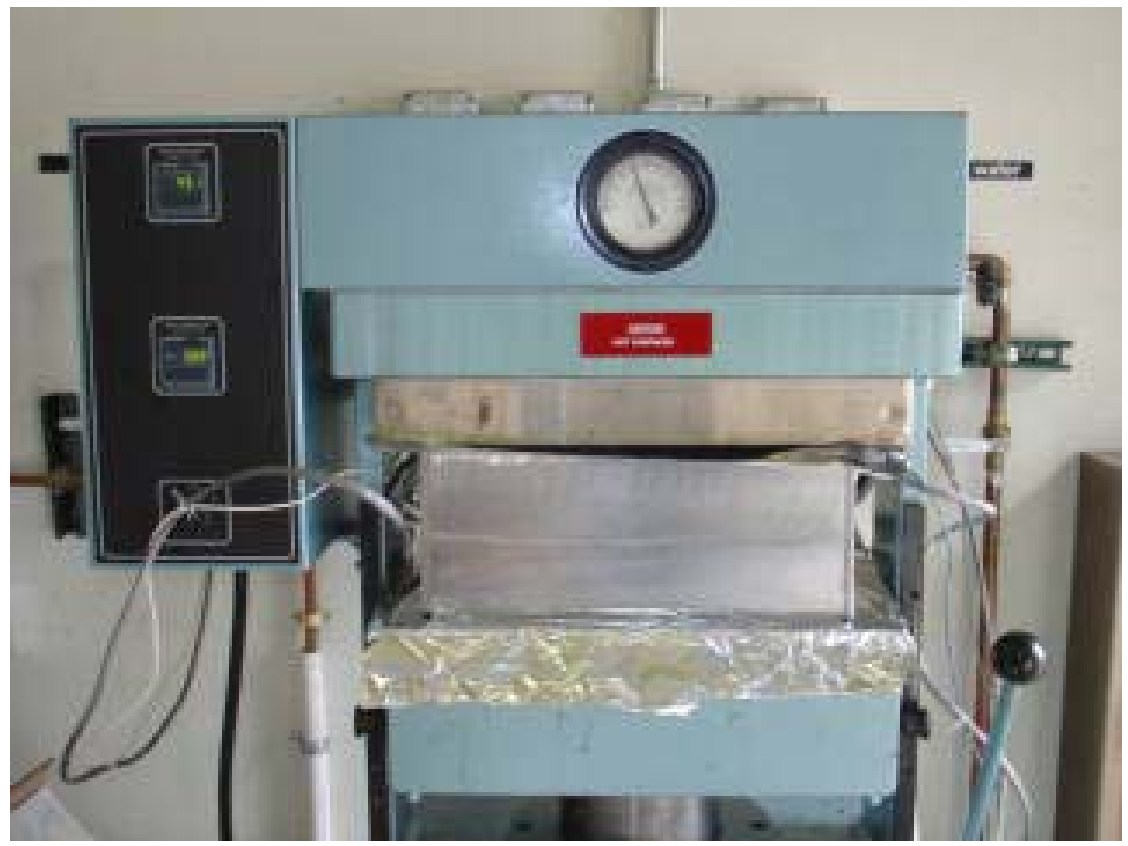

Figure 6-12 Mold being cooled in the compression press under dead load 


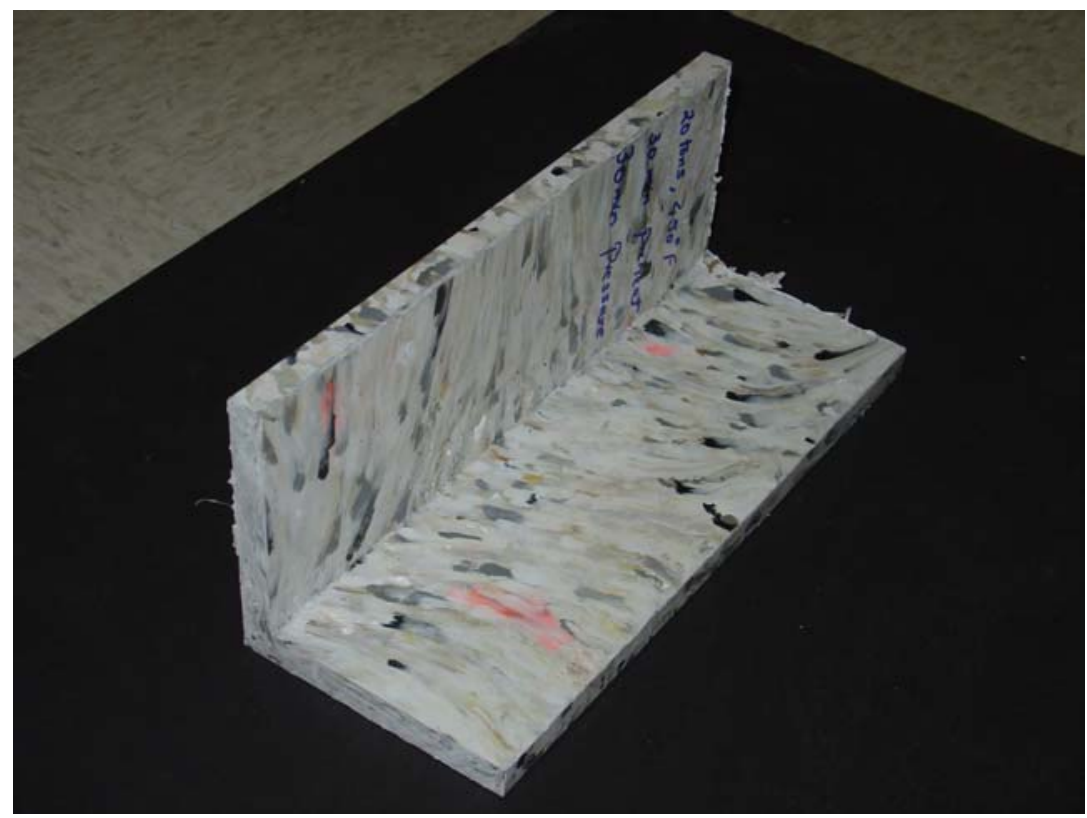

Figure 6-13 Angle made of recycled ABS

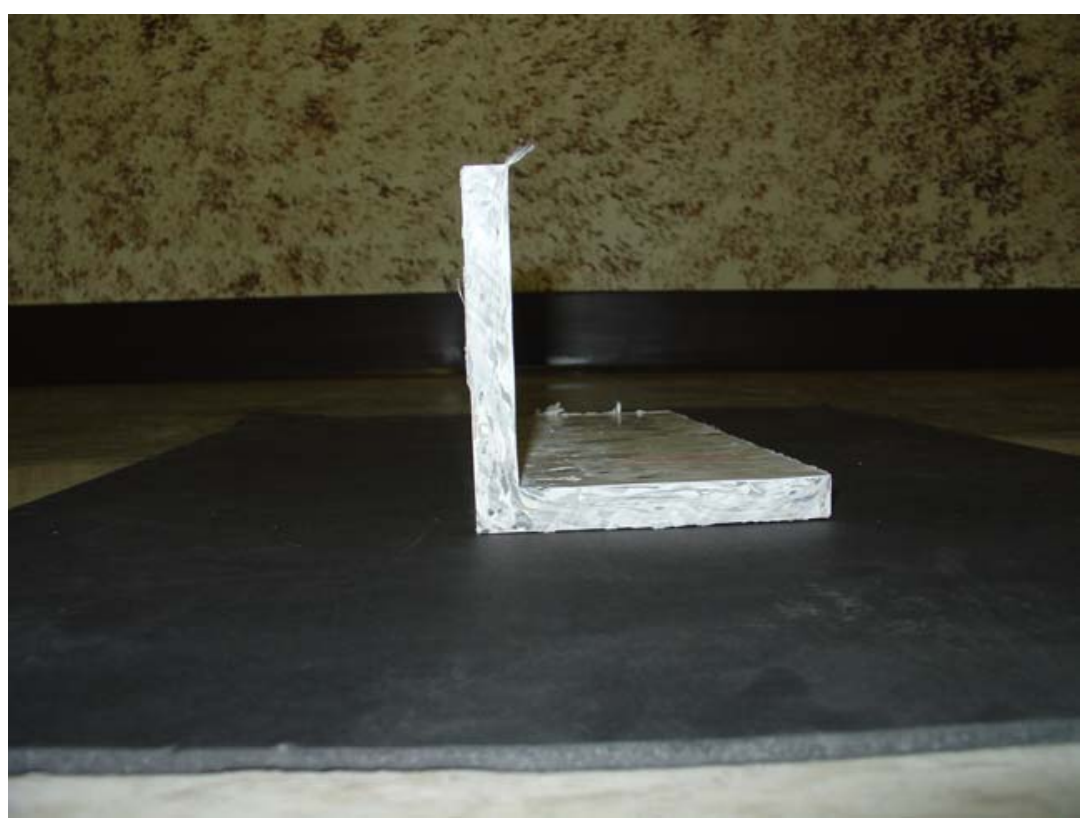

Figure 6-14 Cross-section of the angle 


\subsubsection{Test on angles}

An angle specimen was made from compression molding using the procedure as described above. Specimens were cut from this sample in dog-bone shape for performing tension tests.

\subsubsection{Test specimen}

Dimensions of the cut specimens are presented in Table 6-1. The rectangular specimens were cut to obtain dog-bone shape (Figure 6-15) in accordance with the Type3 specimen ASTM 638.

Table 6-1 Dimensions of the tension test specimens

\begin{tabular}{|c|c|}
\hline Width Overall (WO) & $1.13 ”$ \\
\hline Width of the narrow section (W) & $0.75^{\prime}$ \\
\hline Length Overall (LO) & $14.5 ”$ \\
\hline Thickness of the sample (T) & $0.625 ”$ \\
\hline
\end{tabular}

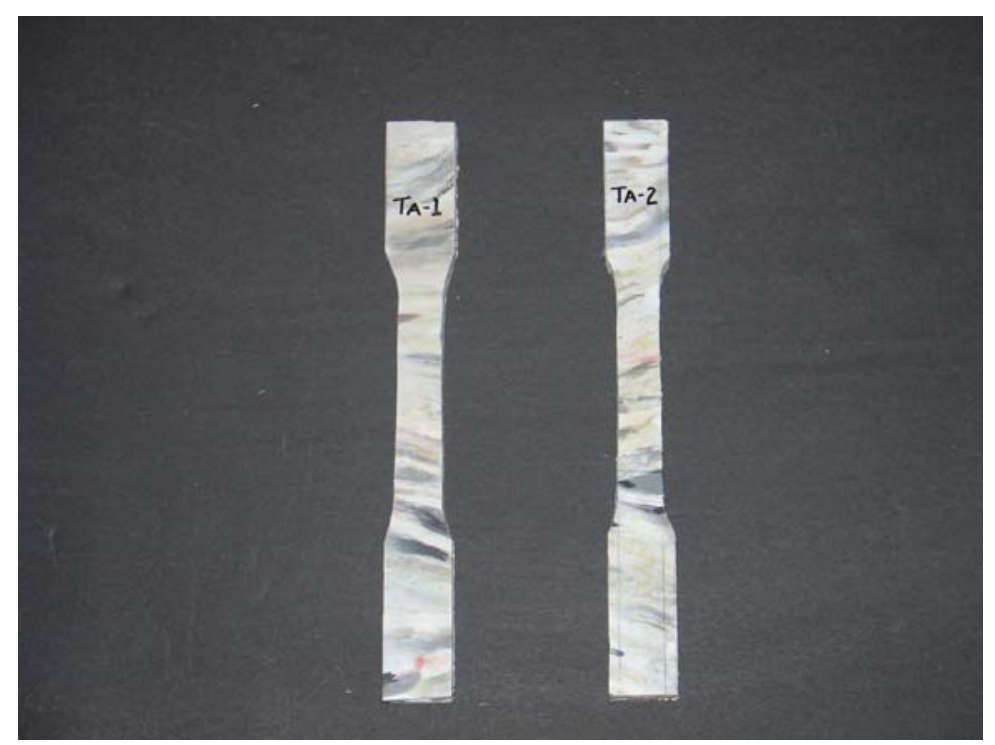

Figure 6-15 Tension coupons cut from angle 


\subsubsection{Specimen preparation}

A strain gauge was installed on the sample at its mid-span in order to measure tensile strains. Surface preparation consisted of: sanding with a 320 grid paper, cleaning with degreaser, neutralizing with alkaline solution, followed by attaching the strain gauge by using M-bond adhesive.

\subsubsection{Test procedure}

Baldwin machine (UTM) was used to conduct the tension test on the samples cut from the angles. Load data was directly recorded from the Baldwin machine, whereas the strain data was recorded using data acquisition system (Figure 6-16). The test was computer controlled and the initial strain values were zeroed before starting the test. The specimens were loaded until failure.

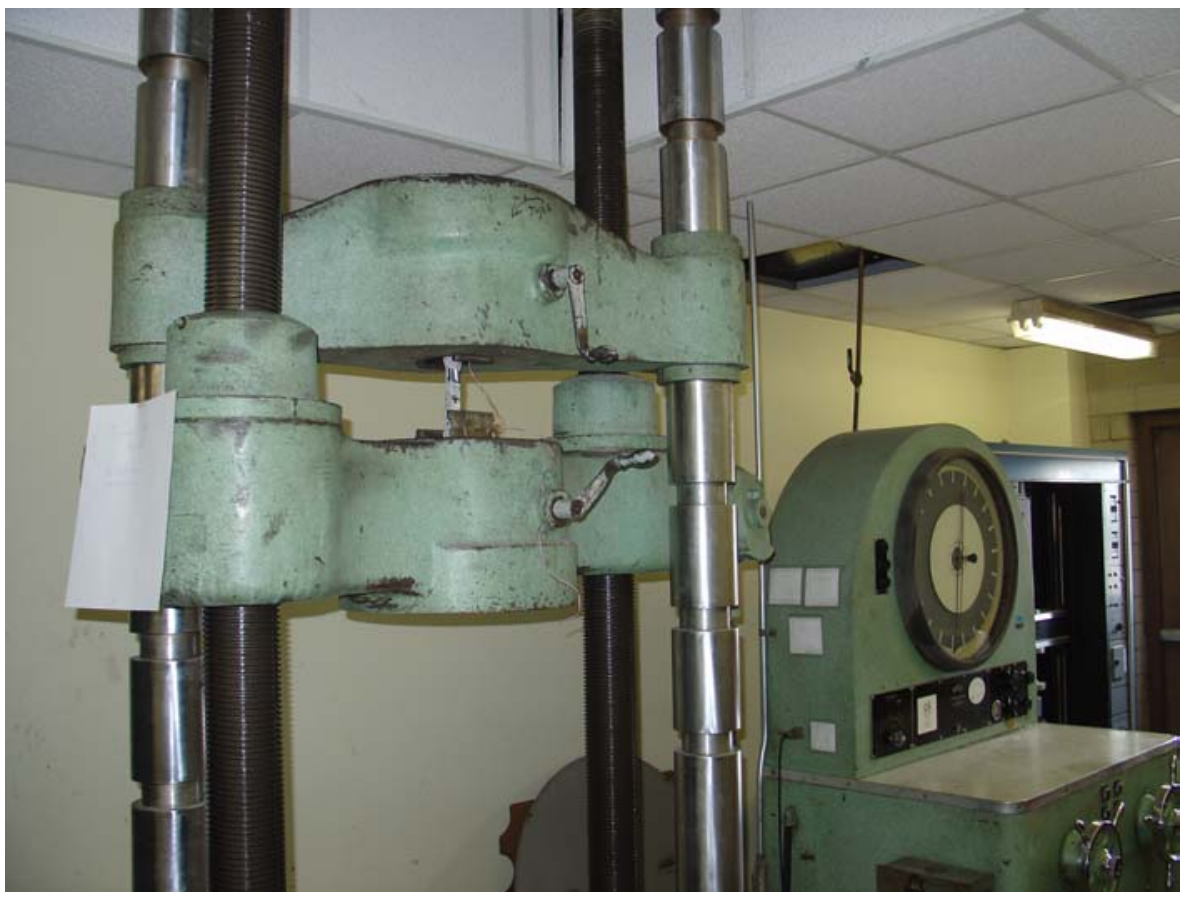

Figure 6-16 Tension test specimen in Baldwin machine 


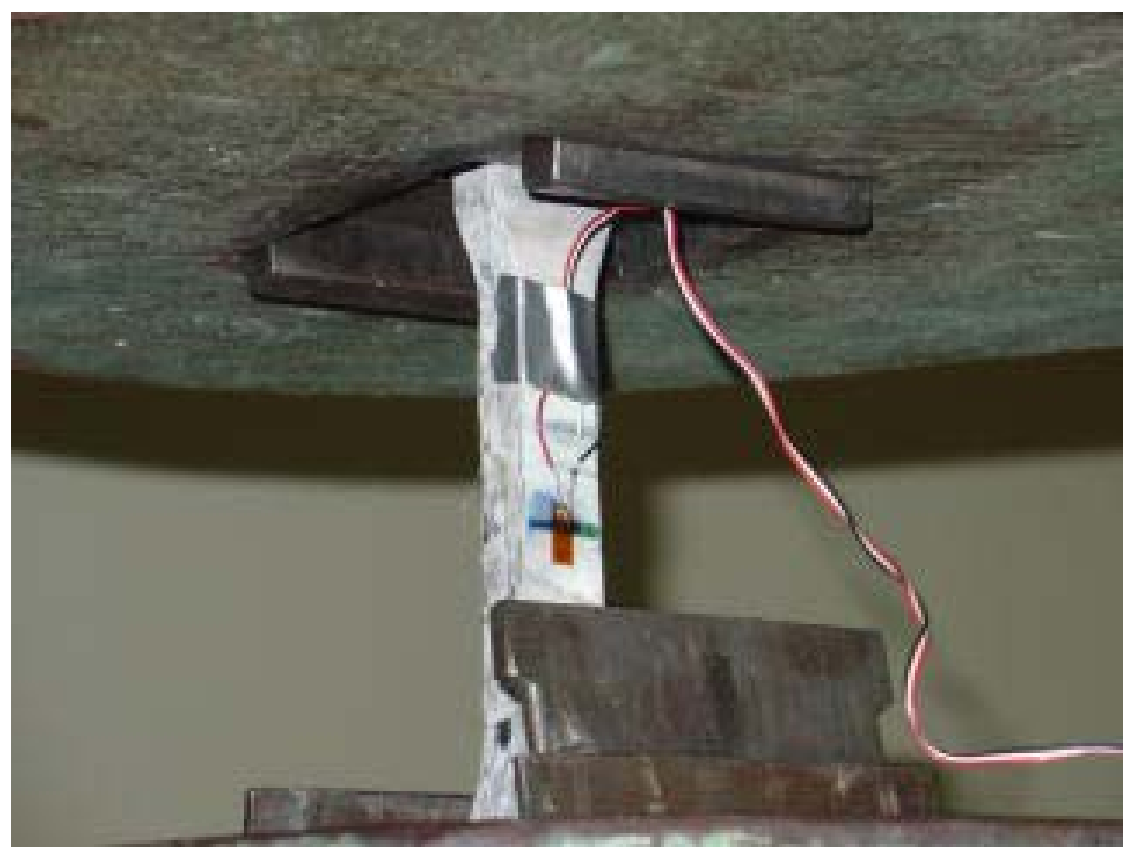

Figure 6-17 Close up of the Tension test setup

\subsubsection{Results}

Figure 6-18 shows the tensile stress vs. strain relation for the coupon cut from an angle specimen (Figure 6-15). Strength and stiffness values are presented in Table 6-2.

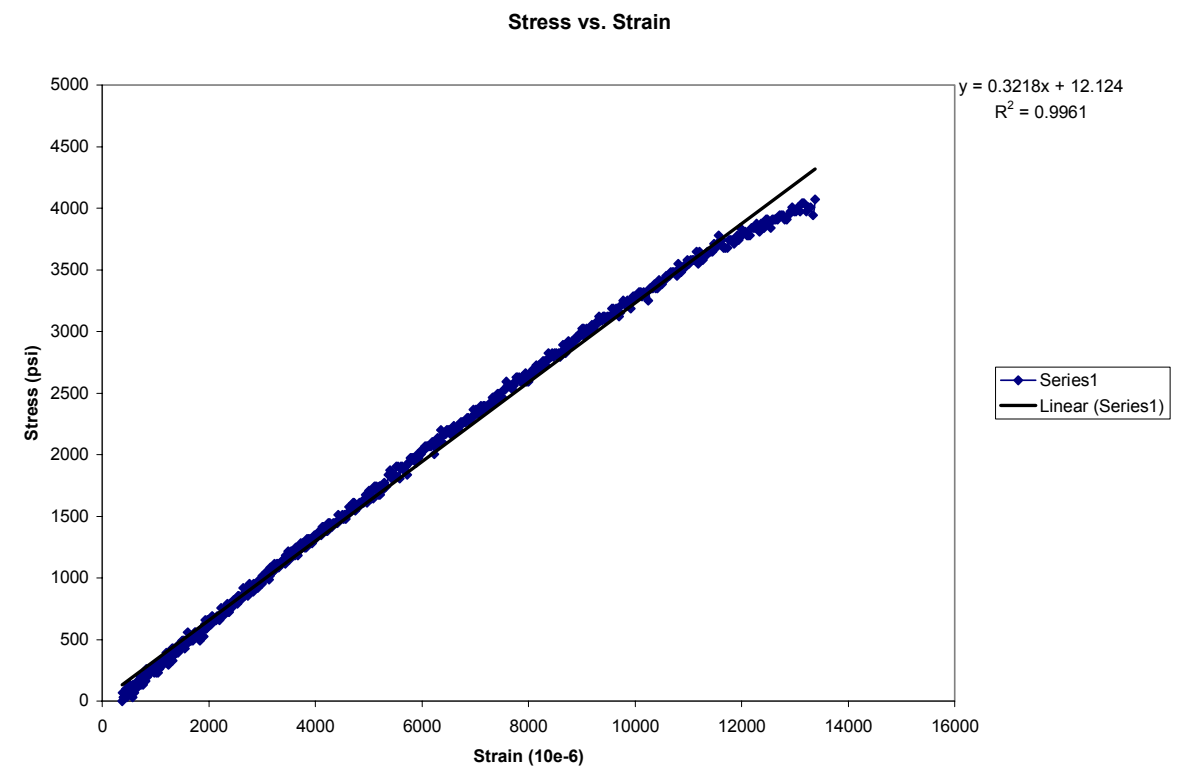

Figure 6-18 Stress vs. Strain graph of tension specimen-1 cut from the angle 
Table 6-2 Maximum tensile strength and stiffness values for the tensile test samples

\begin{tabular}{|c|c|c|}
\hline Specimen & Maximum stress (psi) & Stiffness $\left(\times 10^{6}\right)$ \\
\hline TAA-1 & 4072.533 & 0.3218 \\
\hline
\end{tabular}

Note: TAA-1: Tension test ABS specimen \#1 cut from the Angle

\subsubsection{Remarks}

The glass fabric used in manufacturing the angles was found to be incompatible with ABS thermoplastics resin. Thus, the coupon specimens cut from the molded angles when tested in tension gave low strength and stiffness values.

\subsection{Summary}

The processing parameters for the manufacture of composite dowel bars and angles made from recycled thermoplastic resins were determined. A sequential procedure was laid out for the manufacture of these composite products and this procedure could be modified to suit various specimen sizes. Structural strength and stiffness of these products could be improved with the use of compatible glass fabrics. These angles could be manufactured as prototype signposts and vertical posts for guardrail systems on bridges and highways. 


\section{CHAPTER 7}

\section{THERMO-MECHANICAL PROPERTIES OF THE OFFSET BLOCK}

\subsection{Infrared Thermography}

\subsubsection{Introduction}

Non-destructive methods have been gaining importance in the material testing techniques quite rapidly in comparison with the other testing methods (American Society of Non-destructive Testing). Non-Destructive Inspection and Evaluation (NDI\&E) is a valuable tool in any phase of a product's design and manufacturing process, including materials selection, research and development, assembly, quality control and maintenance.

Some of the commonly used NDI techniques include liquid penetrant, magnetic particle, eddy current and radiographic inspection, ultrasonic and infrared inspection, tomography, real-time radiography, ground penetrating radar, and fiber optics.

Infrared imaging (thermography) used in this study is a non-contact optical method where an accurate two- dimensional mapping of steady or transient thermal profile is constructed from the measurement of infrared energy emitted by the target. By implementing real time infrared image acquisition and processing we can:

- Detect sub surface imperfections.

- Evaluate composition of materials and products in terms of structural discontinuities.

Infrared imaging can be carried out by portable hardware that provides rapid data acquisition of the infrared images that are easy to interpret. It utilizes the heat energy radiated by an object to characterize its subsurface conditions. The subsurface defects 
affect the rate of heat transfer through the thickness of the structural member and hence result in surface temperature differentials with respect to defect-free areas.

The areas of a specimen subjected to thermography are differentiated in varying colors and the color contour is explained with a color-temperature graph shown next to the image.

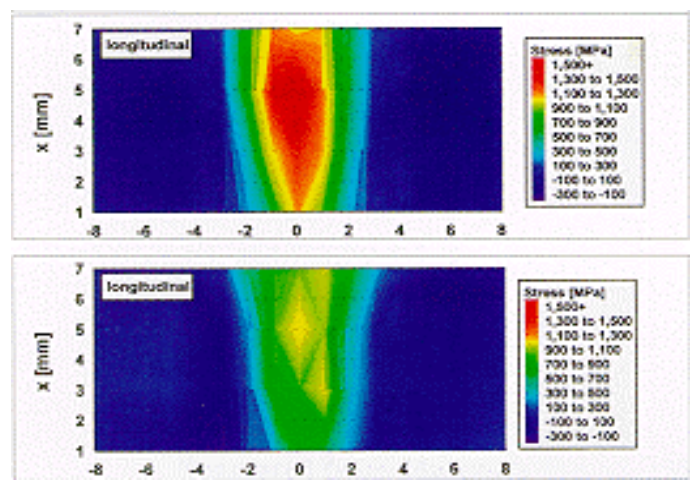

Figure 7-1 Sample infrared image with color-temperature graph

\subsubsection{ThermaCAMTM $S 60$}

The ThermaCAM ${ }^{\mathrm{TM}}$ S60 (FLIR Systems) infrared condition monitoring system consists of an advanced digital infrared camera and associated image processing software. The ThermaCAM ${ }^{\mathrm{TM}}$ lightweight, portable camera (Figure 7.2) is a handheld unit with a built-in $24^{\circ}$ lens.

Some of its features are:

- An integral digital color camera, a laser pointer, a 4" color LCD.

- Measurable temperature ranges are +32 to $+932^{\circ} \mathrm{F}\left(0\right.$ to $\left.+500^{\circ} \mathrm{C}\right),-40$ to $+248^{\circ} \mathrm{F}(-$ 40 to $\left.+120^{\circ} \mathrm{C}\right)$ and +662 to $+2732^{\circ} \mathrm{F}\left(+350\right.$ to $\left.1500^{\circ} \mathrm{C}\right)$.

- Measurement accuracy of $\pm 2{ }^{\circ} \mathrm{C}$ or $\pm 2 \%$ of reading in ${ }^{\circ} \mathrm{C}$. 
- Images can be analyzed either in the field by using the real-time measurement markers built into the camera software, or in a PC using FLIR Systems software.

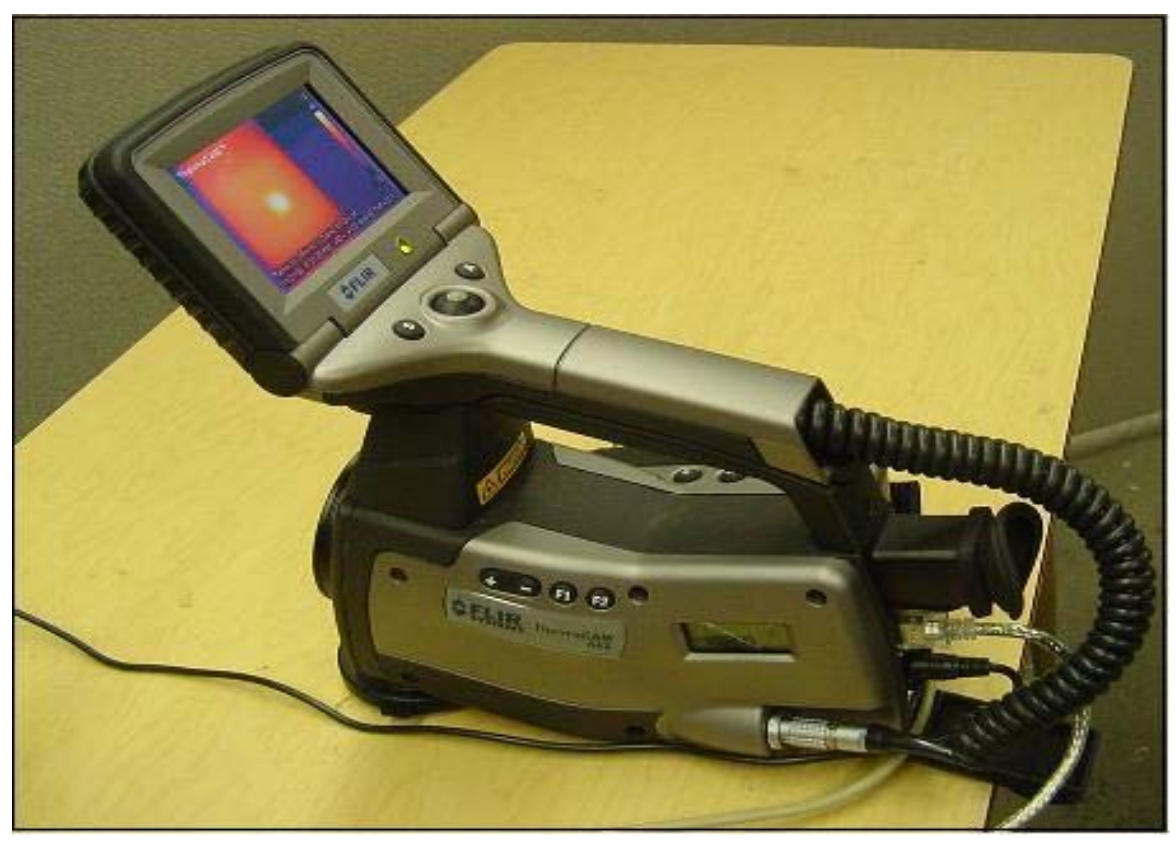

Figure 7-2 Infrared camera, ThermaCAMTM S60

\subsubsection{Testing Procedure}

\subsubsection{Summary}

Manufacturing process of the Guardrail Offset block was monitored with ThermaCAM ${ }^{\mathrm{TM}} \mathrm{S} 60$ to study the temperature profile and heat distribution within the mold filled with ABS thermoplastic resin. Inadequate heat distribution within the block during compression molding process was suspected to be the main cause of improper resin pellet blending. Thus, thermal imaging technique was used to study the heat propagation within the mold filled with all ingredients of the block, i.e., resin, rubber strips, and glass fabric. Presence of rubber (insulator) tires along with low thermal conductivity of recycled plastics were some of the reasons for non-uniform heat propagation. 


\subsubsection{Approach}

Manufacturing process of the block was monitored using infrared thermography to study heat propagation during the process. No external heating, other than the heaters of the press and side heaters on the mold needed for manufacturing the block, was used for this experiment. Existing temperature differences within the various mold constituents (rubber strips, resin pellets and glass fabric) were used to establish necessary temperature patterns. This approach is commonly used to assess or monitor the state of industrial process in the manufacturing stage (Maldague 2001).

The infrared camera allows the images to be recorded first and then viewed at a later time with a different temperature/color intensity scale to improve the contrast. The temperature corresponding to any point could be obtained by using the spot temperature measurement option provided by the analysis software.

\subsubsection{Process}

Composite manufacturing process was carried out along with the infrared imaging process to study the heat flow pattern during the process. A bench was positioned near the compression press so that the hot mold can be placed on it when it is intermittently taken out for the thermal imaging. The imaging set-up was positioned at a distance wherein clear images could be obtained. Images were taken at specific time intervals from the beginning of the manufacturing process and continued until the cooling phase. Figures 7-3 (a), (b), (c) and (d) are the thermal images taken during manufacturing process. 


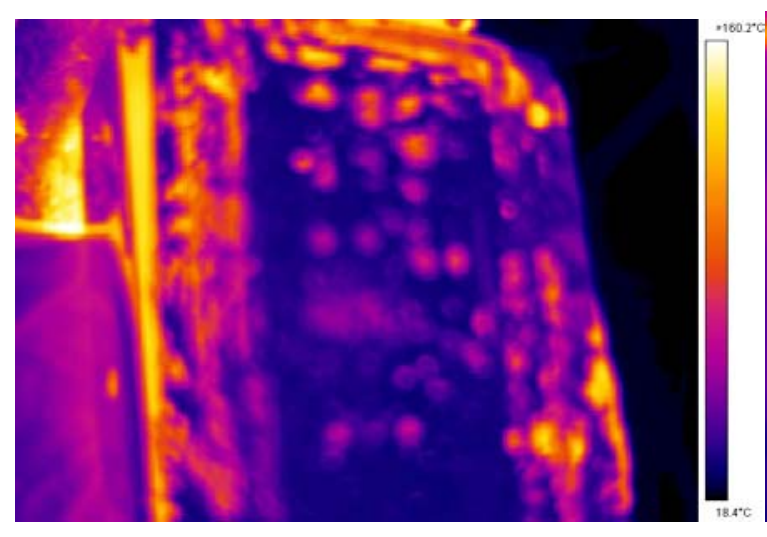

(a) End of preheating (30 $\mathrm{min})$ at $450^{\circ} \mathrm{F}$

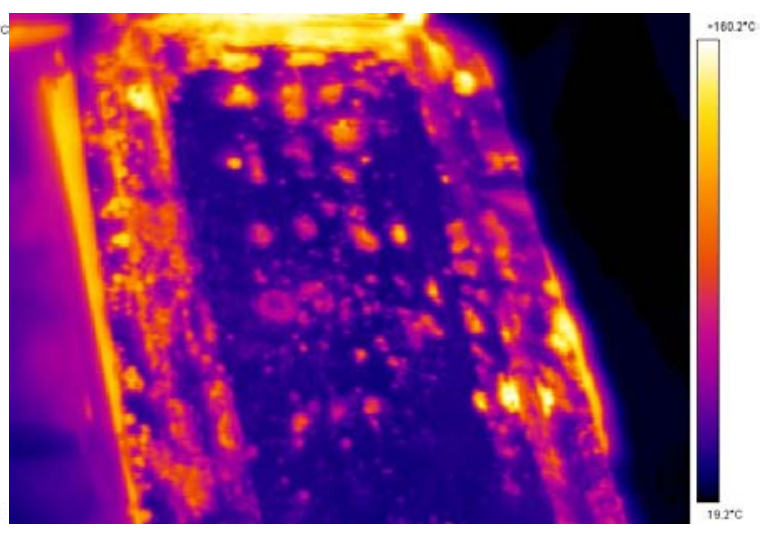

(b) End of 6 min of pressure (20 tons)

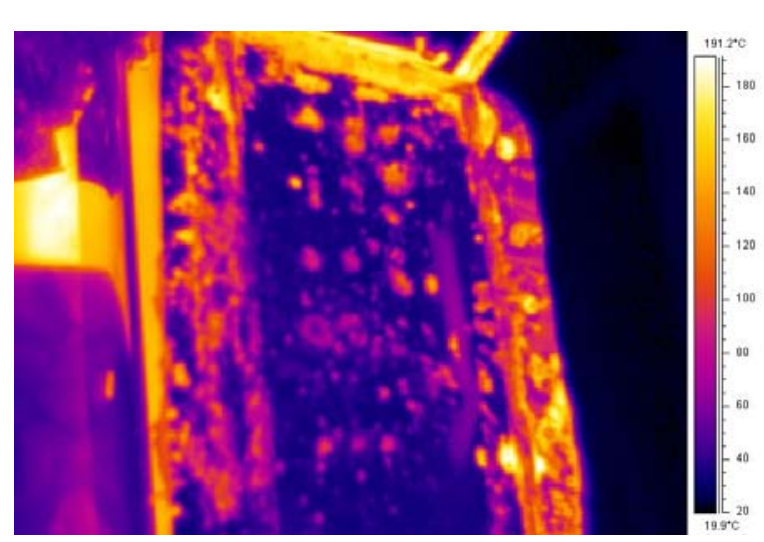

(c) End of $11 \mathrm{~min}$ of pressure (20 tons)

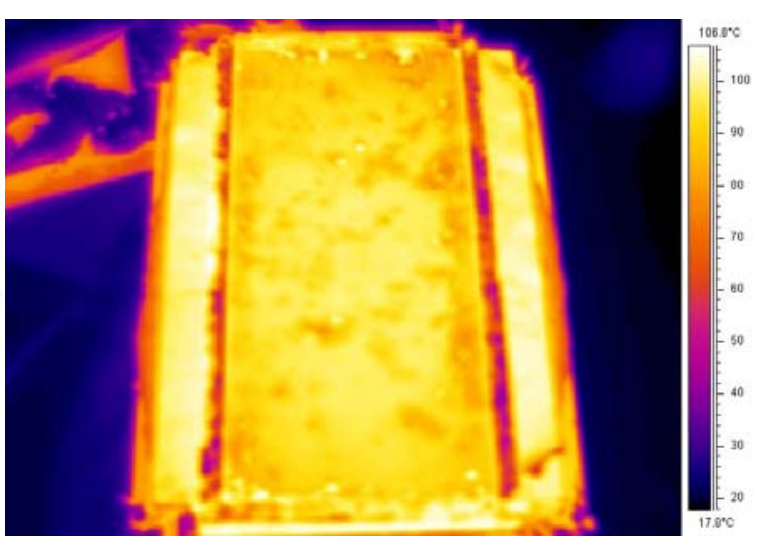

(d) Cooling phase-230 ${ }^{\circ} \mathrm{F}$ (5tons)

Figure 7-3 Thermal images of the hot mold taken at various time intervals during the manufacturing process of the block

\subsubsection{Limitations of infrared imaging}

The measurement of the surface temperature profile by infrared camera is effected by environmental parameters such as solar radiation, air temperature, wind, rain, surface stains and patches and shadows of adjacent structures and trees (Halabe et al. 1995). It is not possible to detect micro-cracks or very small defects using the infrared technique. It cannot detect the depth of the thickness of a defect. 


\subsubsection{Summary}

The attempt of studying the heat propagation in the mold during the compression manufacturing process by taking thermal images using the infrared technique was partly successful owing to its decreasing accuracy in increasing depths. Surface temperature profile (Figure. 7-3 (a), (b), (c) and (d)) was studied as varying function of time as can be observed from the infrared images.

\subsection{Characterization of thermal propagation properties}

An experiment was carried out on a sliced section of the guardrail-offset block to find its heat conduction properties. The aim of the experiment was to find the heat transfer properties of the sample by measuring the temperature variation at different distances from heat source with respect to time when exposed to higher surface temperature.

\subsubsection{Experimental set-up}

Guardrail offset block was manufactured with rubber tire core and glass reinforced recycled Acrylonitrile Butadiene Styrene (ABS) plastic shell. The block was sliced to obtain its representative element, for the heat conduction experiment. The sliced portion was placed on the heated platen surface $\left(250^{\circ} \mathrm{F}\right)$ of the press, with the rest of the platen insulated with wooden blocks, styrofoam and rubber tires to minimize heat losses. Infra red images of the sample were taken at every 5-minute interval for 60 minutes (heating phase). Then, the sample was removed from the heat source and placed on a table surface maintained at room temperature (about $70^{\circ} \mathrm{F}$ ). Again, infrared images were taken at every 5-minute interval for about 60 minutes (cooling phase). Thus, heat transfer 
within the test sample was studied by observing the change in temperature at different distances from heat source with respect to time in the heating and cooling phases.

A finite element model was created with similar conditions and analyzed for prevailing temperature variations. The results from finite element analysis and infrared thermography are further discussed in Chapter 8 .

\subsection{Summary}

Infrared imaging technique was used to study the guardrail-offset block surface temperature profile during manufacturing. Presence of non-conducting constituents in the block like rubber was evident from the low temperature zones observed in the thermal images. By using a better monitoring process, heat transfer/propagation at various points within the mold during manufacturing phase can be studied (analyzed) and methods to improve the manufacturing process could be suggested. Finite element analysis was conducted on a sliced section of the block and analyzed for the temperature profile at different distances from heat source with respect to time. Those results were compared with results from the experiment conducted as described earlier. These are discussed in detail in Chapter 8. 


\section{CHAPTER 8}

\section{FINITE ELEMENT ANALYSIS}

\subsection{Introduction}

Finite element model of a sliced section of the guardrail-offset block was created and analyzed for its behavior under the application of surface thermal loads with respect to time. ABAQUS was used to analyze the offset block and FEMAP was used as pre/post processor. Material properties for the constituents of the block- resin (ABS) with glass fabric and rubber were used as inputs for creating the finite element model. The analysis aimed at studying the temperature profile at different distances from heat source in a sliced section of a guardrail-offset block with respect to time.

\subsection{Creating the geometry}

Initially, work plane dimensions were fixed to a required size and a rectangle with two inner rectangles was created. A solid shell and core of different materials were created using these rectangles. A composite solid $(6 " \times 6 " \times 2$ ") with two different materials (recycled ABS shell and rubber as shown in Figure 8-1) was created and the material properties were defined as explained in the following section. Presence of any air voids and pockets were not considered in this model. A perfect bond was assumed between the polymer and rubber layers and respective boundary nodes were merged.

\subsection{Define materials and properties}

Different layers were created in the work plane to separate the entities (core and shell) of the model created in earlier steps. Solid model thus created was sliced into simple sections and distributed within different layers. Material properties, loads and constraints were then assigned to these entities in separate layers. 
Material properties of recycled ABS known from previous research (Bargo, 2000) and GE plastics website (www.Geplastics.com) were assigned to the solid shell in the model. Properties of rubber were assigned to the solid core in the model. Thermal conductivities of ABS and rubber are 2.8895e-6 and 2.27238e-6 Btu/lbs-sec-in ${ }^{2}-\mathrm{F} / \mathrm{in}$.

Table 8-1 Thermal properties of fiber reinforced polymers

\begin{tabular}{|c|c|c|c|c|c|}
\hline \multicolumn{1}{|c|}{ Material } & $\begin{array}{c}\text { Specific heat } \\
\mathrm{C} \\
\left(\mathrm{J} \mathrm{kg}^{-1} \mathrm{C}^{-1}\right)\end{array}$ & $\begin{array}{c}\rho \\
\left(\mathrm{kg} \mathrm{m}^{-3}\right)\end{array}$ & $\begin{array}{c}\rho \mathrm{C} \\
\left(\mathrm{J} \mathrm{m}^{-3} \mathrm{C}^{-1}\right)\end{array}$ & $\begin{array}{c}\text { Thermal } \\
\left(\mathrm{W} \mathrm{m}^{-1} \mathrm{C}^{-1}\right)\end{array}$ & $\begin{array}{c}\text { Thermal } \\
\text { diffusivity } \\
\delta \\
\left(\mathrm{m}^{2} \mathrm{~s}^{-1}\right)\end{array}$ \\
\hline $\mathrm{CFRP}^{\mathrm{b}}\left(\_\right.$fibers $)$ & 1200 & 1600 & $1.9 \times 10^{6}$ & 0.8 & $0.42 \times 10^{-6}$ \\
\hline $\mathrm{CFRP}^{\mathrm{b}}(\|$ fibers $)$ & 1200 & 1600 & $1.9 \times 10^{6}$ & 7 & $3.7 \times 10^{-6}$ \\
\hline $\mathrm{GFRP}^{\mathrm{c}}\left(\_\right.$fibers $)$ & 1200 & 1900 & $2.3 \times 10^{6}$ & 0.3 & $0.13 \times 10^{-6}$ \\
\hline $\mathrm{GFRP}^{\mathrm{c}}(\|$ fibers $)$ & 1200 & 1900 & $2.3 \times 10^{6}$ & 0.38 & $0.17 \times 10^{-6}$ \\
\hline
\end{tabular}

Defined as $\delta=\mathrm{K} / \rho \mathrm{C}$, where $\mathrm{K}$ is the thermal conductivity, $\rho$ is mass density is the specific heat, and $\rho \mathrm{C}$ is the heat capacity.

${ }^{\mathrm{b}}$ Carbon fiber reinforced polymer.

${ }^{\mathrm{c}}$ Glass fiber reinforced polymer

After creating material and properties, meshing was done to generate nodes and elements. Loads and constraints were applied on the nodes of the solid elements created.

\subsection{Meshing}

Tetrahedral or hexagonal meshing can be done using FEMAP software. Hexagonal meshing was used so that nodes at the interface between the outer shell and inner core could be merged. Edges of these solids were divided into equal segments to obtain predetermined number of elements and nodes. Then, nodes at common edges were merged, allowing transfer of load from outer to inner solid.

The hollow ABS plastic shell prevents direct hexagonal meshing and hence it was sliced. The outer core was sliced into 4 parts. Each solid section was placed in a separate 
layer and sliced down to simple shapes. Curves forming the solid were divided into segments of particular length such that each division represented 0.25 ". Then, the solid was meshed using specified mesh size, followed by addition of the solids. Curves on opposite surfaces as well as on outer and inner solids were subdivided such that they had matching element divisions and consistent mesh sizing. After meshing, all the parts were added to retain the original geometry of the outer shell.

Hexagonal meshing generates elements of "C3D8" type which were later changed in the ABAQUS input file as "C3D8T" type elements to allow imposing of thermal load (intended load pattern). All solid segments were then merged by checking for coincident nodes and the meshing process was completed.

\subsection{Applying loads}

Surface thermal load was applied to the guardrail offset block model in the form of temperature, which was later converted into nodal and elemental temperatures upon translation or expansion. Surface temperature load of $250^{\circ} \mathrm{F}$ was applied to the model for 60 minutes and analyzed in steps of 5-minute increments. The analysis was continued by changing surface load to room temperature $\left(70^{\circ} \mathrm{F}\right)$ and analyzing the terms of response at every 5-minute increment for 60 minutes.

\subsection{Applying constraints}

In the experiment, test sample cut from the offset block was placed on the platen

of the press heated to $250^{\circ} \mathrm{F}$. Only thermal load in the form of surface temperature and no mechanical load was imposed on the sample. To implement support conditions similar to field installed offset block in finite element analysis, 6 " $\times 2$ " face of the block (bottom surface of the model) of the test sample modeled was fixed to avoid displacements, and 
surface temperature was applied on it. Fixed condition implies zero displacements and rotations when applied to a node, element and curve of a surface or solid.

\subsection{Exporting the analysis model}

Boundaries of the finite element model created were constrained and temperature (thermal load) was applied in FEMAP, and then exported to ABAQUS for solving. An input file was automatically created with the extension "inp" and necessary changes were made to modify the "C3D8" type elements to "C3D8T" type, thus completing the export process.

\subsection{Solving the model and viewing the results}

The input file generated after exporting the model created in FEMAP to ABAQUS through challenge server was opened in word file and necessary changes were made. Model was solved in ABAQUS using standard commands and output file with extension "fil" was imported and opened in the FEMAP active window. The "fil" file was imported back to FEMAP and opened to observe the temperature parameters as results of the analysis.

\subsection{Results}

Results from the finite element analysis were obtained in the form of temperature profiles in the test sample as seen from several snap shots in Figure 8-2. Temperature contours with respect to time at various distances from the heat source were obtained.

Temperature rise and fall during the heating and cooling phases within the test sample with respect to time at $0.25 ", 0.5 "$, and $1 "$ distances from heat source were plotted as graphs to observe heat conduction behavior of the block. 


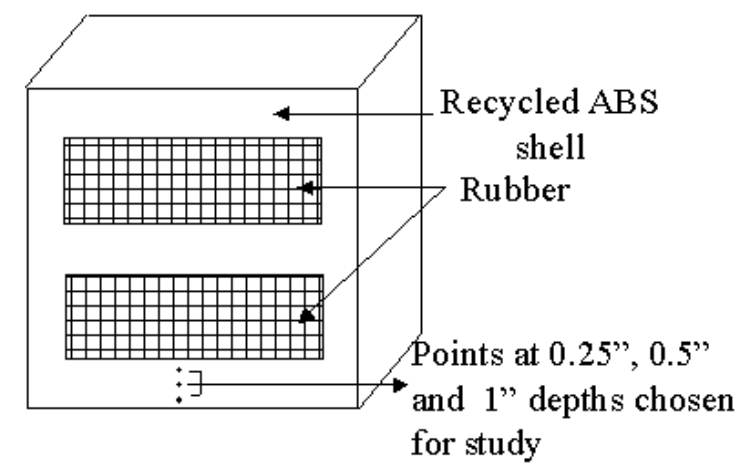

Figure 8-1 Test sample modeled using FEMAP for thermal analysis
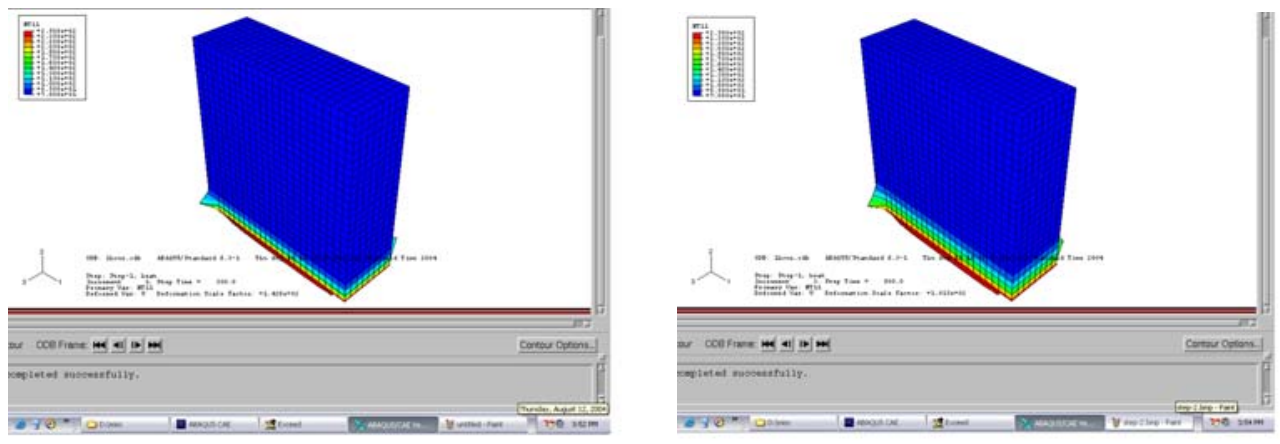

(a) End of 5 minutes (heating at $250^{\circ} \mathrm{F}$ )

(b) End of 10 minutes (heating at $250^{\circ} \mathrm{F}$ )
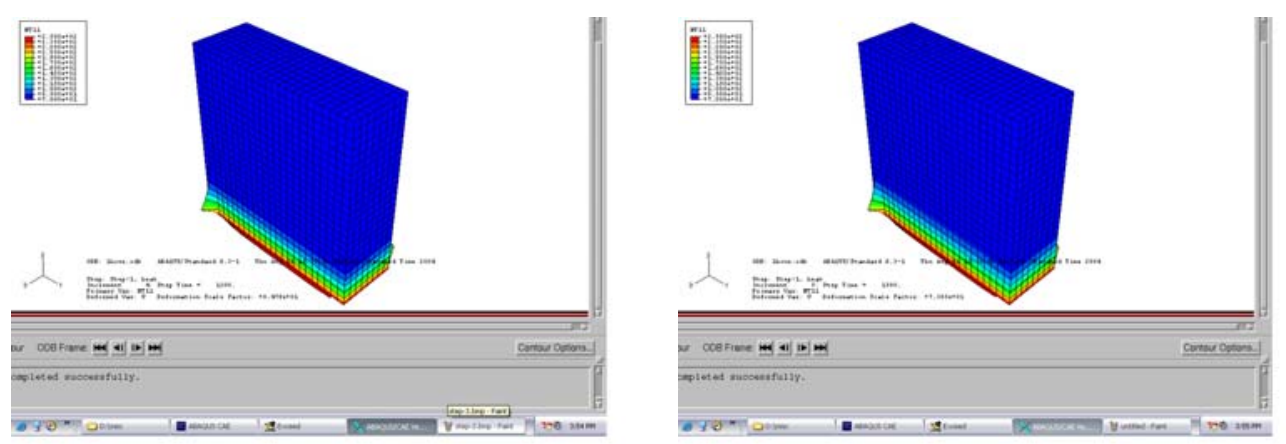

(c) End of 15 minutes (heating at $250^{\circ} \mathrm{F}$ )

(d) End of 20 minutes (heating at $250^{\circ} \mathrm{F}$ ) 

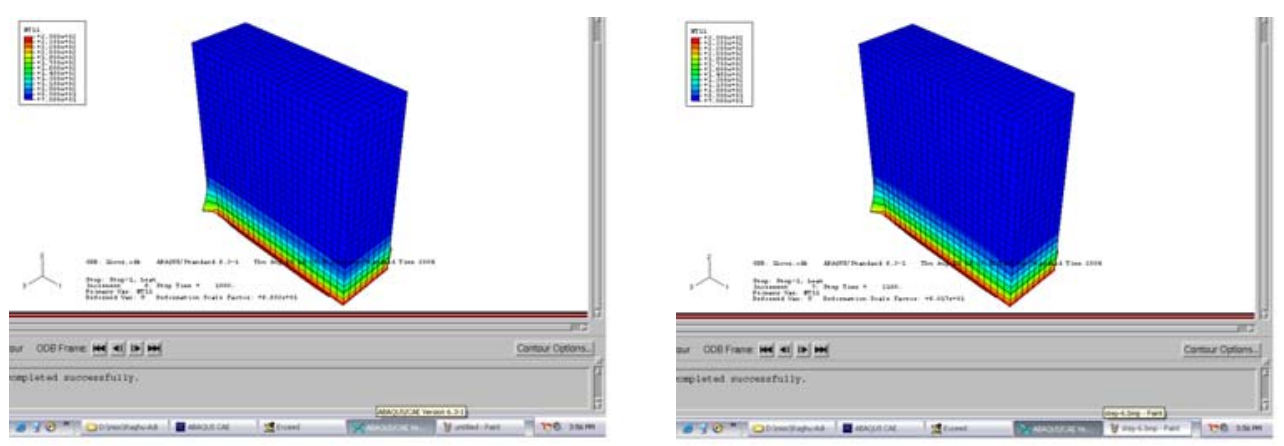

(e) End of 25 minutes (heating at $250^{\circ} \mathrm{F}$ ) (f) End of 30 minutes (heating at $250^{\circ} \mathrm{F}$ )
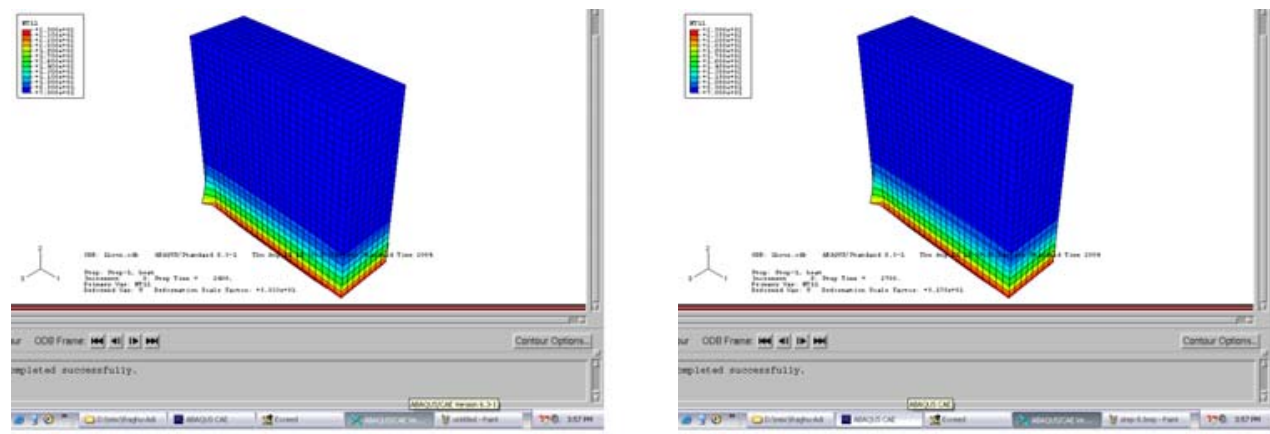

(g) End of 35 minutes (heating at $250^{\circ} \mathrm{F}$ )

(h) End of 40 minutes (heating at $250^{\circ} \mathrm{F}$ )
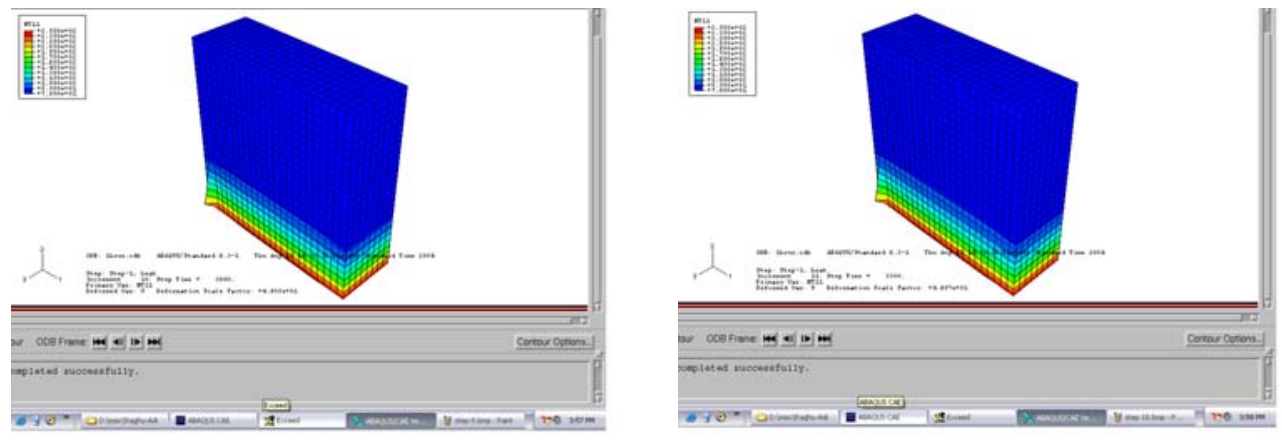

(i) End of 45 minutes (heating at $250^{\circ} \mathrm{F}$ )

(j) End of 50 minutes (heating at $250^{\circ} \mathrm{F}$ ) 

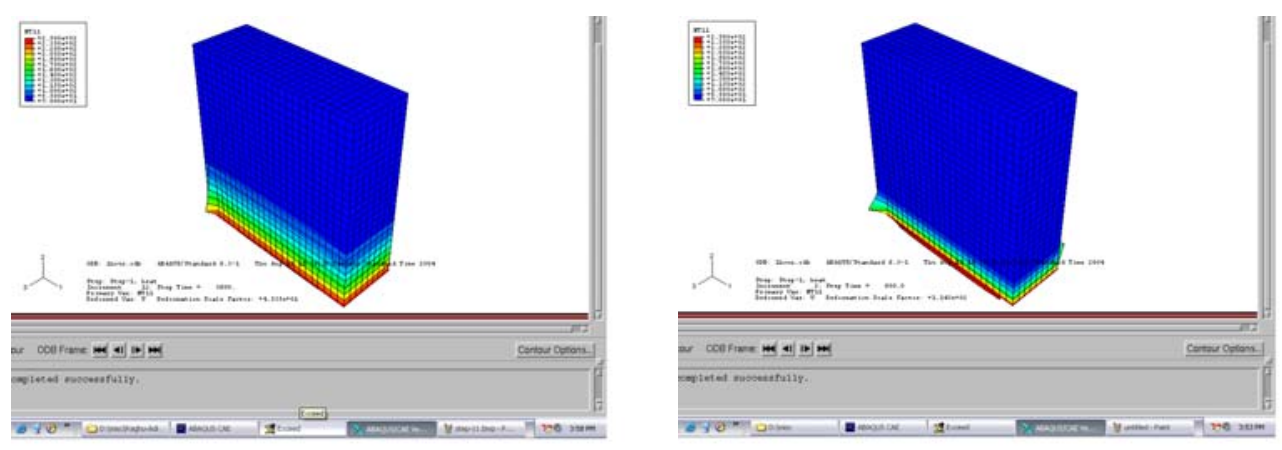

(k) End of 55 minutes (heating at $250^{\circ} \mathrm{F}$ ) (l) End of 60 minutes (heating at $250^{\circ} \mathrm{F}$ )

Figure 8-2 Finite Element images of the offset-block sliced section during heating phase
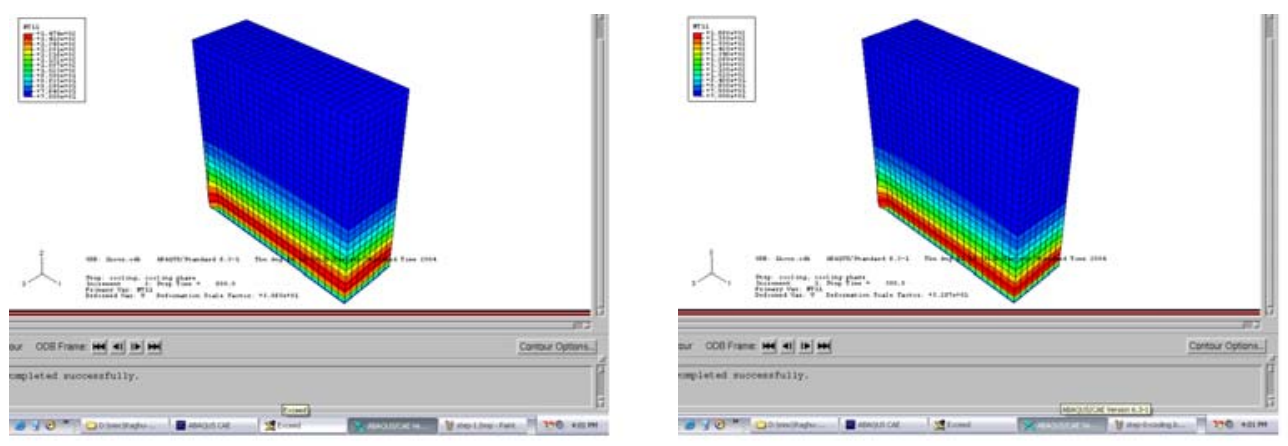

(a) End of 5 minutes (cooling at $70^{\circ} \mathrm{F}$ )

(b) End of 10 minutes (cooling at $70^{\circ} \mathrm{F}$ )
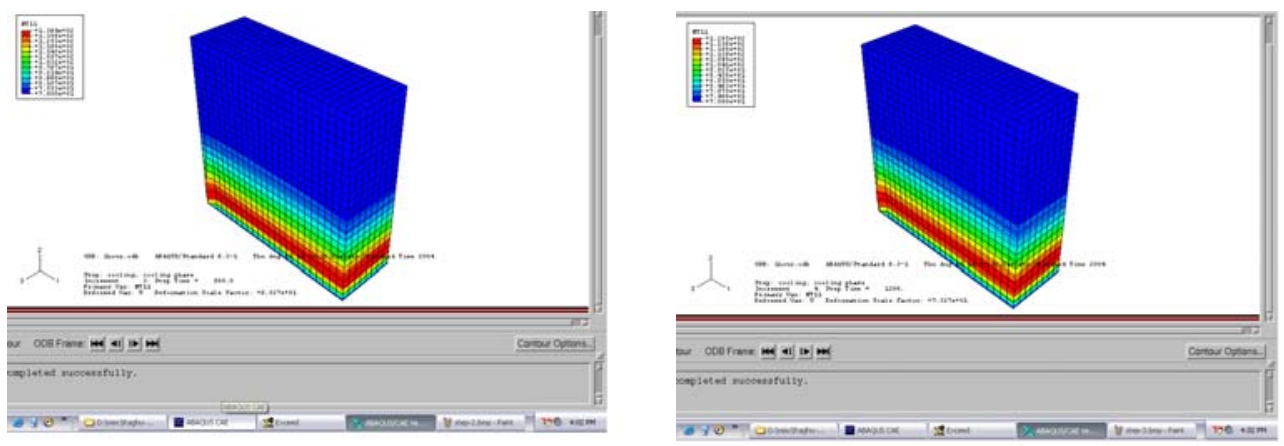

(c) End of 15 minutes (cooling at $70^{\circ} \mathrm{F}$ )

(d) End of 20 minutes (cooling at $70^{\circ} \mathrm{F}$ ) 


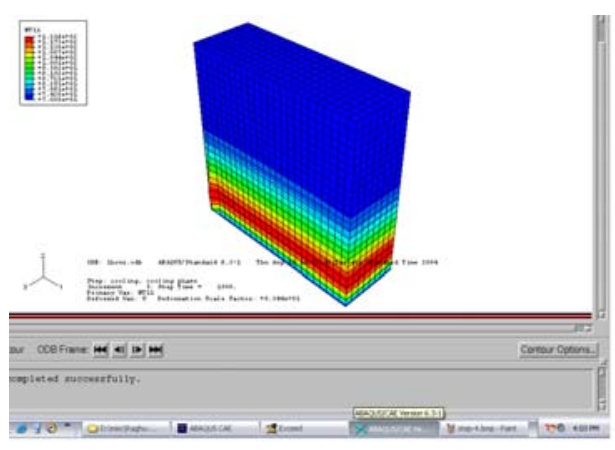

(e) End of 25 minutes (cooling at $70^{\circ} \mathrm{F}$ )

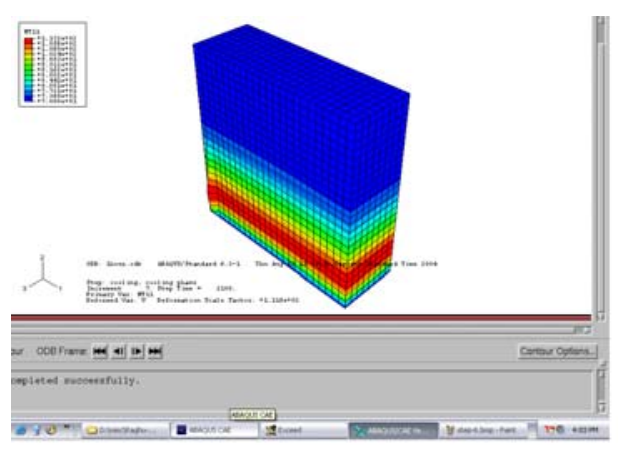

(g) End of 35 minutes (cooling at $70^{\circ} \mathrm{F}$ )

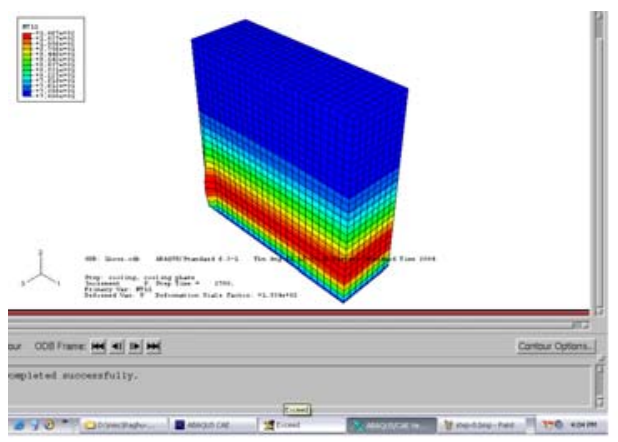

(i) End of 45 minutes (cooling at $70^{\circ} \mathrm{F}$ )

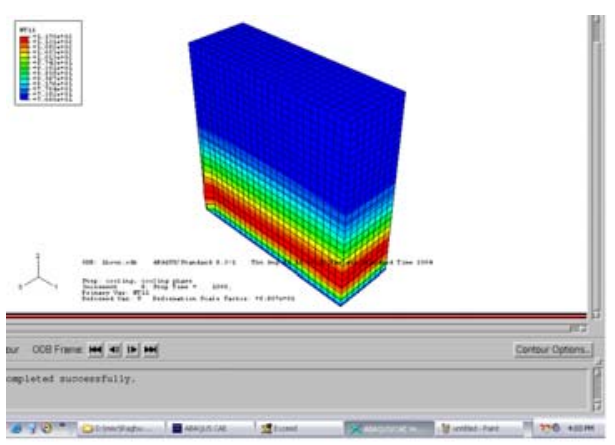

(f) End of 30 minutes (cooling at $70^{\circ} \mathrm{F}$ )

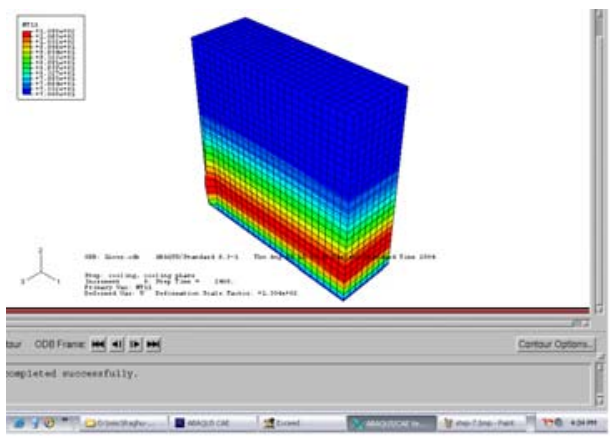

(h) End of 40 minutes (cooling at $70^{\circ} \mathrm{F}$ )

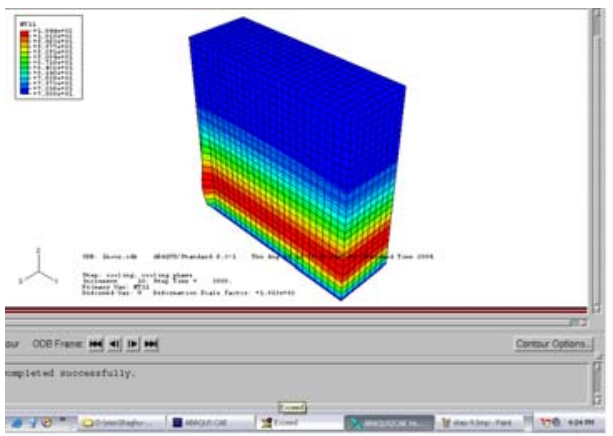

(j) End of 50 minutes (cooling at $70^{\circ} \mathrm{F}$ ) 

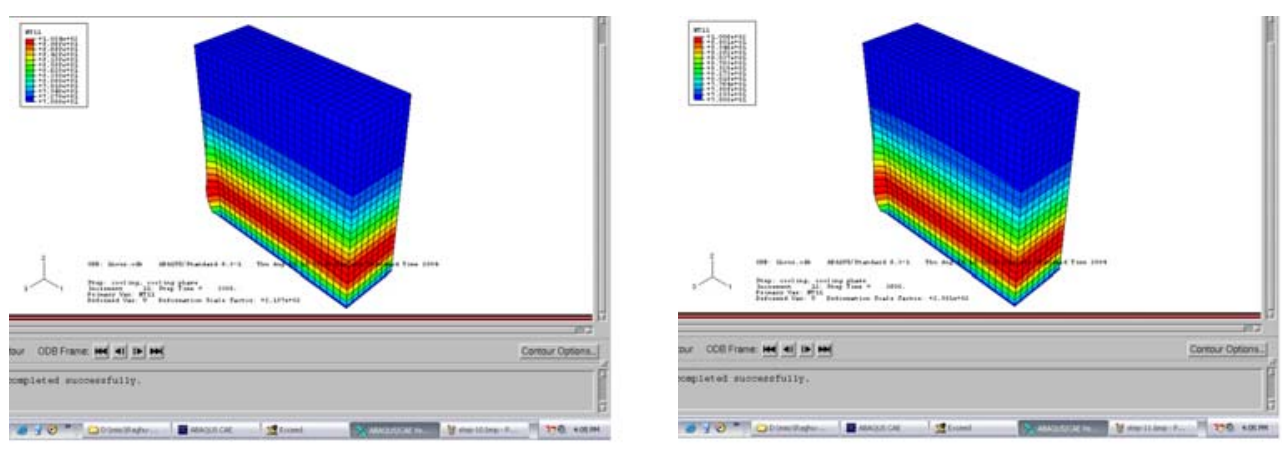

(k) End of 55 minutes (cooling at $70^{\circ} \mathrm{F}$ )

(l) End of 60 minutes (cooling at $70^{\circ} \mathrm{F}$ )

Figure 8-3 Finite element images of the offset-block sliced section during cooling phase

Figures 8-4 and 8-5 show changes in temperature at $0.25 ", 0.5 ”, 1 "$, and $2.5 "$ distance away from the heated surface of the offset block specimen with respect to time.

Time vs. Temp - Heating

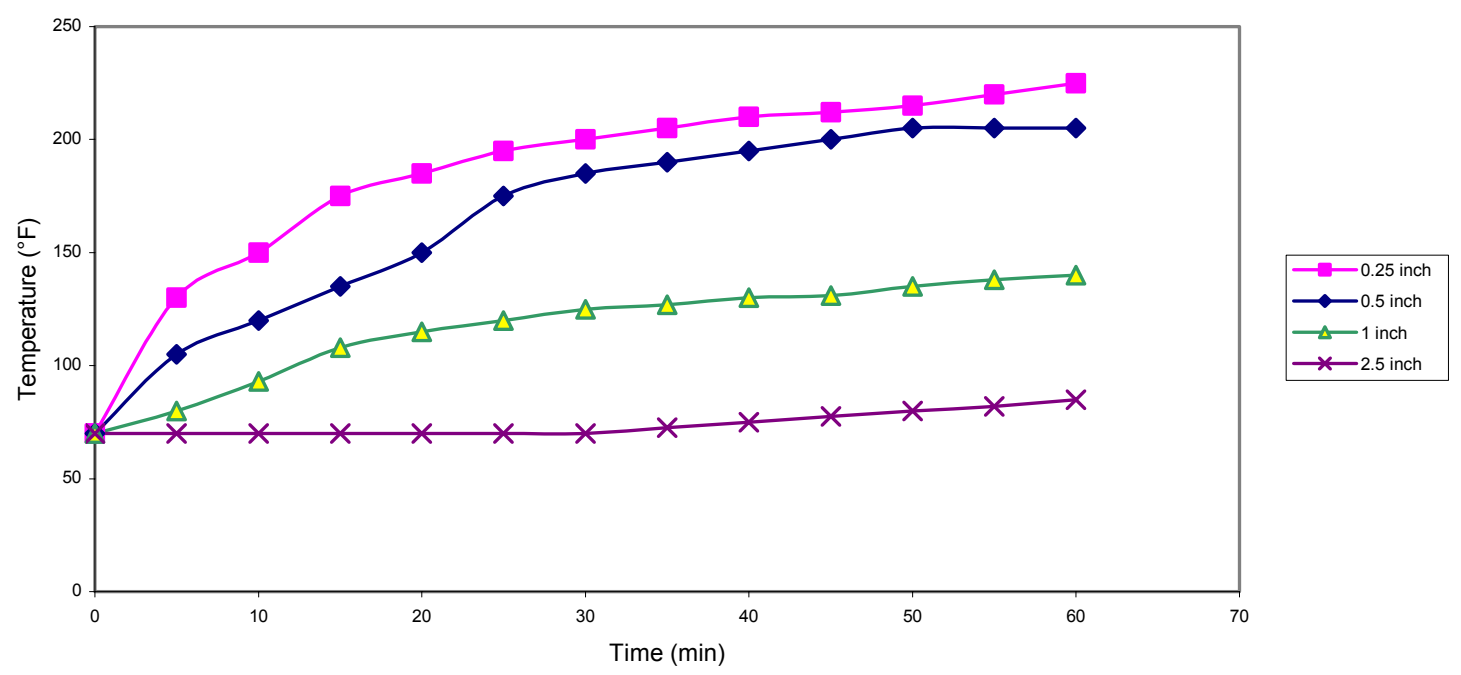

Figure 8-4 Temperature curves at different distances from heat source in the test sample vs. time (heating phase) 
Time vs. Temp (cooling)

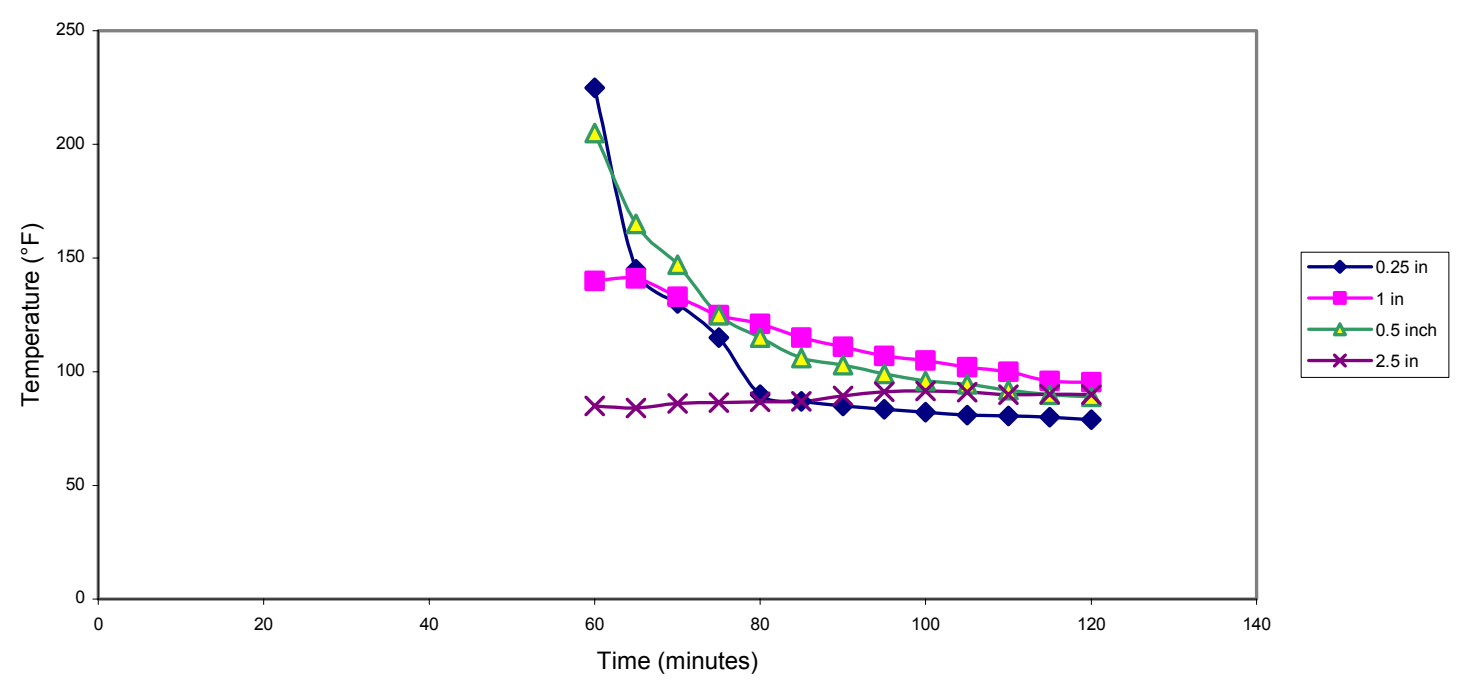

\section{Figure 8-5 Temperature curves at different distances from heat source in the test sample vs. time (cooling phase)}

The analysis was initially done with ABS thermoplastic resin and rubber core and the plots were obtained as shown in Figures 8-4 and 8-5. Then, as an approximation the thermal conductivity value of the outer shell was increased from that of pure ABS $(k=$ $2.27238 \times 10^{-6}$ Btu-in/(s-in $\left.\left.{ }^{2}{ }^{\circ} \mathrm{F}\right)\right)$ to glass fiber reinforced polymer $(\mathrm{GFRP})\left(\mathrm{k}^{\prime}=\right.$

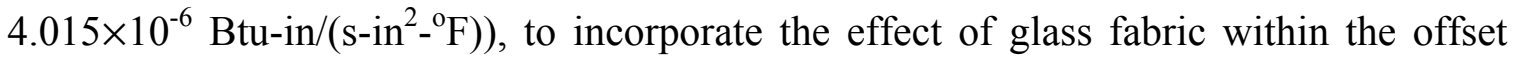
block. Temperatures vs. time plots of the updated analysis are shown in Figures 8-6 and $8-7$. 
Time vs Temperature-Heating (New k' values)

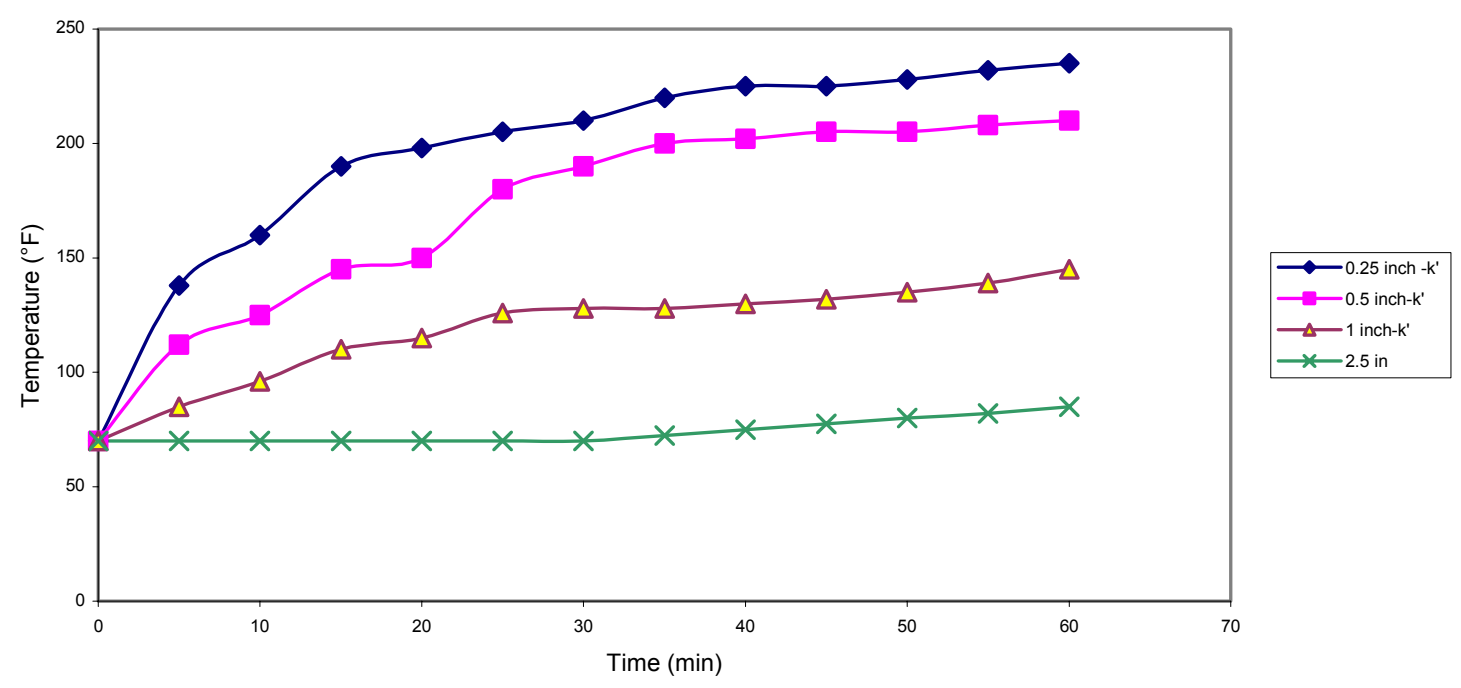

Figure 8-6 Temperature curves at different distances from heat source in the test sample with changed thermal conductivity ( $\left.k^{\prime}\right)$ value vs. time (heating phase)

Time vs Temperature-cooling (New k' value)

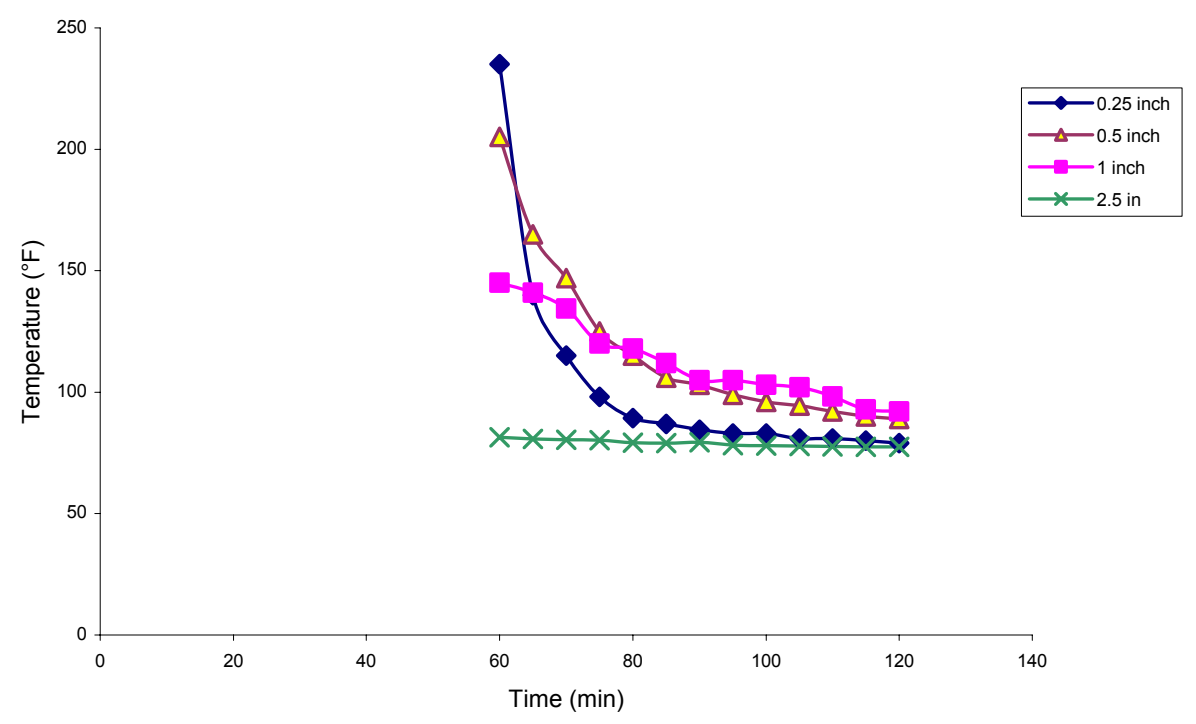

Figure 8-7 Temperature curves at different distances from heat source in the test sample with changed thermal conductivity ( $\left.k^{\prime}\right)$ value vs. time (cooling phase) 
Figures 8-8, and 8-9 were plotted by superimposing results from Figures 8-4, 8-5, 8-6 and 8-7 to represent the difference in temperature propagation due to change in thermal conductivity value $(\mathrm{k})$.

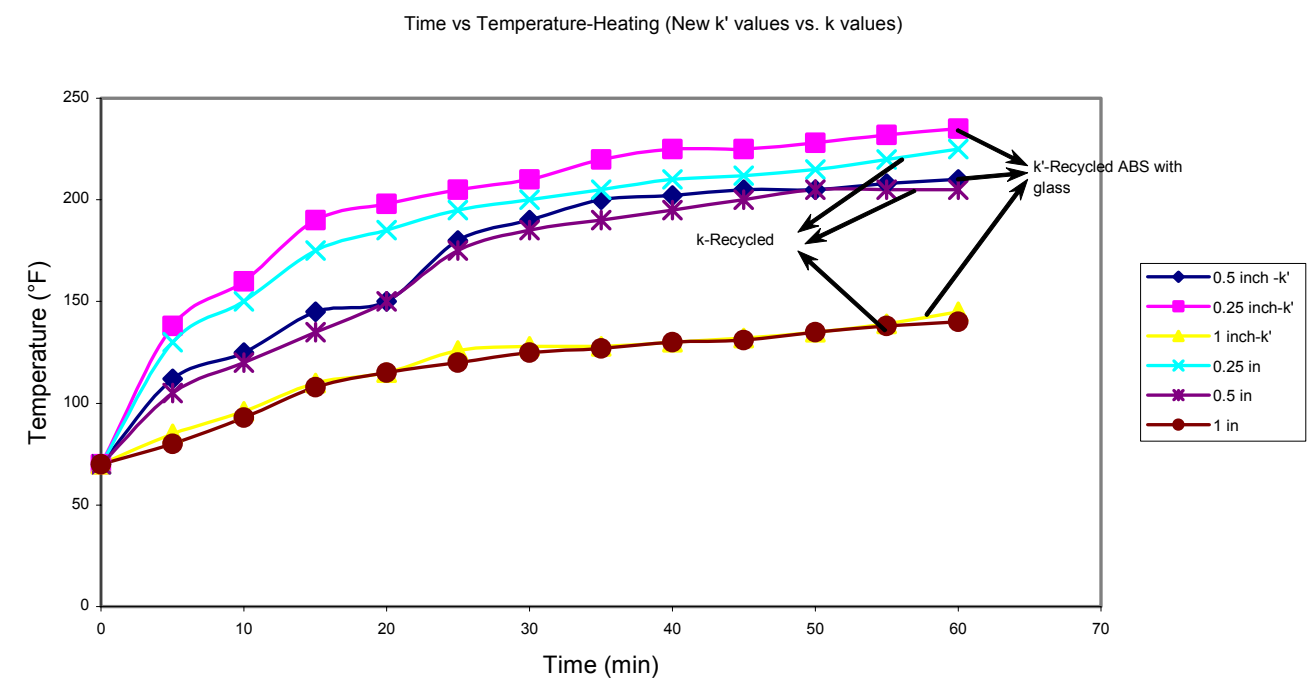

Figure 8-8 Variation in temperature progression due to change in thermal conductivity (k) values in heating phase

Time vs Temperature-cooling ( $\mathrm{k}^{\prime}$ value vs. $\mathrm{k}$ value)

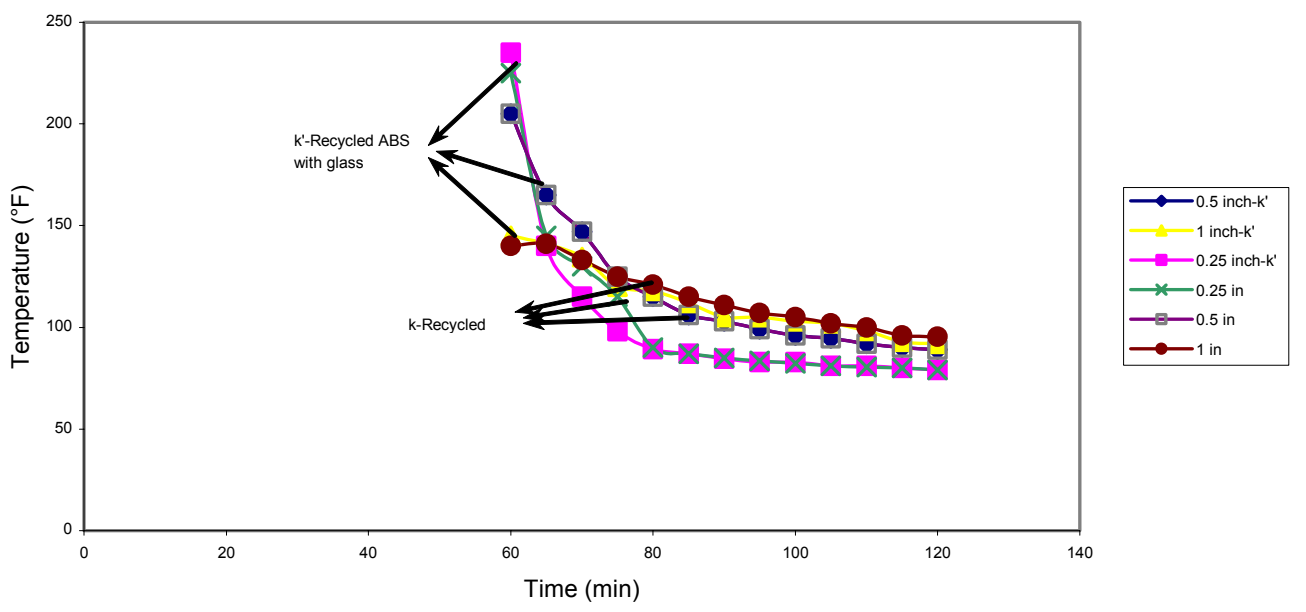

Figure 8-9 Variation in temperature progression due to change in thermal conductivity $(k)$ values in cooling phase 


\subsection{Summary}

Following summary is provided based on the finite element analysis results:

- Heat propagation within the composite with respect to time was studied using this analysis.

- At the end of 60 minutes of unidirectional $250^{\circ} \mathrm{F}$ heat application, the temperatures at $0.25 ", 0.5^{\prime}$ and $1 "$ distances from heat source were $225^{\circ} \mathrm{F}, 205^{\circ} \mathrm{F}$ and $140^{\circ} \mathrm{F}$ respectively.

- The low final temperatures are due to the poor thermal conductivity values of the polymer and rubber constituents of the block as well as the type of heat source provided (unidirectional).

- The temperatures at $0.25 ", 0.5 "$ and $1 "$ after the cooling phase due to applied $70^{\circ}$ $\mathrm{F}$ heat were $79^{\circ} \mathrm{F}, 89^{\circ} \mathrm{F}$ and $95^{\circ} \mathrm{F}$, respectively.

- Difference in temperature values at a given distance from heat source and at a given time due to changes in thermal conductivity between recycled ABS with glass fabric and plain recycled ABS were:

$\circ$ About $8^{\circ} \mathrm{F}$ more in heating phase, and about $2^{\circ} \mathrm{F}$ more during cooling phase at 0.25 in for ABS with glass fabric.

$\circ$ About $5^{\circ} \mathrm{F}$ more in heating phase, and about $1^{\circ} \mathrm{F}$ more during cooling phase at 0.5 in for ABS with glass fabric.

$\circ$ About $2^{\circ} \mathrm{F}$ more in heating phase, and about $1.5^{\circ} \mathrm{F}$ more during cooling phase at $1 "$ for ABS with glass fabric. 
- The heat transmission rates in this case are not linear. Thus, this model could be extended from a transient isotropic analysis to complex non-linear thermodynamic analysis.

\subsection{Limitations of FE analysis}

- The finite element model does not take into account the melt-flow and viscosity properties of the polymer, thus is not the exact representation of the original problem.

- Thermal properties of the polymer are temperature dependent and thus, a special software package may be used to arrive at a better solution.

Study of heat flow properties of the constituents of polymer products would provide information that can be used in its manufacturing process. The time and temperature process parameters can be decided based upon their melt flow characteristics. Some of the expensive software packages that include such features and even predict the movement of the resin in the mold during the manufacturing phase are C-MOLD, MOLD-FLOW, and CADPRESS-THERMOPLASTIC etc.

\subsection{Experimental study of the heat propagation within a sliced portion of the manufactured guardrail offset block}

- A sliced portion of the offset block was taken as test sample for the experiment.

- One face of the block was exposed to constant temperature source (platen of the press heated to $250^{\circ} \mathrm{F}$ ), with rest of the heated platen insulated using rubber tires/wooden blocks/styrofoam. (Figure. 8-10)

- Temperature readings on the surface of the block were studied using infrared thermography at constant time intervals. 
- The infrared images obtained enabled study of temperature (heat transfer) at various points on the surface of the block.

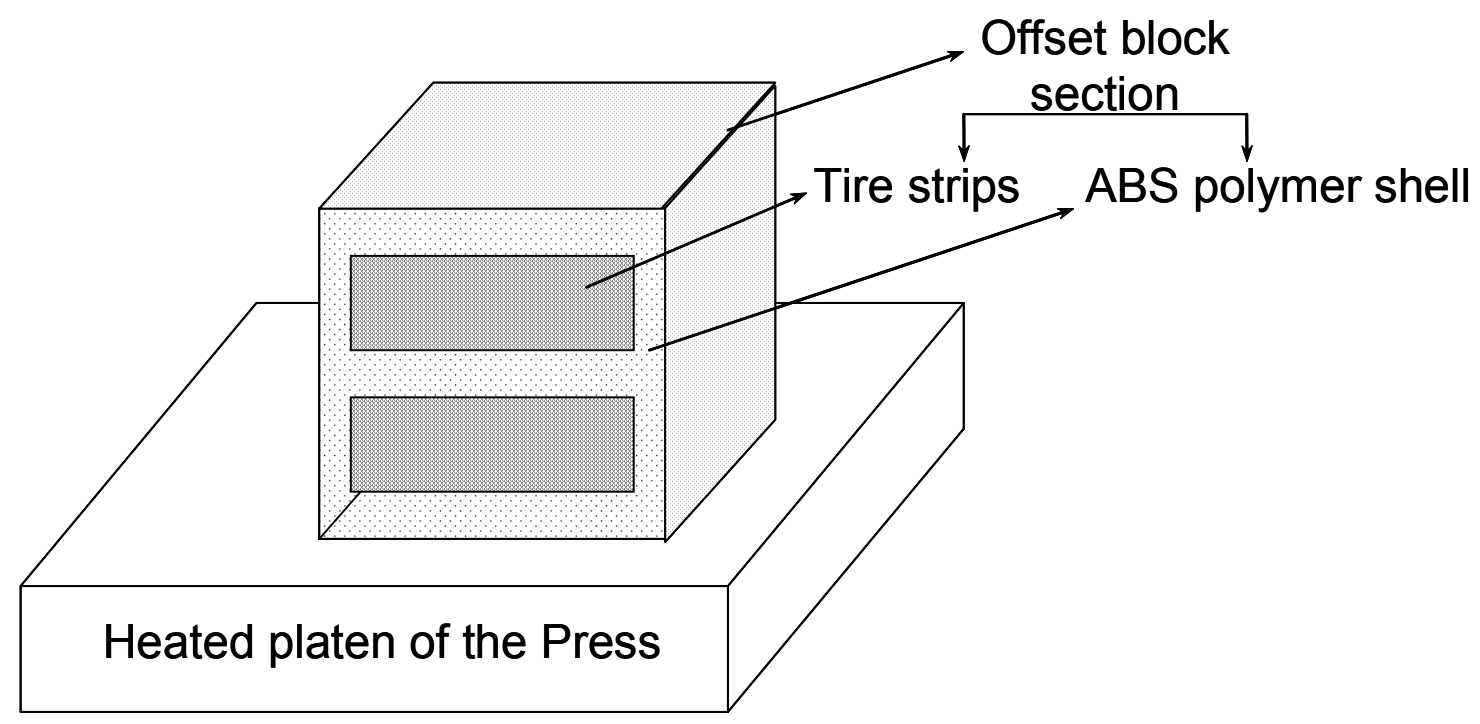

Figure 8-10 Sliced offset block on heated platen

The results from this experiment are represented in Figures 8-11 and 8-13 as follows:

Temperature vs. Time $\left(250^{\circ} \mathrm{F}\right)$-experimental results

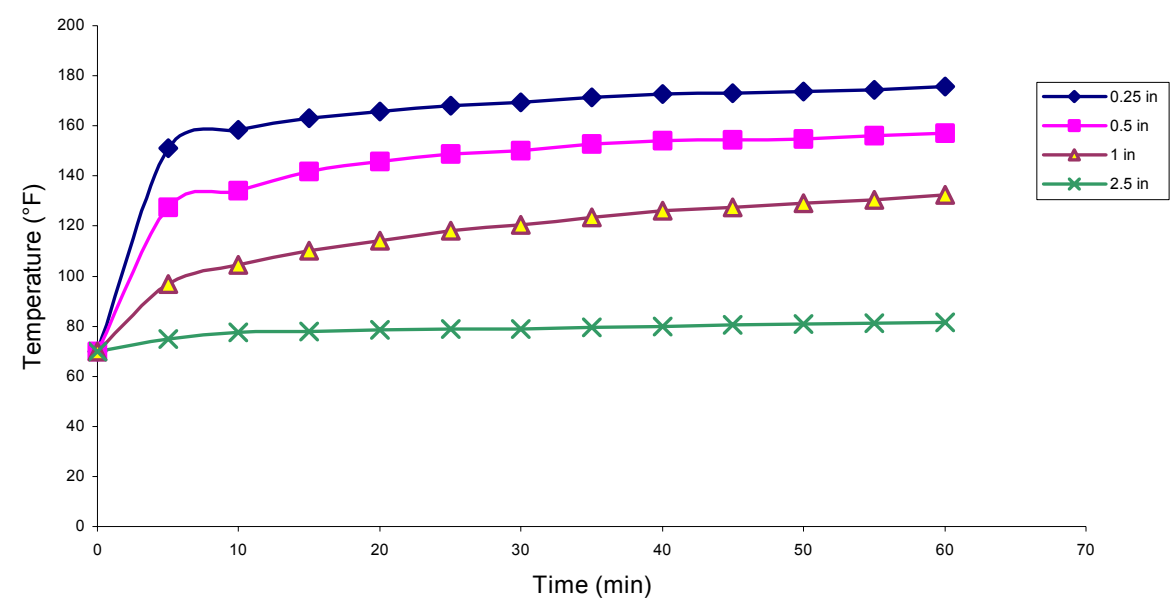

Figure 8-11 Time vs. Temperature curves from Infrared images for points at different distances from heat source during heating phase $\left(250^{\circ} \mathrm{F}\right)$ 


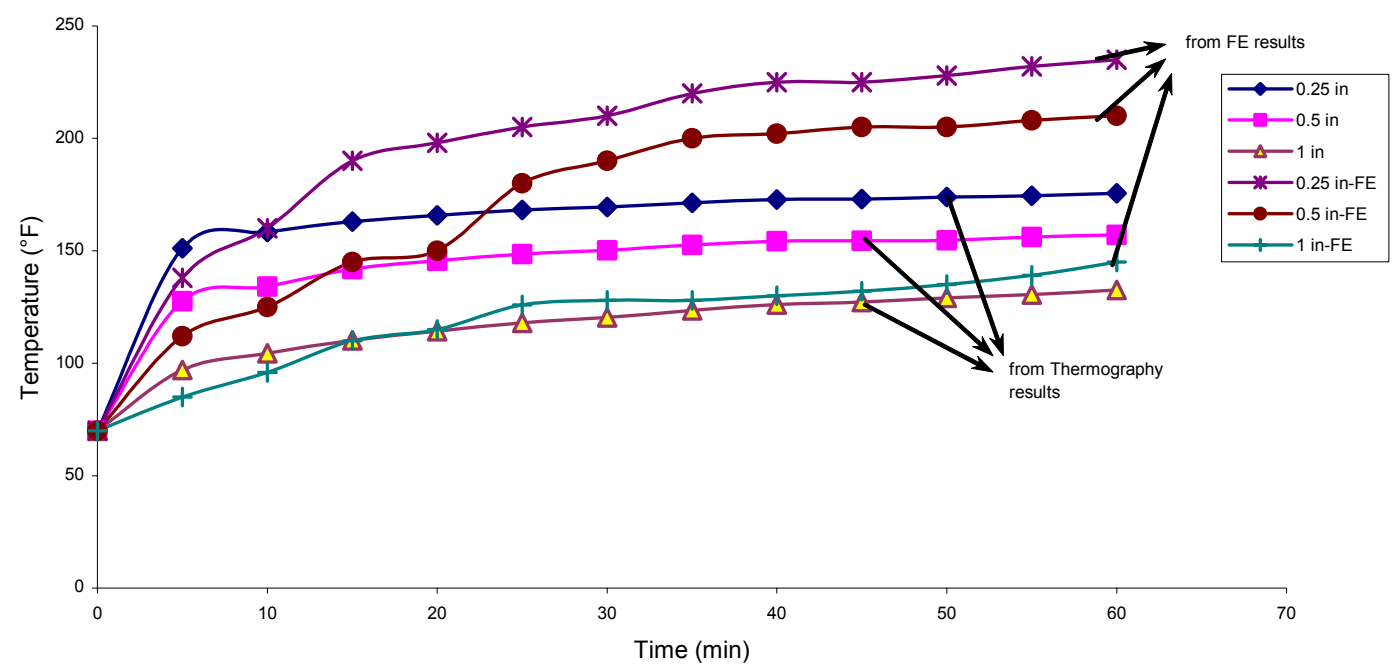

Figure 8-12 Time vs. Temperature curves from both Infrared images and FE analysis for points at different distances from heat source during heating phase $\left(250^{\circ} \mathrm{F}\right)$

Temperature vs. Time $\left(70^{\circ} \mathrm{F}\right)$-experimental results

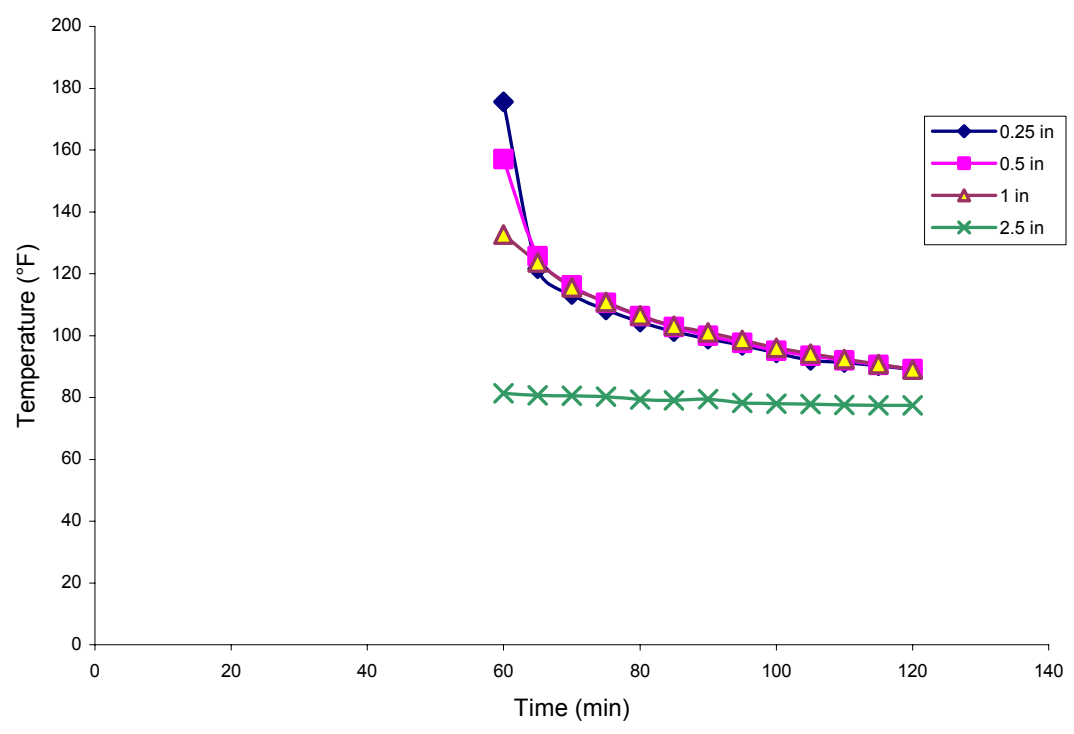

Figure 8-13 Time vs. Temperature curves for points at different distances from heat source from Infrared images during cooling phase $\left(70^{\circ} \mathrm{F}\right)$ 
Temperature vs. Time $\left(70^{\circ} \mathrm{F}\right)$-experimental results

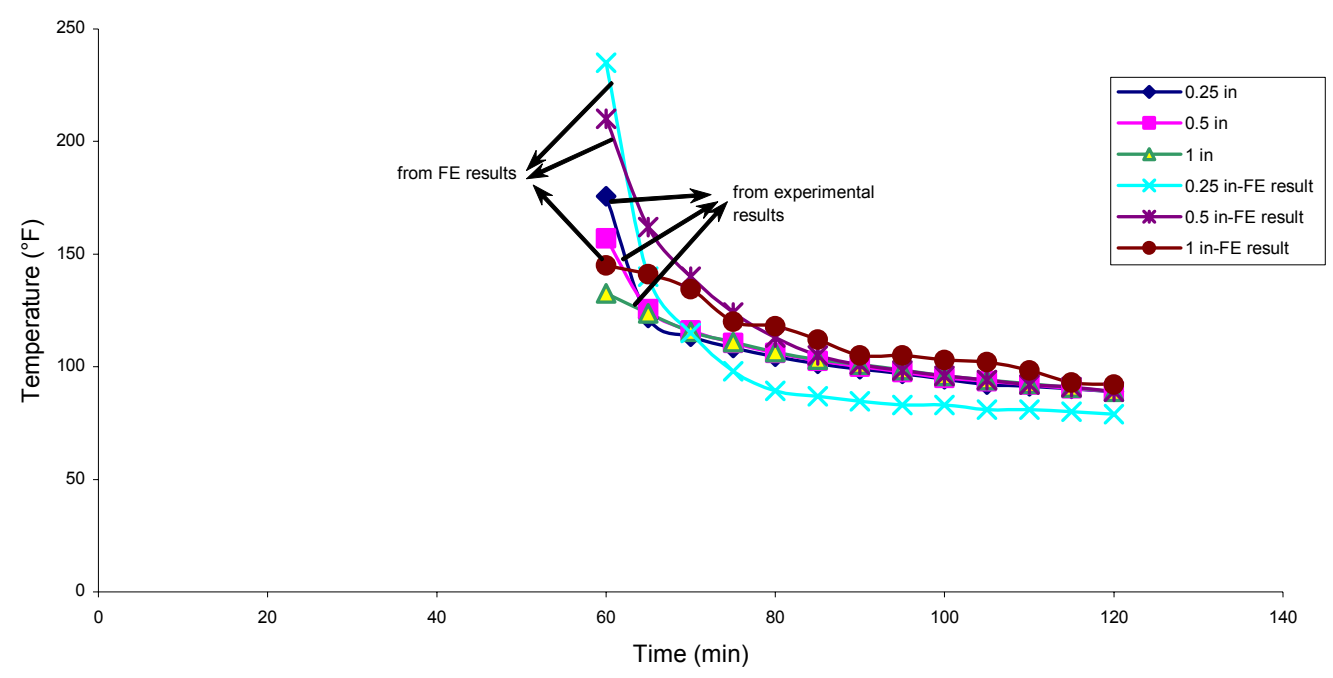

Figure 8-14 Time vs. Temperature curves for points at different distances from heat source from both Infrared images and $\mathrm{FE}$ analysis during cooling phase $\left(\mathbf{7 0}^{\circ} \mathrm{F}\right)$

\subsection{Summary}

- Thermal images were automatically recorded at every 5-minute interval from the beginning of the experiment.

- Software used for viewing the thermal images enabled determination of temperatures at different distances from heat source, i.e., bottom of the test sample. Temperature data collected at $0.25 \%, 0.5 "$ and $1 "$ for different time intervals during heating and cooling phases were plotted and analyzed.

- Slope of the curves decreased as the distance from heat source increased indicating non-linear heat transfer. Low heat transmission rates can be accounted due to low thermal conductivity of plastic, rubber tires and imperfections such as holes, gaps and voids in the specimen. 
- The temperature values obtained from the experiment vary from those obtained from the finite element results due to the presence of air voids, gaps and heat losses in the specimen that were not considered.

- The final temperatures (after heating and cooling stages) at distances $0.25 ", 0.5$ ", and 1 " from heat sources were $89^{\circ} \mathrm{F}, 89.2^{\circ} \mathrm{F}$, and $89^{\circ} \mathrm{F}$ respectively.

\subsection{Observing temperature effect on test sample by analyzing FE model at $0^{\circ} \mathrm{F}$, -} $20^{\circ} \mathrm{F}$ and $-40^{\circ} \mathrm{F}$

Further study was conducted on the temperature progression within the test sample (sliced from offset block) by analyzing the finite element model at low temperatures. Analysis was carried out for $0^{\circ} \mathrm{F},-20^{\circ} \mathrm{F}$ and $-40^{\circ} \mathrm{F}$ temperature application and temperature variation at $0.25 ", 0.5$ " and 1 " distances from heat source (from bottom of the sample) was plotted as a function of time. Figure 8-15 shows variation in temperature progression with respect to time at $0.25 ", 0.5$ " and 1 " distances from heat source (from bottom of the sample).

\section{Analysis at $0^{\circ} \mathrm{F}$}

Results from our analysis of the model with a surface thermal load of $0^{\circ} \mathrm{F}$ is referred to as phase 1 (Figure 8-15). Continuation of the analysis with the sample maintained at $70^{\circ} \mathrm{F}$ is referred to as phase 2 and its results are shown in Figure 8-16. 
Temperature vs. Time $\left(0^{\circ} \mathrm{F}\right)$ - Phase 1

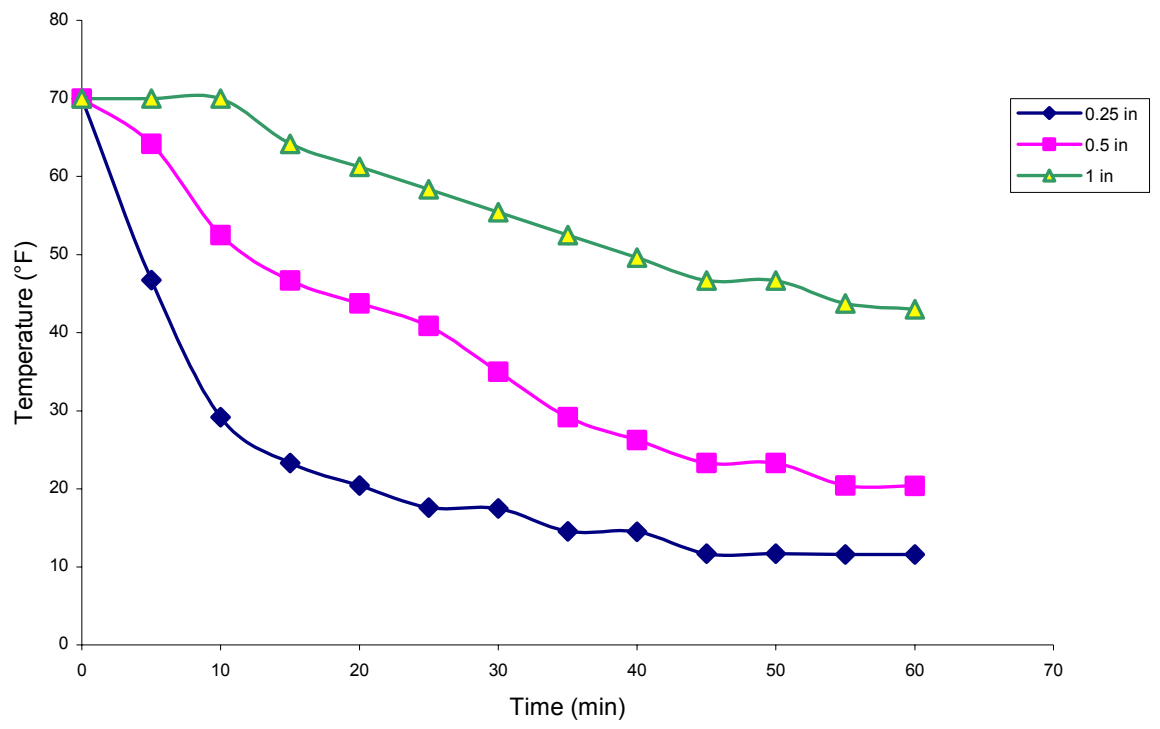

Figure 8-15 Temperature vs. Time $\left(0^{\circ} \mathrm{F}\right)$ at different distances from heat source

Temperature vs. Time - Phase 2

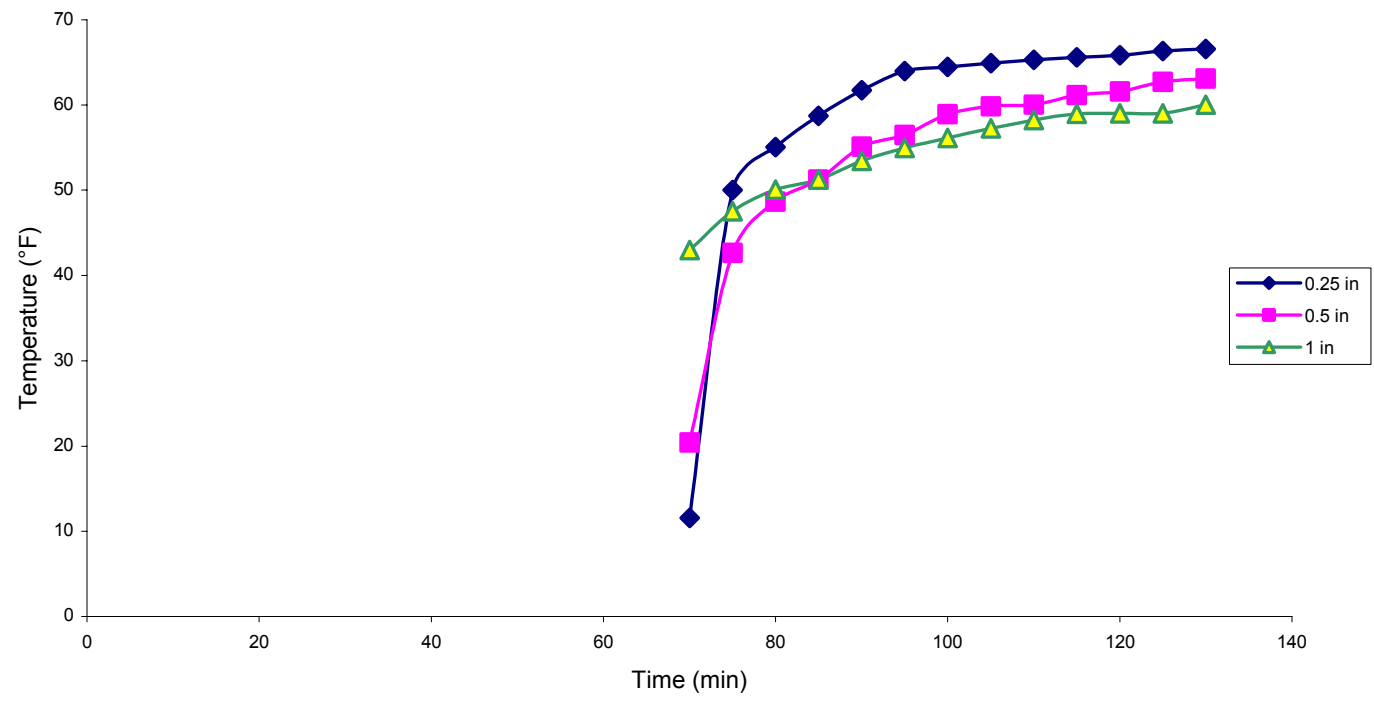

Figure 8-16 Temperature vs. Time $\left(70^{\circ} \mathrm{F}\right)$ at different distances from heat source 


\section{Analysis at $-20^{\circ} \mathrm{F}$}

Results of the analysis run with thermal load of $-20^{\circ} \mathrm{F}$ in phase 1 (60 minute duration) are presented in Figure 8-17 and its continuation with sample maintained at $70^{\circ}$ $\mathrm{F}$ in phase 2 (60 minute duration) is represented in Figure 8-18.

\section{Analysis at $-40^{\circ} \mathrm{F}$}

Results of the analysis run with thermal load of $-40^{\circ} \mathrm{F}$ in phase 1 (60 minute duration) are presented in Figure 8-19 and its continuation with sample maintained at $70^{\circ}$ $\mathrm{F}$ in phase 2 (60 minute duration) is represented in Figure 8-20.

Temperature vs. Time $\left(-20^{\circ} \mathrm{F}\right)$ - Phase 1

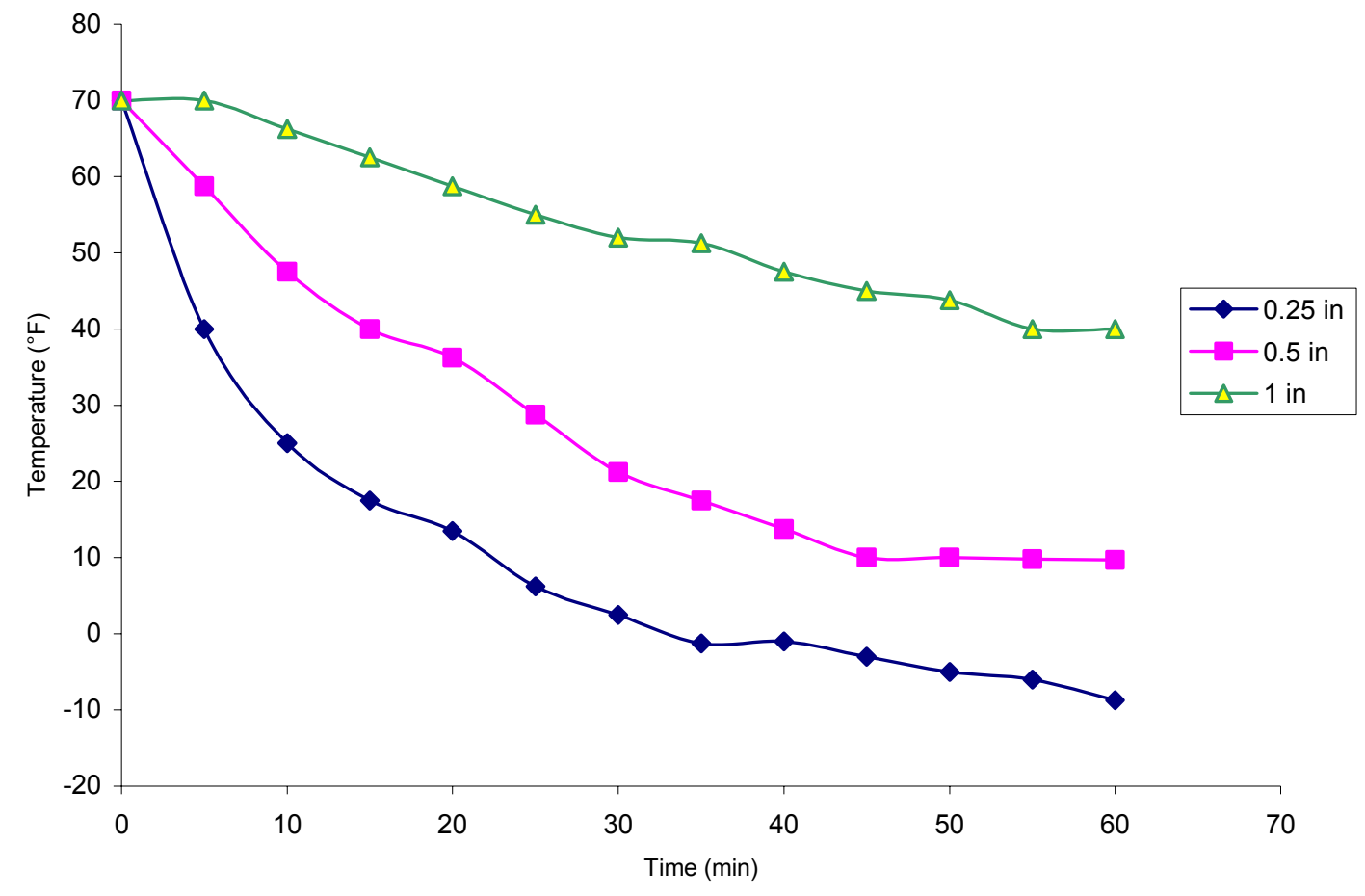

Figure 8-17 Temperature vs. Time $\left(-20^{\circ} \mathrm{F}\right)$ at different distance from heat source 
Temperature vs. Time $\left(-20^{\circ} \mathrm{F}\right)$ - Phase 2

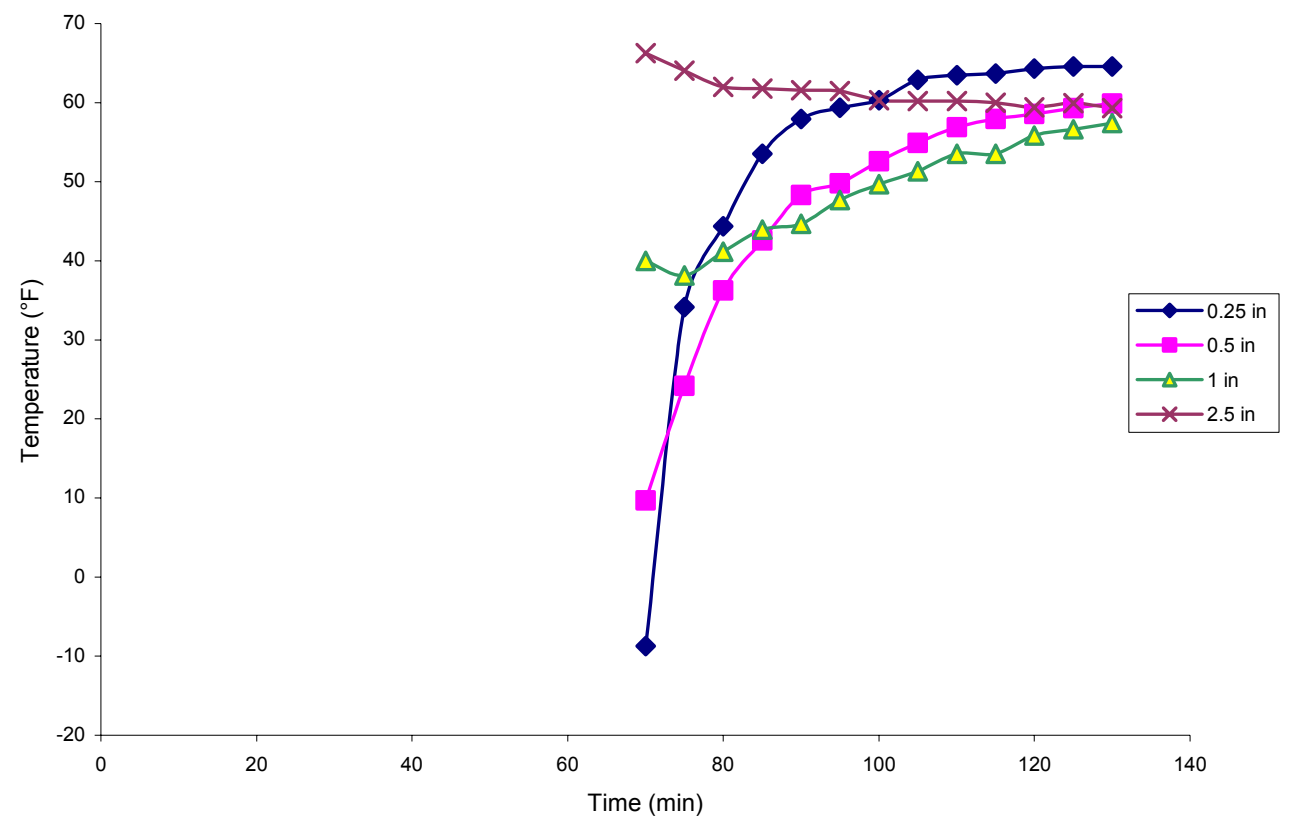

Figure 8-18 Temperature vs. Time $\left(70^{\circ} \mathrm{F}\right)$ at different distances from heat source

Temperature vs. Time (-40 deg F) - Phase 1

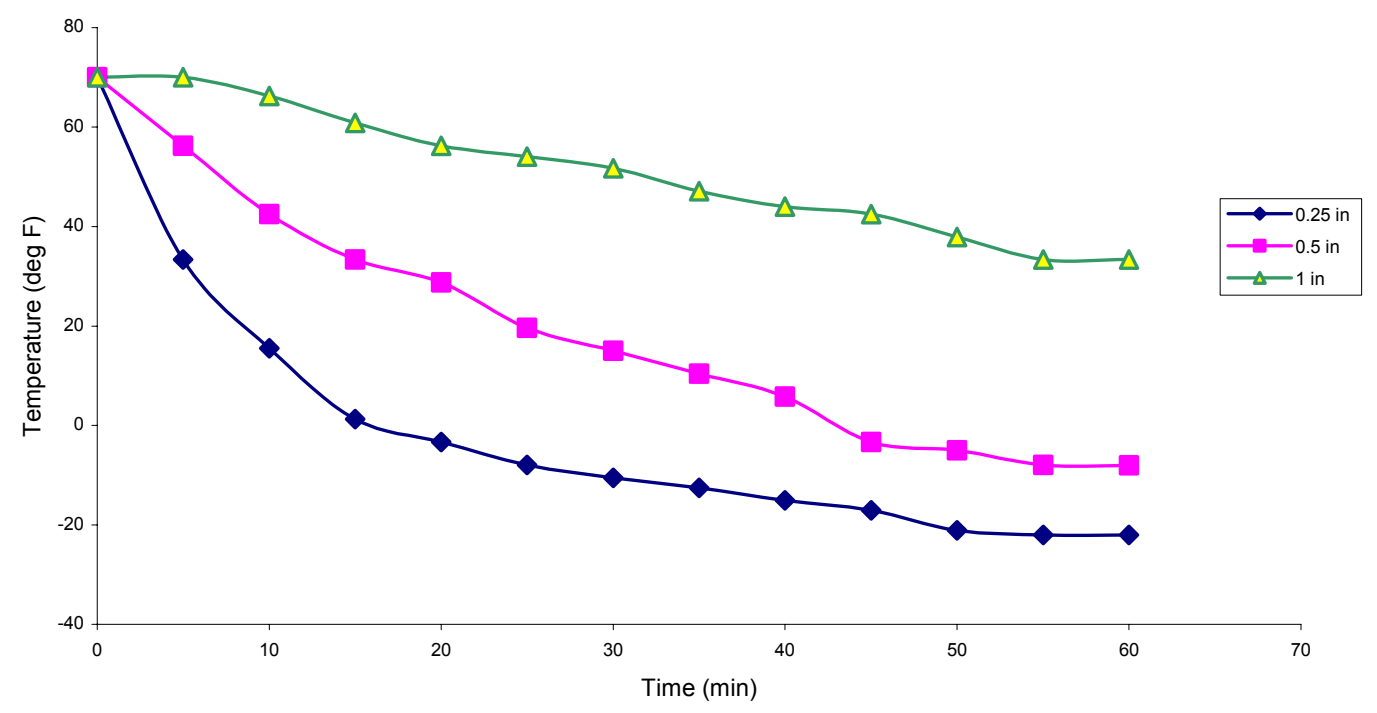

Figure 8-19 Temperature vs. Time $\left(-40^{\circ} \mathrm{F}\right)$ at different distance from heat source 


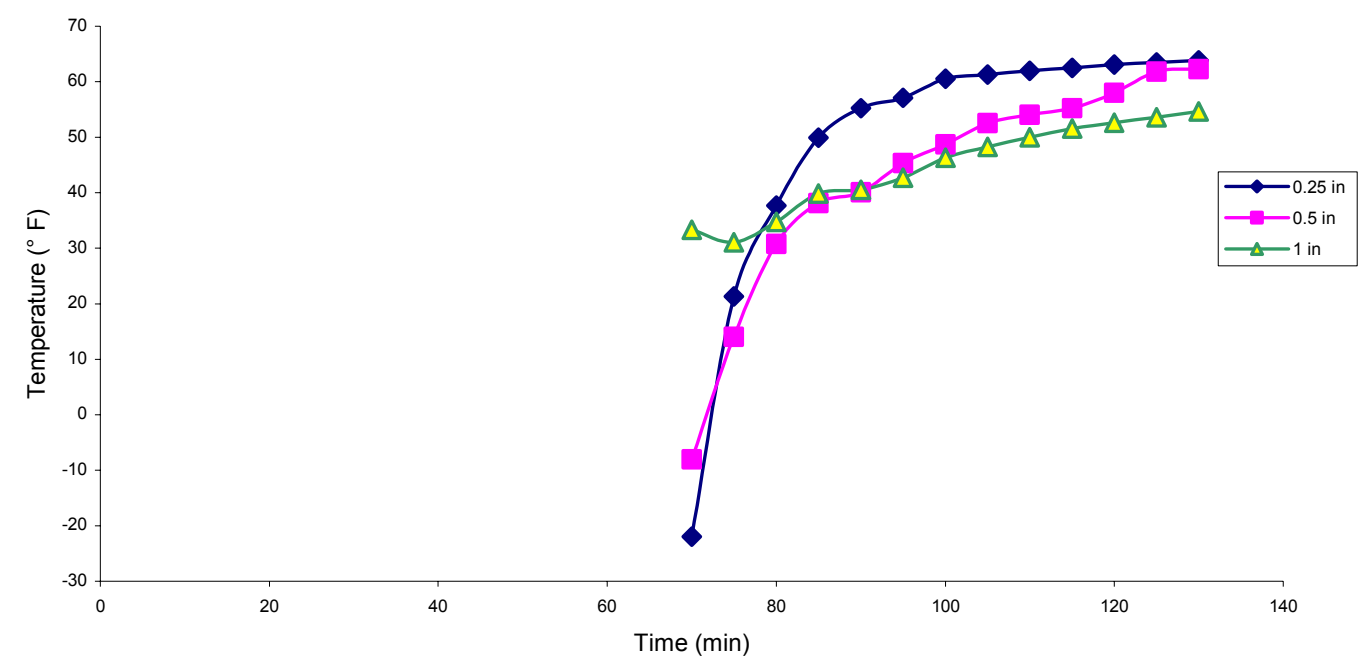

Figure 8-20 Temperature vs. Time $\left(70^{\circ} \mathrm{F}\right)$ at different distances from heat source

\subsection{Summary}

Tables 8-1 to 8-3 represent time taken to attain different fractions of final temperature attained by the offset block for 60 minutes. Table $8-1$ shows time taken to attain $60 \%, 75 \%, 85 \%$ and $90 \%$ of final temperature at $0.25 \%$ distance from the heat source. Phase 1 refers to exposing one surface of the sample to $0^{\circ} \mathrm{F} /-20^{\circ} \mathrm{F} /-40^{\circ} \mathrm{F}$ for a duration of 60 minutes followed by phase 2 , where the same surface was exposed to $70^{\circ}$ F for 60 minutes. Similarly, Tables $8-2$ and 8-3 show the time taken to attain various fractions of final temperature at 0.5 " and 1 " distance from the heat source. 
Table 8-2 Time taken to attain fraction of final temperature at 0.25 " distance from heat source

\begin{tabular}{|c|c|c|c|c|}
\hline \multicolumn{5}{|c|}{ Distance $=0.25 "$} \\
\hline \multicolumn{5}{|c|}{ Applied temp. $=0^{\circ} \mathrm{F}$ in phase 1 and $70^{\circ} \mathrm{F}$ in phase 2} \\
\hline & Phase $1\left({ }^{\circ} \mathrm{F}\right)$ & Time (min) & Phase $2\left({ }^{\circ} \mathrm{F}\right)$ & Time (min) \\
\hline \multirow{2}{*}{$\begin{array}{l}\text { Final temperature } \\
\text { attained }\end{array}$} & 11.6 & 60 & 66.56 & 60 \\
\hline & & & & \\
\hline $60 \%$ final & 34.96 & 7 & 39.936 & 2 \\
\hline $75 \%$ final & 26.2 & 12.5 & 49.92 & 5 \\
\hline $85 \%$ final & 20.36 & 20 & 56.576 & 11 \\
\hline $90 \%$ final & 17.44 & 30 & 59.904 & 18 \\
\hline \multicolumn{5}{|c|}{ Applied temp. $=-20^{\circ} \mathrm{F}$ in phase 1 and $70^{\circ} \mathrm{F}$ in phase 2} \\
\hline & Phase $1\left({ }^{\circ} \mathrm{F}\right)$ & Time (min) & Phase $2\left({ }^{\circ} \mathrm{F}\right)$ & Time (min) \\
\hline \multirow{2}{*}{$\begin{array}{l}\text { Final temperature } \\
\text { attained }\end{array}$} & -8.75 & 60 & 64.59 & 60 \\
\hline & & & & \\
\hline $60 \%$ final & 22.75 & 7 & 38.754 & 8 \\
\hline $75 \%$ final & 10.9375 & 22 & 48.4425 & 12 \\
\hline $85 \%$ final & 3.0625 & 27 & 54.9015 & 16.5 \\
\hline $90 \%$ final & -0.875 & 33 & 58.131 & 22 \\
\hline \multicolumn{5}{|c|}{ Applied temp. $=-40^{\circ} \mathrm{F}$ in phase 1 and $70^{\circ} \mathrm{F}$ in phase 2} \\
\hline & Phase $1\left({ }^{\circ} \mathrm{F}\right)$ & Time (min) & Phase $2\left({ }^{\circ} \mathrm{F}\right)$ & Time (min) \\
\hline $\begin{array}{l}\text { Final temperature } \\
\text { attained }\end{array}$ & -22 & 60 & 63.84 & 60 \\
\hline & & & & \\
\hline $60 \%$ final & 14.8 & 8 & 38.304 & 11 \\
\hline $75 \%$ final & 1 & 14 & 47.88 & 14 \\
\hline $85 \%$ final & -8.2 & 26 & 54.264 & 18.5 \\
\hline $90 \%$ final & -12.8 & 36 & 57.456 & 26 \\
\hline
\end{tabular}


Table 8-3 Time taken to attain different fractions of final temperature at 0.5 " distance from heat source

\begin{tabular}{|c|c|c|c|c|}
\hline \multicolumn{5}{|c|}{ Distance $=0.5^{\prime \prime}$} \\
\hline \multicolumn{5}{|c|}{ Applied temp. $=0^{\circ} \mathrm{F}$ in phase 1 and $70^{\circ} \mathrm{F}$ in phase 2} \\
\hline & Phase $1\left(^{\circ} \mathrm{F}\right)$ & Time (min) & Phase $2\left(^{\circ} \mathrm{F}\right)$ & Time (min) \\
\hline Final temperature & 20.4 & 60 & 63.13 & 120 \\
\hline attained & & & & \\
\hline $60 \%$ final & 40.24 & 25 & 37.878 & 2.5 \\
\hline $75 \%$ final & 32.8 & 33 & 47.3475 & 8 \\
\hline $85 \%$ final & 27.84 & 38 & 53.6605 & 17 \\
\hline $90 \%$ final & 25.36 & 42 & 56.817 & 25 \\
\hline \multicolumn{5}{|c|}{ Applied temp. $=-20^{\circ} \mathrm{F}$ in phase 1 and $70^{\circ} \mathrm{F}$ in phase 2} \\
\hline & Phase $1\left({ }^{\circ} \mathrm{F}\right)$ & Time (min) & Phase $2\left(^{\circ} \mathrm{F}\right)$ & Time (min) \\
\hline Final temperature & 9.7 & 60 & 59.91 & 120 \\
\hline Attained & & & & \\
\hline $60 \%$ final & 33.82 & 22 & 35.946 & 9 \\
\hline $75 \%$ final & 24.775 & 28 & 44.9325 & 18 \\
\hline $85 \%$ final & 18.745 & 36.5 & 50.9235 & 26 \\
\hline $90 \%$ final & 15.73 & 38 & 53.919 & 23 \\
\hline \multicolumn{5}{|c|}{ Applied temp. $=-40^{\circ} \mathrm{F}$ in phase 1 and $70^{\circ} \mathrm{F}$ in phase 2} \\
\hline & Phase $1\left(^{\circ} \mathrm{F}\right)$ & Time (min) & Phase $2\left({ }^{\circ} \mathrm{F}\right)$ & Time (min) \\
\hline Final temperature & -8 & 60 & 62.29 & 120 \\
\hline Attained & & & & \\
\hline $60 \%$ final & 23.2 & 22 & 37.374 & 16.5 \\
\hline $75 \%$ final & 11.5 & 33.5 & 46.7175 & 27 \\
\hline $85 \%$ final & 3.7 & 42 & 52.9465 & 36 \\
\hline $90 \%$ final & -0.2 & 43 & 56.061 & 46 \\
\hline
\end{tabular}


Table 8-4 Time taken to attain different fractions of final temperature at 1" distance from heat source

\begin{tabular}{|c|c|c|c|c|}
\hline \multicolumn{5}{|c|}{ Distance = 1" } \\
\hline \multicolumn{5}{|c|}{ Applied temp. $=0^{\circ} \mathrm{F}$ in phase 1 and $70^{\circ} \mathrm{F}$ in phase 2} \\
\hline & Phase $1\left(^{\circ} \mathrm{F}\right)$ & Time (min) & Phase $2\left(^{\circ} \mathrm{F}\right)$ & Time $(\min )$ \\
\hline \multirow{2}{*}{$\begin{array}{l}\text { Final temperature } \\
\text { attained }\end{array}$} & 43 & 60 & 60.019 & 120 \\
\hline & & & & \\
\hline $60 \%$ final & 53.8 & 33 & 36.0114 & \\
\hline $75 \%$ final & 49.75 & 40 & 45.01425 & 3 \\
\hline $85 \%$ final & 47.05 & 44 & 51.01615 & 12 \\
\hline $90 \%$ final & 45.7 & 52 & 54.0171 & 25 \\
\hline \multicolumn{5}{|c|}{ Applied temp. $=-20^{\circ} \mathrm{F}$ in phase 1 and $70^{\circ} \mathrm{F}$ in phase 2} \\
\hline & Phase $1\left(^{\circ} \mathrm{F}\right)$ & Time (min) & Phase $2\left(^{\circ} \mathrm{F}\right)$ & Time (min) \\
\hline \multirow{2}{*}{$\begin{array}{l}\text { Final temperature } \\
\text { attained }\end{array}$} & 40 & 60 & 57.39 & 120 \\
\hline & & & & \\
\hline $60 \%$ final & 52 & 30 & 34.434 & 3 \\
\hline $75 \%$ final & 47.5 & 40 & 43.0425 & 14 \\
\hline $85 \%$ final & 44.5 & 46 & 48.7815 & 28 \\
\hline $90 \%$ final & 43 & 49 & 51.651 & 35 \\
\hline \multicolumn{5}{|c|}{ Applied temp. $=-40^{\circ} \mathrm{F}$ in phase 1 and $70^{\circ} \mathrm{F}$ in phase 2} \\
\hline & Phase $1\left({ }^{\circ} \mathrm{F}\right)$ & Time (min) & Phase $2\left({ }^{\circ} \mathrm{F}\right)$ & Time (min) \\
\hline \multirow{2}{*}{$\begin{array}{l}\text { Final temperature } \\
\text { attained }\end{array}$} & 33.33 & 60 & 54.59 & 120 \\
\hline & & & & \\
\hline $60 \%$ final & 47.998 & 34 & 32.754 & 4 \\
\hline $75 \%$ final & 42.4975 & 43 & 40.9425 & 20 \\
\hline $85 \%$ final & 38.8305 & 48 & 46.4015 & 30 \\
\hline $90 \%$ final & 36.997 & 52 & 49.131 & 37 \\
\hline
\end{tabular}




\subsection{Conclusions}

- This analysis gives an idea about the time taken for material to conduct heat and attain different fractions $(85 \%, 90 \%)$ of the final temperature.

- Time taken to attain $85 \%$ of final temperature at 0.25 " distance from heat source was about 20 minutes for $0^{\circ} \mathrm{F}, 27$ minutes for $-20^{\circ} \mathrm{F}, 26$ minutes for $-40^{\circ} \mathrm{F}$ and 30 minutes for $250^{\circ} \mathrm{F}$ respectively.

- Time taken to attain certain temperature levels at specified distances away from heat source $\left(250^{\circ} \mathrm{F}\right)$ was successfully observed from infrared thermography and compared with FE results.

o Time taken to attain $165^{\circ} \mathrm{F}$ (90\% of maximum temperature attained) was 17 minutes at $0.25 "$ distance away from heat source.

- Time taken to attain same temperature at same distance from heat source from FE results was 11 minutes.

- Time taken to attain $149^{\circ} \mathrm{F}(90 \%$ of maximum temperature attained) at 0.5 " distance away from heat source was 25 minutes from infrared thermography results.

- Time taken to attain same temperature at same distance from heat source was 18 minutes as known from FE results.

- Similarly, Time taken to attain $126^{\circ} \mathrm{F}$ (90\% of maximum temperature attained) at 1" distance away from heat source was 38 minutes from infrared thermography results.

- Time taken to attain same temperature at same distance from heat source was 26 minutes as known from FE results. 
- Thermography results indicate increase in time to attain particular temperature value as compared to FE results. It should be noted that the specimen used in thermography possessed realistic gaps, voids and temperature leaks near the surface.

- By supplying heat in more than one direction, temperature gains at different interior points can be attained in lesser time. 


\section{CHAPTER 9}

\section{CONCLUSIONS}

\subsection{Introduction}

In this research, offset blocks for highway and bridge guardrail systems were developed using recycled polymer reinforced with glass fabric as shell and discarded tire strips/wood as core materials. Optimum compression molding process parameters for manufacturing guardrail-offset blocks using recycled polymers, glass fabric and rubber tire strips were determined as a part of this research. In order to evaluate mechanical properties of recycled polymers (ABS) used to manufacture these blocks, coupon specimens were manufactured with and without glass fabric and tested in compression, tension, bending, and impact. A limited comparison was made with vinyl ester (thermoset) specimens with and without glass fabric and specimens cut from a fieldinstalled wooden offset block. A sliced section of guardrail-offset block manufactured was experimentally tested for its heat conduction properties using infrared thermography. A finite element model was created to represent the sample used in the experiment and analyzed under the effect of thermal loading. Additional composite products like angle plates, dowel bars were manufactured using recycled polymers (ABS) and their properties were evaluated. Dowel bars were also manufactured using another type of thermoplastic resin coated fibers ( 1 " in length), commercially known as "Twintex."

\subsection{Summary of offset block manufacturing}

- Several refinements were made to manufacture prototype-offset block in the laboratory for highway and bridge guardrail system. 
- Using additional heaters on all the side plates of the mold to improve heat transfer from mold to offset block during manufacturing. Successful results in the form of products with better uniformity in blending and homogeneity were observed.

- Using commercially available thermoplastic pipe (cut to a required height) as a premolded insert during the last stage of manufacturing to reduce insufficient heat transfer problems along block thickness.

- In addition to discarded rubber tire strips, compressed wooden shavings were also successfully used as a core material.

- Optimum process parameters for recycled resins that were used for offset block manufacture were determined after several compression molding trials.

○ Optimum process parameters for manufacturing core block modules $(12.5 " \times 4.5 " \times 2 ")$ were: 20 minutes of preheating followed by 15 tons of load application at $450^{\circ} \mathrm{F}$ for about 15 minutes.

o Optimum process parameters for manufacturing prototype offset block were: preheating for about 30 minutes at $450^{\circ} \mathrm{F}$ followed by application of 30 tons load for about 30 minutes at the same temperature. (Thirty minutes of heating is also justified by infrared thermography and finite element modeling results)

- Final procedure for producing a good prototype offset block in the laboratory includes:

○ Molding two core block modules $(12.5 " \times 4.5 " \times 2 ")$ with discarded rubber tire strips/wood and recycled polymer shell. 
- Reinforcing those core block modules with glass fabric, and drilling holes at the center to create a hole in final product to accommodate field installation with the aid of bolting.

- Compression molding the core modules placed one on top of the other with a pipe insert in the middle and additional resin all around placement under required heat and pressure application.

- Note: Lower pressure or time resulted in insufficient compacting of the resins with the tire strips and product with unblended constituents was observed. Increase in processing time and temperature resulted in appearance of burn marks on the products, along with blisters and holes.

- Prototype offset blocks were successfully installed near Star City Bridge, Morgantown, WV. They were found to be in excellent shape after 8 months of installation based on visual inspection (Figure 9-1).

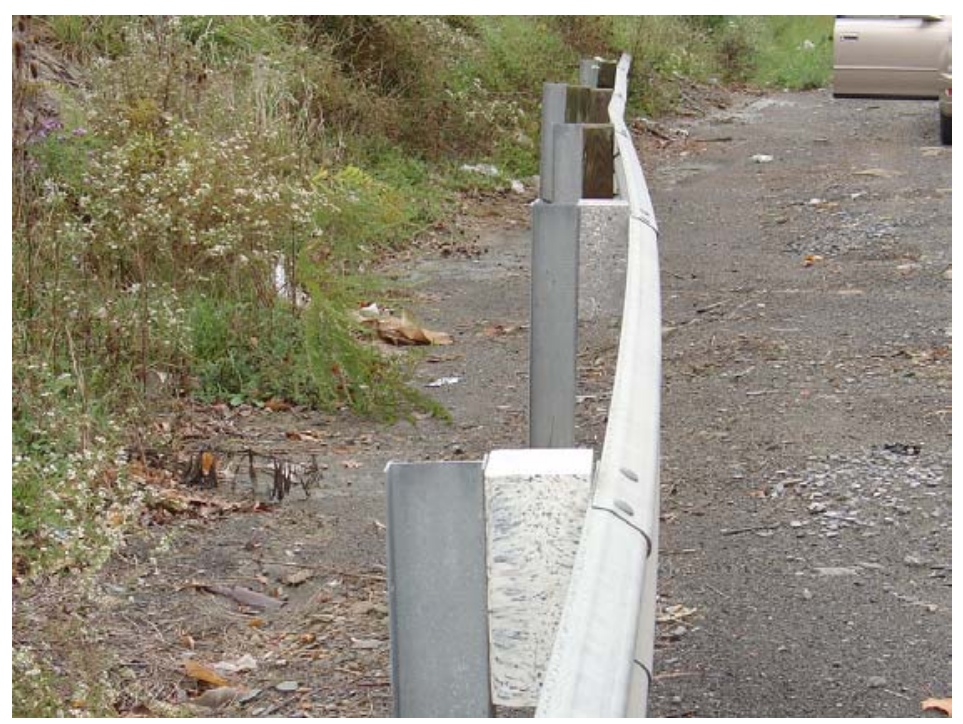

Figure 9-1 Guardrail offset blocks near Star city bridge, WV after 8 months of field installation 


\subsection{Summary of coupon specimens}

Coupon specimens (with and without glass fabric) conforming to ASTM standards were made of recycled ABS (thermoplastic) and vinyl ester (thermoset), and tested in compression, tension, bending and impact. Fiber volume fraction of $3.68 \%$ was maintained in tension, bending and impact test specimens, while fiber volume fraction of compression test specimens was $1.84 \%$.

\subsubsection{Compressive strength}

- Compressive strength increased by $28.16 \%$ (6616 psi to 8479 psi) and compressive stiffness increased by $28.98 \%\left(0.16 \times 10^{6}\right.$ psi to $\left.0.21 \times 10^{6} \mathrm{psi}\right)$ on an average in ABS specimens due to glass fabric reinforcement.

- Compressive strength increased by $23.75 \%$ (10803 psi to 14423 psi) and compressive stiffness increased by $33.5 \%\left(0.23 \times 10^{6}\right.$ psi to $0.29 \times 10^{6}$ psi) on an average in vinyl ester specimens due to glass fabric reinforcement.

- Average compressive strength of specimens cut from field installed wooden guardrail offset block was 5317.74 psi and average stiffness was $0.15 \times 10^{6}$ psi.

- Average compressive strength of ABS with glass fabric (8479.805 psi) was about 1.6 times higher than that of wood (5317.4 psi).

- Average compressive stiffness value of ABS with glass fabric specimens $\left(0.21 \times 10^{6} \mathrm{psi}\right)$ was about 1.4 times higher than that of wooden specimens $(0.15$ $\left.\times 10^{6} \mathrm{psi}\right)$.

- Note: It should be noted that wood with fiber being parallel to the loading axis and ABS with proper glass fiber/fabric configuration could exceed the 
strength and stiffness values than those obtained in this limited investigation.

\subsubsection{Tensile strength}

- Tensile strength increased by 5.21\% (4413 psi to 4643 psi) and tensile stiffness increased by $18.49 \%\left(0.31 \times 10^{6}\right.$ psi to $\left.0.37 \times 10^{6} \mathrm{psi}\right)$ on an average in ABS specimens due to glass fabric reinforcement. However, problems were noted in resin compatibility with fabric and some void formations. Hence, additional testing is necessary to draw further conclusions on test specimens.

- Tensile strength increased by $14.7 \%$ (5264 psi to 6038 psi) and tensile stiffness increased by $15.8 \%\left(0.37 \times 10^{6}\right.$ psi to $\left.0.43 \times 10^{6} \mathrm{psi}\right)$ on an average in thermoset vinyl ester samples due to glass fabric reinforcement.

- Average stiffness value of wooden tension specimen cut from a field installed guardrail offset block was $0.579 \times 10^{6}$ psi.

\subsubsection{Bending strength}

- Bending strength increased by $45.12 \%$ (from 11865 psi to 17219 psi) and bending stiffness increased by $26.87 \%$ (from $0.38 \times 10^{6}$ psi to $0.48 \times 10^{6}$ psi) on an average in ABS specimens due to glass fabric reinforcement.

- Bending strength increased by $42.59 \%$ (16522 psi to 23561 psi) and bending stiffness increased by $20.29 \%\left(0.70 \times 10^{6}\right.$ psi to $\left.0.84 \times 10^{6} \mathrm{psi}\right)$ on an average in vinyl ester specimens due to glass fabric reinforcement.

- Average bending stiffness value of specimen cut from a field installed wooden guardrail offset block was $0.665 \times 10^{6}$ psi. 


\subsubsection{Impact strength}

- From previous study (Basto, 2002) decrease in impact strength $(2.17 \mathrm{lbf} /$ in to 0.96 lbf/in) was observed in recycled ABS specimens due to addition of chopped glass fibers.

- In this study, recycled ABS resin used with continuous fabric having bidirectional fibers resulted in an increase in impact strength $(4.631 \mathrm{bf} /$ in from $2.411 \mathrm{bf} / \mathrm{in})$ due to better energy dissipation.

- Impact strength of recycled ABS specimens with continuous glass fabric (4.631bf/in) was found to be 1.45 times more than specimens cut from field installed wood offset blocks (3.192lbf/in).

- In this study, vinyl ester samples used with continuous glass fabric having bidirectional fibers resulted in an increase in impact strength $(0.661 \mathrm{bf} /$ in from $0.34 \mathrm{lbf} / \mathrm{in})$ due to better energy dissipation.

\subsubsection{Conclusions}

- Use of continuous (particularly bi-directional) fabric instead of chopped fibers resulted in better impact resistance. ABS specimens with continuous fabric having bi-directional fibers also showed higher impact strength compared to specimens cut from a field installed wooden offset block (4.63lbf/in from 3.192lbf/in).

- Glass fabric used for molding the specimens was compatible with thermoplastic resins as verbally stated by the manufacturer. However, it does not provide increase in strength and stiffness during tension tests and resulted in premature failures along fiber/resin interface. Further tests have to be done with a fabric that is truly compatible with thermoplastics. 


\subsubsection{Recommendations}

- Large scale manufacturing of offset blocks could be done easily and in a very short time with preheated, extruded and melted resin (charge).

- With the use of preheated resin (extruded mass of resin) as a charge, heat transfer problems during manufacturing could be eliminated (associated with direct pellet heating).

- Removing curvature of the tire strips will help reduce voids in the final offset blocks. The steel mesh in the rubber tires helps maintain undesirable tire curvature, which needs to be reduced to possible extent using techniques such as "Shear crimping".

- A two-step procedure was followed using premolded side plates and core blocks during manufacturing of offset block. This could be reduced to one step manufacturing procedure by remodeling the mold, modifying resin-filling procedure, and introducing preheated and melted resins (charge).

\subsection{Thermo-mechanical properties of the offset block}

\subsubsection{Infrared thermography}

Thermal propagation from heated mold surface to its constituents during manufacturing process of offset blocks was studied using infrared thermography. Presence of core material like rubber, along with polymer pellets around it, reduces rate of heat transmission owing to their low thermal conductivities.

An experiment was conducted with a sliced section of offset block exposed to unidirectional heat transfer. One surface of the section was exposed to $250^{\circ} \mathrm{F}\left(\mathrm{T}_{1}\right)$ temperature in phase 1 (heating) and $70^{\circ} \mathrm{F}\left(\mathrm{T}_{2}\right)$ temperature in phase 2 (cooling). 
Progression of temperature with respect to time at various depths was observed using infrared thermography method and also modeled using finite element analysis.

- Surface temperature measurement of the guardrail-offset block was done using infrared thermography during manufacturing process at every 5-minute interval.

- Results from the infrared thermography conducted on sliced section of offset block were compared with those from finite element analysis.

- Time taken to attain certain temperature levels at specified distances away from heat source was successfully observed from infrared thermography.

○ Time taken to attain $165^{\circ} \mathrm{F}$ ( $90 \%$ of maximum temperature attained) was 17 minutes at 0.25 in distance away from heat source.

- Time taken to attain same temperature at same distance from heat source from FE results was 11 minutes.

- Time taken to attain $149^{\circ} \mathrm{F}$ ( $90 \%$ of maximum temperature attained) at 0.5 in distance away from heat source was 25 minutes from infrared thermography results.

- Time taken to attain same temperature at same distance from heat source was 18 minutes as known from FE results.

- Similarly, Time taken to attain $126^{\circ} \mathrm{F}$ (90\% of maximum temperature attained) at 1 in distance away from heat source was 38 minutes from infrared thermography results.

- Time taken to attain same temperature at same distance from heat source was 26 minutes as known from FE results. 


\subsubsection{Limitations}

- Only surface imperfections can be studied using this technique.

- Measurement of the surface temperature profile by infrared camera is affected by environmental parameters such as solar radiation, air temperature, wind, rain, surface stains and patches and shadows.

- Infrared camera used to obtain pictures of the mold during manufacturing process has decreasing accuracy with increasing depths.

\subsubsection{Finite element analysis}

- Finite element model of the offset block was created similar to the experiment described in section 9.4.1, and temperature progression was studied at various distances from heat source with respect to time.

- Time taken to attain $85 \%$ of final temperature at 0.25 " distance from heat source was about 20 minutes for $0^{\circ} \mathrm{F}, 28$ minutes for $-20^{\circ} \mathrm{F}$ and 26 minutes for $-40^{\circ} \mathrm{F}$ respectively.

- Similarly, time taken to attain $90 \%$ of final temperature at 0.25 " distance from heat source was about 30 minutes for $0^{\circ} \mathrm{F}, 33$ minutes for $-20^{\circ} \mathrm{F}$ and 36 minutes for $-40^{\circ} \mathrm{F}$ respectively.

- Time taken to attain $85 \%$ of final temperature at 0.25 " distance from heat source was about 30 minutes for $250^{\circ} \mathrm{F}$.

- Similarly, time taken to attain $90 \%$ of final temperature at 0.25 " distance from heat source was about 34 minutes for $250^{\circ} \mathrm{F}$.

- Finite element analysis supports the optimum heating duration used in this study. 
○ Core block with $2 "$ thickness having $\approx 1.5 "$ thick rubber block needed 20 minutes of preheating followed by 15 minutes of molding under 15 tons load at $450^{\circ} \mathrm{F}$. Melting temperature of $\mathrm{ABS}$ is $\approx 400^{\circ} \mathrm{F}$.

○ Final stage manufacturing of a block with 6" thickness having 3" thick rubber needed 30 minutes of preheating followed by 30 minutes of molding under 30 tons load at $450^{\circ} \mathrm{F}$.

- Considering time as an important criterion in large-scale manufacturing, these results provide useful data regarding heat progression or cooling rate with respect to time through the thickness. This can also be used to verify temperature progression in a finished product cooled at room temperature in an industry.

\subsubsection{Recommendations}

- Temperature values from the infrared images were obtained by spot measurement tool provided by the camera software. Collecting values through this method is approximate with a possible variation of $\pm 2^{\circ} \mathrm{C}$ or $\pm 2 \%$ of measured value in $\mathrm{C}$. Hence, for accurate thermal evaluation refined thermal measurements have to be used.

- The finite element model does not take into account melt-flow and viscosity properties of the polymer, thus is not exact representation of the actual molding process. Also, properties of the melted polymer being heated and cooled is temperature dependent and thus a special software package must be used to arrive at a better solution. 
- Defects in the specimen like voids, air gaps (heat losses also) etc were not considered in the finite element model and thus results deviate from the actual ones (infrared thermography test results).

- By using better software (e.g., CADPRESS, MOLDFLOW etc), heat propagation within mold contents, resin flow characteristics etc can be studied. That would be a closer representation of practical scenario, and be helpful in suggesting changes for improving end-product quality.

\subsection{Summary of additional composite products}

Some additional recycled composite products like angle plates and dowel bars were manufactured using recycled ABS (thermoplastic) resins through compression molding process.

\subsubsection{Dowel bars}

- Dowel bar manufacturing process required three cycles of molding for each successful product in terms of blending and uniform melting of resins.

- Optimum process parameters for each cycle to manufacture dowel bars were: 10 minutes of preheating at $450^{\circ} \mathrm{F}$, followed by 35 minutes of load application. Heaters were used only on two sides of the mold and load application was just sufficient to close the mold.

- In addition, a dowel bar was also manufactured using commercial thermoplasticcoated 1" long fibers called "Twintex." Manufacturing trials to determine its process parameters indicated higher process temperature requirement than that is available with current set of heaters. 


\subsubsection{Recommendations}

- Heaters if used on all sides, would increase heat transfer within the mold contents, thereby reducing number of cycles and duration of each cycle.

- Use of preheated resin would eliminate heat transfer problems and simplify mold setup by reducing number of heaters.

- Resin with chopped fiber and/or continuous fibers could be used to obtain products with higher strength/stiffness values suitable for field installation.

\subsubsection{Angles}

- Optimum process parameters for manufacturing angle plates with recycled ABS thermoplastic resins reinforced with glass fabric were found to be: preheating the mold with its contents (glass fabric and recycled ABS pellets) at $450^{\circ} \mathrm{F}$ for 25 minutes and load (20 tons) application for about 30 minutes at same temperature.

- Manufacturing two right-angled legs of an angle plate through pressure application in compression molding process was successfully achieved by designing a $\mathrm{V}$-mold. The $\mathrm{V}$-mold was designed such that pressure was exerted on both legs of the angle plate, producing a good product with regards to uniformity in blending.

Some of the problems encountered during the process were:

- Placing lead electrical wires coming out of the top portion of the mold away from hot $\mathrm{mold} / \mathrm{platen}$ of the press surfaces.

- Placement and alignment of glass fabric. 


\subsubsection{Recommendations}

- Use of resin with chopped fibers would eliminate problems in placing glass fabric in the mold.

- Use of preheated, melted and extruded resin (as charge) would eliminate heat transfer problems and reduce wastage of the material in the form of flash (excess resin oozing out of the mold).

- By using fibers/fabrics that are compatible with thermoplastic resins, angle plates with high stiffness and strength values can be manufactured and used for field installation.

\subsection{Recommendations for future research work}

- Use of preheated resin in manufacturing composite products with recycled resins will improve manufacturing efficiency. Offset block manufacturing process could be simplified with some modifications and can be used for large-scale manufacturing such as reinforced railroad ties.

- Offset blocks manufactured through compression molding process have to be evaluated through crash tests.

- Manufacturing procedures for additional composite products like angle plates and dowel bars should be further refined with respect to optimizing process parameters and dimensions including time.

- Resins with chopped fibers should be used to manufacture recycled composite products and tested for field installation purposes.

- Long-term properties (creep and aging) of recycled composite products have to be researched. 
- Finite element analysis could be done with better software that predicts resin flow behavior during product manufacturing process. Continuous monitoring of manufacturing process can be achieved by this method and changes could be incorporated into processing to improve end-product quality. 


\section{REFERENCES}

Bargo, J. E. (2000). Mechanical property characterization of recycled thermoplastics.CFC Report No. 00-287 and Thesis Report, Constructed Facilities Center, West Virginia University, West Virginia.

Basto, R Jose (2002). Thermo-Mechanical characterization of aged recycled polymers and applications. CFC Report No. 02-110 and Thesis Report, Constructed Facilities Center, West Virginia University, West Virginia.

Bennett, R. A. (1992). Recycled plastics. Product applications and potential. In Gerald D Andrews and Pallatheri M. Subramanian (Ed.), ACS Symposium Series: Vol. 513.Emerging Technologies in Plastic Recycling (pp. 26-38). Washington, DC: American Chemical Society.

BLI Series Operation Manual for Impact Testing (1999).

Descul M (2004). Environmentally conscious designs, take-back programs, and legislative measures aim to embed more recycling within the electronics culture, Electronic Design

Dutta, P. K. (1998). Investigations of plastic composite materials for highway safety structures (CRREL Rep. No. 98-7). Hanover, NH: US Army Corps Engineers.

http://www-cee.engr.ucf.edu/classes/env4341/char6.htm

http://www.belvac.com

http://www.dencities.com/denmall/denmall-rugs5a.html

http://www.easybarrow.co.uk/barrows/big_page_crs01.html

http://www.fluorplast.fi/termoplastisetletkut.html

http://www.garrattindustries.com/separator_410B.html 
http://www. geplastics.com

http://www.plasticsresource.com

http://www.smc-alliance.com/gallery/gallery.html

http://www.trashtransformers.com.au/recycling_how_what.html

http://www.vaec.gov.vn/ ITRRE/TTTK.htm

Instron Series 8500 Two-Column Load Frame Operating Manual (1999).

Kobler, R (December 2002), Plastics Recovery Technology Developer Tackles PostConsumer Electronics Scrap, Modern Plastics, pp 65

Liu, Xiaodong and Bertilsson, Hans (1999), Recycling of ABS and ABS/PC blends, Journal of Applied Polymer Science, Volume 74, pp 510-515

Mallik, P. K. and Newman, S (1990), Composite Materials Technology Process and Properties, Hanser publishers, Munich Vienna New York.

Recycled Plastic Products Source Book, The American Plastics Council (Plastics Recycling, 2000)

Stevens, E.S (2002), An Introduction to the New Science of Biodegradable Plastics

Swiss Precision Instruments Manual (1999). 


\section{APPENDIX-A \\ EXPERIMENTAL ERROR}

\section{Experimental error in calculating stress/strength}

If load $=\mathrm{P}$, thickness $=\mathrm{T}$ and width $=\mathrm{W}$

Error in load measurement $=1 \%$ (Ref: Instron Series 8500 Two-Column Load Frame

Operating Manual, 1999)

Error in thickness and width measurement $=0.004$ units (Ref: Swiss Precision

Instruments Manual, 1999)

Error in load $=\mathrm{P} \pm 0.01 \mathrm{P}$

Error in area $=(\mathrm{T} \pm 0.004) *(\mathrm{~W} \pm 0.004)=\mathrm{TW} \pm 0.004(\mathrm{~T}+\mathrm{W})$

Error in stress $=$ Error in load /error in area

Minimum stress value $=\frac{(P-0.01 P)}{(T W+0.004(T+W))}$

Maximum stress value $=\frac{(P+0.01 P)}{(T W-0.004(T+W))}$

Error $= \pm \frac{(\text { Maximum stress value }- \text { Minimum stress value })}{2}$

An illustration of error in stress calculation for an average stress in compression test is as shown

Stress $=$ load $/$ area $=6616.05 \mathrm{psi}$

Specimen dimensions : $\mathrm{T}=0.5$ inch and $\mathrm{W}=0.5$ inch

From Eq-(1)

Minimum stress value $=\frac{(P-0.01 P)}{(T W+0.004(T+W))}$ 


$$
\begin{aligned}
& =\frac{P}{T W} \frac{(1-0.01)}{\left(1+0.004\left(\frac{1}{W}+\frac{1}{T}\right)\right)} \\
& =6616.05 \frac{(1-0.01)}{\left(1+0.004\left(\frac{1}{0.5}+\frac{1}{0.5}\right)\right)} \\
& =6446.74 \mathrm{psi}
\end{aligned}
$$

From Eq-(2)

$$
\begin{aligned}
\text { Maximum stress value } & =\frac{(P+0.01 P)}{(T W-0.004(T+W))} \\
& =\frac{P}{T W} \frac{(1+0.01)}{\left(1-0.004\left(\frac{1}{W}+\frac{1}{T}\right)\right)} \\
& =6616.05 \frac{(1+0.01)}{\left(1-0.004\left(\frac{1}{0.5}+\frac{1}{0.5}\right)\right)} \\
& =6790.87 \mathrm{psi}
\end{aligned}
$$

From Eq-(3)

$$
\begin{aligned}
\text { Error } & = \pm \frac{(\text { Maximum stress value }- \text { Minimum stress value })}{2} \\
& = \pm \frac{(6790.87-6446.74)}{2} \\
& = \pm 172.06 \mathrm{psi}
\end{aligned}
$$

Percentage error in stress $=\frac{172.06}{6616.05} \times 100=2.6$

The above explained error calculation procedure was repeated for compression, tension and bending tests. Errors in stress measurement are given in table 
Table A-1 Error in stress calculation

\begin{tabular}{|c|c|c|c|c|}
\hline Type of test/specimen & $\begin{array}{c}\text { Minimum } \\
\text { stress (psi) }\end{array}$ & $\begin{array}{c}\text { Maximum } \\
\text { stress (psi) }\end{array}$ & $\begin{array}{c}\text { Error } \\
\text { (psi) }\end{array}$ & $\begin{array}{c}\text { Percentage } \\
\text { error }\end{array}$ \\
\hline Compression test & $\mathrm{T}=0.5$ inch W= $=0.5$ inch \\
\hline ABS without fabric & 6446.74 & 6790.87 & \pm 172.06 & 2.6 \\
\hline ABS with fabric & 8262.89 & 8703.96 & \pm 220.53 & 2.6 \\
\hline Vinyl ester without fabric & 10527.10 & 11089.03 & \pm 280.96 & 2.6 \\
\hline Vinyl ester with fabric & 14054.42 & 148.4 .63 & \pm 375.1 & 2.6 \\
\hline Wood & 5181.65 & 5458.24 & \pm 138.29 & 2.6 \\
\hline Tension test $\mathrm{T}=0.25$ inch W $=0.5$ inch \\
\hline ABS without fabric & 4267.06 & 4567.36 & \pm 150.14 & 3.4 \\
\hline ABS with fabric & 4388.99 & 4697.87 & \pm 154.43 & 3.4 \\
\hline Vinyl ester without fabric & 5089.46 & 5447.63 & \pm 179.08 & 3.4 \\
\hline Vinyl ester with fabric & 5837.99 & 6248.84 & \pm 205.42 & 3.4 \\
\hline Wood & 6050.45 & 6476.25 & \pm 212.9 & 3.4 \\
\hline Bending test & $\mathrm{T}=0.25$ inch W=0.5 inch \\
\hline ABS without fabric & 11471.67 & 12278.99 & \pm 403.66 & 3.4 \\
\hline ABS with fabric & 16647.51 & 17819.09 & \pm 585.79 & 3.4 \\
\hline Vinyl ester without fabric & 15974.31 & 17098.52 & \pm 562.1 & 3.4 \\
\hline Vinyl ester with fabric & 22778.98 & 24382.07 & \pm 801.54 & 3.4 \\
\hline Wood & 14300.8 & 15307.2 & \pm 503.21 & 3.4 \\
\hline
\end{tabular}

\section{Experimental error in calculating stiffness/elastic modulus}

Elastic modulus $=$ slope $=$ stress $/$ strain

Error in strain measurement $= \pm 1\left(10^{-6} \mathrm{in} / \mathrm{in}\right)$

Maximum error in slope $=\frac{\text { maximum stress value }}{\text { minimum strain value }}$

Minimum error in slope $=\frac{\text { minimum stress value }}{\text { maximum strain value }}$

Error $= \pm \frac{(\text { Maximum slope }- \text { Minimum slope })}{2}$

$\mathrm{Eq}-(\mathrm{A}-6)$ 
An illustration of error in stress calculation for an average stress in compression test is as shown

Stress $=6616.05 \mathrm{psi}$

Strain $=39634 \times 10^{-6} \mathrm{in} /$ in

Stiffness $=$ slope $=$ stress $/$ strain $=0.1669 \times 10^{6} \mathrm{psi}$

From Eq-(4)

Maximum error slope $=\frac{\text { maximum stress value }}{\text { minimum strain value }}$

$$
\begin{aligned}
& =\frac{6790.87}{39633} \\
& =0.1713 \times 10^{6} \mathrm{psi}
\end{aligned}
$$

From Eq-(5)

Minimum error slope $=\frac{\text { minimum stress value }}{\text { maximum strain value }}$

$$
\begin{aligned}
& =\frac{6446.74}{39635} \\
& =0.1626 \times 10^{6} \mathrm{psi}
\end{aligned}
$$

From Eq-(6)

$$
\begin{aligned}
\text { Error } & = \pm \frac{(\text { Maximum slope }- \text { Minimum slope })}{2} \\
& = \pm \frac{(0.1713-0.1626)}{2} \times 10^{6} \mathrm{psi} \\
& = \pm 0.0043 \times 10^{6} \mathrm{psi}
\end{aligned}
$$

Percentage error $=\frac{0.0043}{0.1169} \times 100=2.6$ 
The above explained error calculation procedure was repeated for compression, tension and bending tests. Errors in stress measurement are given in table

Table A-2 Error in stiffness calculation

\begin{tabular}{|c|c|c|c|c|}
\hline Type of test/specimen & $\begin{array}{l}\text { Maximum } \\
\text { stiffness } \\
\text { (x 106 psi) }\end{array}$ & $\begin{array}{c}\text { Minimum } \\
\text { stiffness } \\
\text { (x 10 10 psi) }\end{array}$ & $\begin{array}{c}\text { Error } \\
\left(1^{6}{ }^{6 s i}\right)\end{array}$ & $\begin{array}{l}\text { Percentage } \\
\text { error }\end{array}$ \\
\hline Compression test & \multicolumn{4}{|c|}{$\mathrm{T}=0.5$ inch $\mathrm{W}=0.5$ inch } \\
\hline ABS without fabric & 0.1713 & 0.1626 & \pm 0.0043 & 2.6 \\
\hline ABS with fabric & 0.221 & 0.2098 & \pm 0.0056 & 2.6 \\
\hline Vinyl ester without fabric & 0.2423 & 0.23 & \pm 0.0061 & 2.6 \\
\hline Vinyl ester with fabric & 0.2999 & 0.2847 & \pm 0.0076 & 2.6 \\
\hline Wood & 0.1533 & 0.1455 & \pm 0.0038 & 2.59 \\
\hline Tension test & \multicolumn{4}{|c|}{$\mathrm{T}=0.25$ inch $\mathrm{W}=0.5 \mathrm{inch}$} \\
\hline ABS without fabric & 0.3280 & 0.3064 & \pm 0.0108 & 3.9 \\
\hline ABS with fabric & 0.3810 & 0.3559 & \pm 0.0125 & 3.5 \\
\hline Vinyl ester without fabric & 0.3885 & 0.3629 & \pm 0.0128 & 3.4 \\
\hline Vinyl ester with fabric & 0.4500 & 0.4203 & \pm 0.0148 & 3.4 \\
\hline Wood & 0.6333 & 0.5916 & \pm 0.0208 & 3.4 \\
\hline Bending test & \multicolumn{4}{|c|}{$\mathrm{T}=0.25 \mathrm{inch} \mathrm{W}=0.5 \mathrm{inch}$} \\
\hline ABS without fabric & 0.3954 & 0.3694 & \pm 0.0130 & 3.4 \\
\hline ABS with fabric & 0.5017 & 0.4687 & \pm 0.0165 & 3.4 \\
\hline Vinyl ester without fabric & 0.7247 & 0.6770 & \pm 0.0238 & 3.4 \\
\hline Vinyl ester with fabric & 0.8718 & 0.8144 & \pm 0.0286 & 3.4 \\
\hline Wood & 0.5553 & 0.5187 & \pm 0.0182 & 3.4 \\
\hline
\end{tabular}

